\title{
Healing Heritage:
}

New Approaches to Commemorating Canada's Indian Residential School System

by

Trina Cooper-Bolam

A thesis submitted to the Faculty of Graduate and Postdoctoral Affairs in partial fulfillment of the requirements for the degree of

Master of Arts

in

Canadian Studies

Carleton University

Ottawa, Ontario

(C) 2014, Trina Cooper-Bolam 


\begin{abstract}
In anticipation of the Final Report of the Truth and Reconciliation Commission of Canada, this thesis examines Canada's federal place-based heritage infrastructure and critiques the policy and practice of the Historic Sites and Monuments Board of Canada (HSMBC) relative to its engagements with the history of Indian residential schools (IRS) and difficult heritage in general. Interpreting IRS Survivor-led commemoration and heritage practices as healing and decolonizing, and drawing on art-as-resistance and social activism-oriented models of commemoration and counter-commemoration, I examine alternative approaches to collective remembering and forgetting within the context of genocide, atrocity, and historic trauma. I argue for a needed shift from dominant heritage paradigms that bind heritage with conservation, to emergent approaches that recognize heritage as a healing practice. In conclusion, I present a series of recommendations to move toward bridging the gap between state practices of heritage, and the needs of Survivors and other IRS stakeholders.
\end{abstract}




\section{Acknowledgements}

In gratitude for his guidance, I would first like to thank my supervisor Peter Hodgins. I would also like to acknowledge and thank my second reader, Susan Ross, and my external reviewer, Glen Lowry. I owe a debt of gratitude to the School of Canadian Studies at Carleton, and in particular the infinitely patient and helpful Lori Dearman.

Finally, I wish to thank Graham Iddon and Clara Bolam for their ongoing support, and for putting up with my mess these past years. 


\section{Table of Contents}

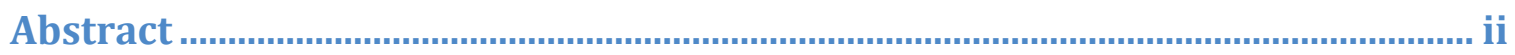

Acknowledgements ...............................................................................

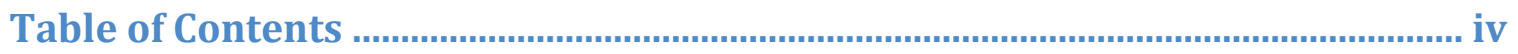

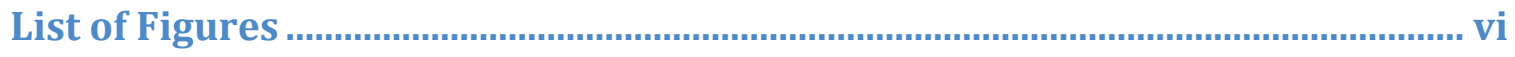

List of Appendices.................................................................................................. vii

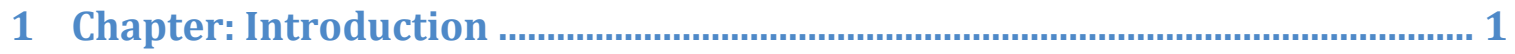

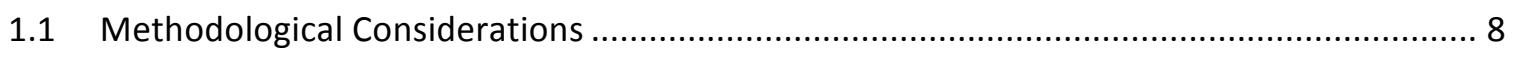

2 Chapter: Remembering IRS: Trauma, Witnessing, Healing ………….............14

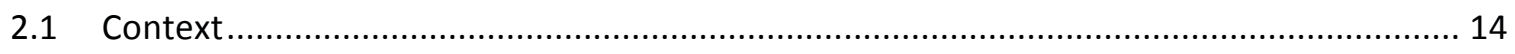

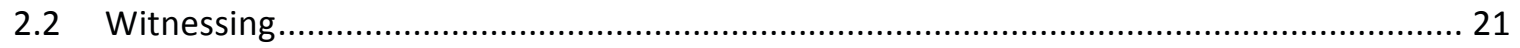

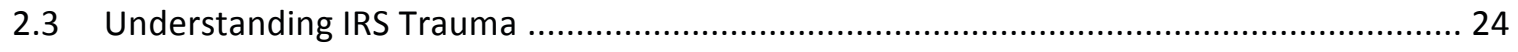

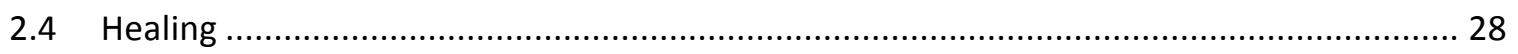

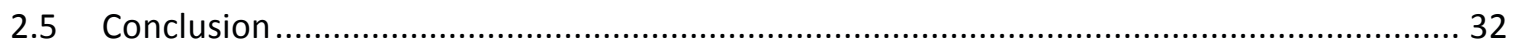

3 Chapter: Forgetting IRS: Containment and Erasure........................................34

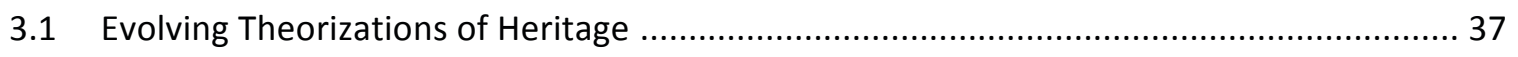

3.2 Canada's Place-based Federal Commemorative Landscape ............................................ 47

3.3 Observations on the HSMBC System Plan (2000) and Guidelines (2008) ......................... 51

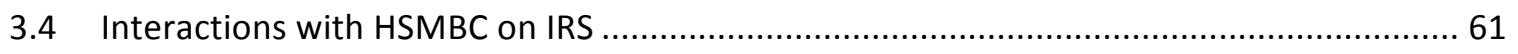

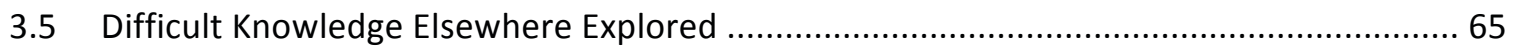

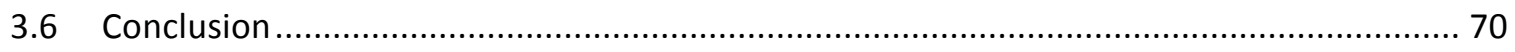


4 Chapter: Actualizing the Will to Remember ..................................................... 73

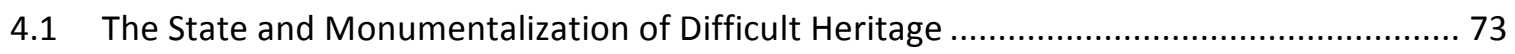

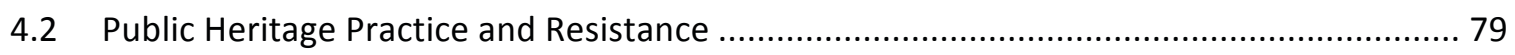

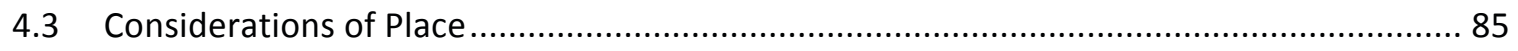

4.4 Heritage Practices of IRS Survivors, their Families, and Communities............................. 93

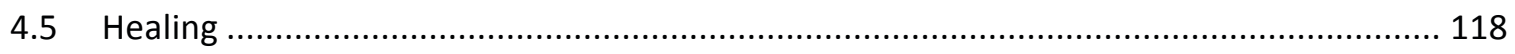

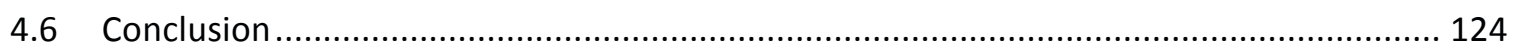

5 Chapter: Conclusion ............................................................................... 126

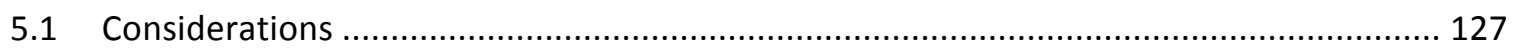

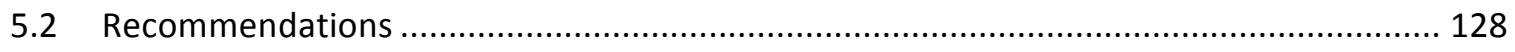

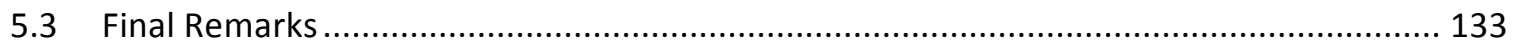

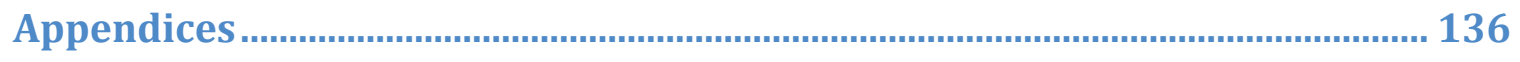

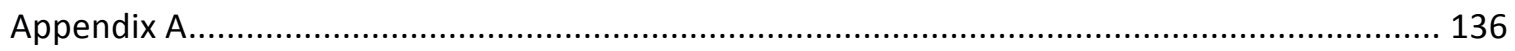

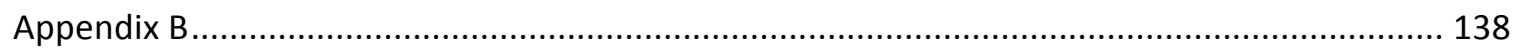

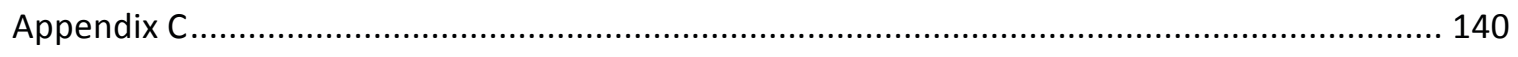

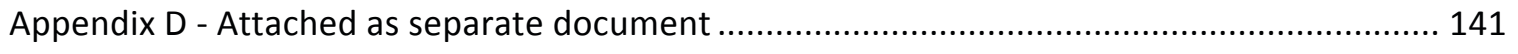

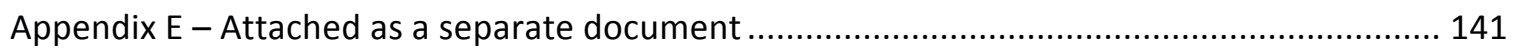

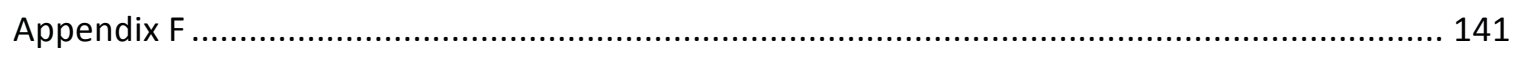

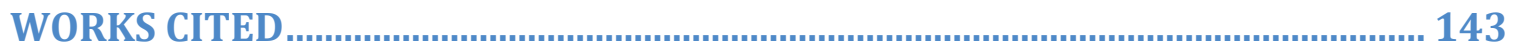




\section{List of Figures}

Figure 1: The Canadian Peacekeeping Monument. Photo Credit: Canada's Capital/Foter/

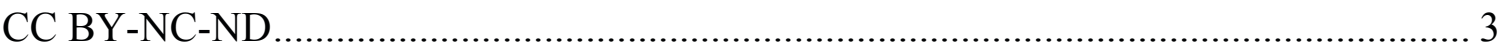

Figure 2: Melody at the Champlain Monument - Seize the Day. Photo, Jeff Thomas....... 5

Figure 3: The Aschrott-Brunnen Monument, Horst Hoheisel, 1987............................... 77

Figure 4: Sir John A. MacDonald defaced in Kingston. Photo attributed to Jeffrey Lowes.

Figure 5: Leah Decter with guests stitching official denial: trade value (in progress), 2010 and ongoing

Figure 6: The Former St. Eugene Indian Residential School adaptively reused as a golf

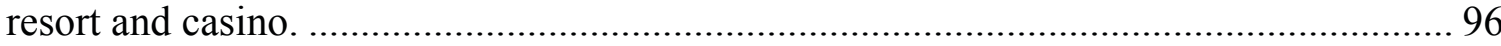

Figure 7: A number of AFN/AHF commemorative monuments mid-fabrication. Photo

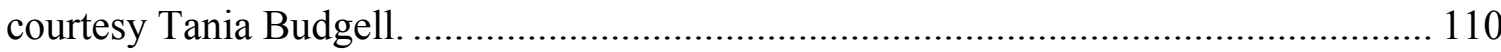




\section{List of Appendices}

Appendix A - IRSSA Commemoration Program Evaluation Grid

Appendix B - IRSSA Commemoration Program Evaluation Results

Appendix C - A Framework for Understanding Trauma and Healing Related to

Residential School Abuse

Appendix D - Healing and Decolonizing Comparative Chart

Appendix E - TRC Commemoration Initiative Call for Proposals Guide

Appendix F - AANDC IRSSA Commemoration Program Project Descriptions

Appendix G - HSMBC Flowchart of the Designation Process 


\section{Chapter: Introduction}

In 2015, the Truth and Reconciliation Commission (TRC) of Canada will "submit to the Parties of the [Indian Residential Schools Settlement] Agreement a report including recommendations to the Government of Canada concerning the Indian residential school (IRS) system and experience including: ... the effect and consequences of IRS... and the ongoing legacy of the residential schools" ("Schedule 'N'"). Although it will be beyond the scope of the report to establish that the IRS System meets the technical and legal criteria for genocide, as defined in the UN Convention, Article 2, Sections C and E, Chief Justice Murray Sinclair, Chair of the TRC, has been clear in characterizing it as such in national media ("Residential schools called a form of genocide"). Conversely, Prime Minister Stephen Harper's depiction of Canada as a country with “...no history of colonialism" ("Every G20 nation wants to be Canada, insists PM") at the G20 Summit in 2009 , only a year after his apology to Survivors of Indian residential school, suggests a radically different understanding of Canada's past. Harper's dismissive tone pervades even the Canadian Museum for Human Rights, which has decidedly refrained from using the word 'genocide' within its Indian residential school exhibition (Winnipegfreepress.com). If Canada has no vocabulary with which to discuss its difficult history and inheritances/heritage, and is struggling to satisfactorily represent genocide and atrocity within its cultural institutions, how can its National Program of Historic Commemoration (NPHC) cope with increasing pressures to commemorate IRS? Are heritage programs focused on historic site designation appropriate mechanisms for commemorating IRS? With sufficient evidence of the promise of alternative, art-based, multi-vocal, community-driven commemoration models, could HSMBC's postmodern 
sensibilities be nurtured such that the structural changes required to allow meaningful commemoration of IRS and other difficult histories be considered and made possible?

The NPHC affords private citizens the opportunity to nominate places, persons, or events, for commemoration. Managed since 1919 by the Historic Sites and Monuments Board of Canada (HSMBC), the NPHC couples commemorative practice with heritage designation. For places, as opposed to persons or events, 'commemorative integrity' underpins criteria (aesthetic, architectural, historical, cultural, and artistic) used to evaluate sites for their heritage value. Those sites deemed to be of heritage value are conferred historic site designation. The resulting commemorations, typically characterized by the application of plaques or monuments, are approved at the discretion and purview of the Minister responsible for Parks Canada. HSMBC, a body that reviews applications based on established guidelines and precedents and directs the research and implementation work of its corresponding secretariat, makes recommendations to the Minister. Although the HSMBC makes judgments on the historical (and cultural) value of places, persons, and events, the current National Historic Sites System Plan - "proudly bringing you Canada at its best" (Parks Canada 2000), provides the over-arching historical framework and context for designations.

Its celebratory character, however, appears to marginalize subjects of 'difficult' commemoration and exclude those that pose a risk of contesting extant national 
narratives/myths. As such, the inherent commemorative integrity ${ }^{1}$ of sites of conscience ${ }^{2}$ remains unrecognized as a potential determinant of heritage value. Thus neither Castle Mountain in Banff, site of internment and forced labour of 70,000 ethnic Ukranians during WW1, nor Lemon Creek, the site of a similar atrocity perpetrated on Japanese (75\% of whom were Canadian citizens) during WW2 (Cameron 2010,112) have been determined worthy of commemoration by the state. Similarly excluded are the over 139 sites of former Indian residential schools (IRS).

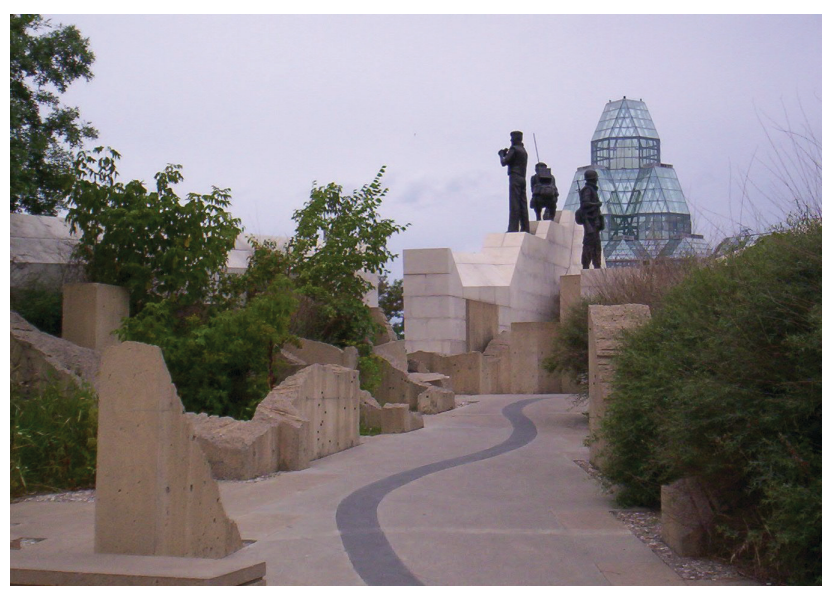

Figure 1: The Canadian Peacekeeping Monument. Photo Credit: Canada's Capital/Foter/ CC BYNC-ND

A network of monuments and plaques mark the 956 sites, across Canada, deemed worthy of heritage designation. American literary and cultural critic, James E. Young (2000),

${ }^{1}$ A discussion of the concept of commemorative integrity and how it is defined and ascertained by Parks Canada appears in Chapter 3.

${ }^{2}$ Here I am using Christina Cameron's definition of sites of conscience as "places that bear witness to human rights abuses including genocide, slavery and other violations of freedom," (2010: 112), as opposed to Liz Ševčenko's more commonly used definition of sites of conscience as those already transformed into places of civic dialogue, "historic places that foster public dialogue on pressing contemporary issues in historical perspective" (Ševčenko and Russell-Ciardi 9). For Ševčenko, a site where atrocities have occurred only becomes a site of conscience through its reclamation and transformation. 
asserts that "the monument - in both idea and practice... [has] undergone a radical transformation over the course of the twentieth century" and that its metamorphosis "from the heroic, self-aggrandizing figurative icons of the later nineteenth century celebrating national ideals and triumph to the antiheroic, often ironic, and self-effacing conceptual installations ... mark the national ambivalence and uncertainty of late twentieth century postmodernism" (93). I would suggest that this has not been the case in Canada, where recently-commissioned monuments, like Reconciliation (Figure 1) and We Were There, hybridize modernist structural elements with statuary evocative of what Brian Osborne (2001) describes as 'statue-mania', a rage for commemorative statues that gripped North America from the 1870s through to the teens of the twentieth century (15). Although monuments to human rights, peacekeeping, and even Aboriginal veterans, offer new subjects for Canada's monument-makers, the monuments themselves reiterate adages of the sort that Young argues "seal memory off from awareness" (1992, 272). Yet artists and members of the public routinely resist the narratives this commemorative landscape constructs, through strategies of supplementation, counter-monumentalization, and other 'unofficial' heritage practices.

Artists like Jeff Thomas reclaim commemorative space, inviting the public to join in contesting heroic colonial and oppositional post-colonial narratives by themselves becoming 'living monuments' (Figure 2). Young (1992) describes counter-monuments as "brazen, painfully self-conscious memorial spaces conceived to challenge the very premise of their being" (271) supporting an interpretation of 'seizing the space' as 
counter-monumental. While Six Nations artist Shelley Niro asserts, "In my culture/there are no monuments" (Lauzon 79), Thomas' spatial interventions effect the transformation of the monumental form and its attendant narratives (Figure 2), an example of what Art Historian Annie Gérin (2006) describes as Derridean supplementation - a postmodernist corrective to Canada's mnemonic promiscuities. ${ }^{3}$

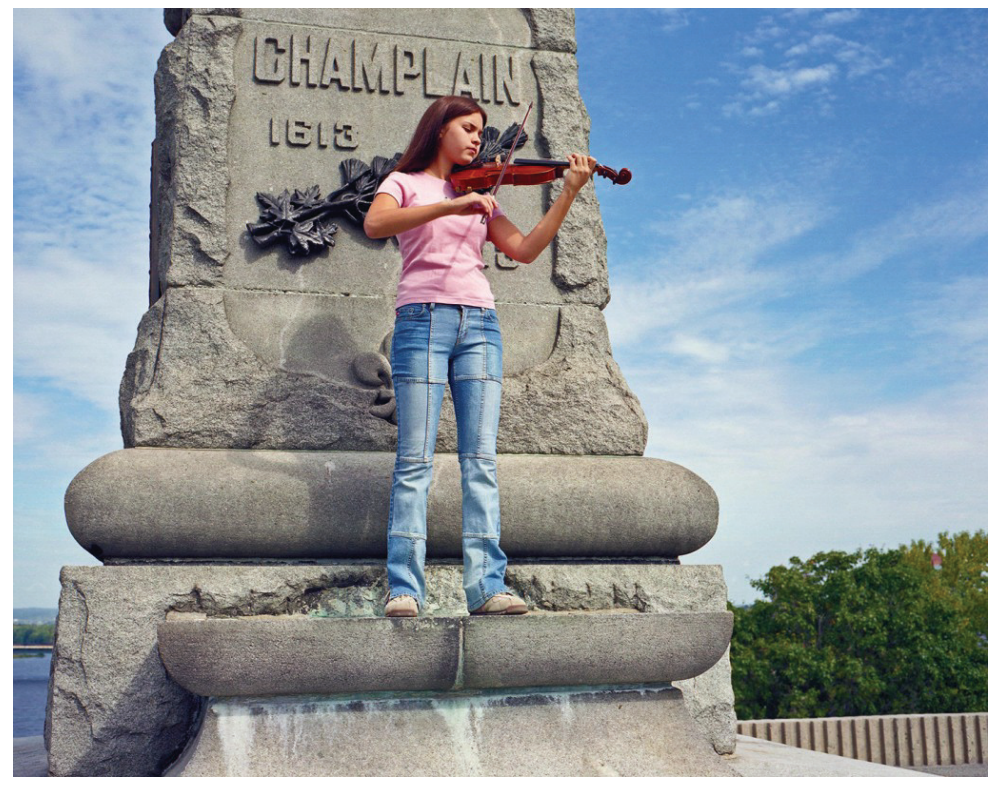

Figure 2: Melody at the Champlain Monument - Seize the Day. Photo, Jeff Thomas.

Aboriginal communities and physical remains of the former IRS also form sites of resistance, remembering, and healing. From 2011- 2014, fulfilling its Indian Residential Schools Settlement Agreement (IRSSA) obligations, Aboriginal Affairs and Northern Development Canada (AANDC) made a sum of 20 million dollars available to Survivor, Indigenous community, and 'reconciliation' advocacy groups for commemoration

${ }^{3}$ Monuments as mnemonic devices allow or create conditions of what Gérin (2006) calls "mnemonic promiscuity," which privileges some narratives while evacuating "bits of inconvenient history (such as the English Conquest and ethnic composition)" (331). 
projects related to Indian residential schools (IRS). Accessing these hard won funds through the TRC, Indigenous groups participated in commemoration projects on an unprecedented scale. Despite some caveats related to limitations and constraints imposed by TRC and AANDC program and funding elements, ${ }^{4}$ the resulting 144 (mostly) Indigenous-led commemorations can tell us a great deal about not only contemporary Indigenous forms of commemoration, but also about Indigenous approaches to commemorating difficult pasts and knowledge. In combination with a survey of Indigenous counter-memorials and other art-as-resistance works related to IRS, as well as case studies of pre-IRSSA IRS commemorations, these projects offer evidence to support the development of a more robust and culturally competent framework for commemorating IRS, which may also have implications on commemoration of subjects of difficult history in general. Through them, we can gain insight into the concerns, values, approaches, and strategies of Survivors and their advocates in confronting and healing from traumatic pasts, and in transforming their enduring legacies.

Despite the fact that commemoration occurs regularly outside the sphere of government influence, federal commemoration programs, such as Canada's National Program of Historic Commemoration, provide the recognition and exposure that have the potential to validate the objects of commemoration on a national, and perhaps international scale. In countries where genocide, atrocities, and historic trauma have occurred, such as Germany, Rwanda, the former Yugoslavia, and Canada, acknowledgement can serve an important role in reconciliation, and has the potential to build social cohesion through

${ }^{4}$ These will be discussed in Chapter 5. 
conciliatory/reconciliatory dialogue and actions. State-led commemorations can create multi-vocal space for formation of new collective memories that differently prioritize remembering, mourning and forgetting, and can support processes of social and cultural renewal and reconciliation, which for Indigenous Peoples involves active decolonization. In order for necessary 'restorying', a foundational element of reconciliation (Corntassel et al. 138), to occur, Canadian cultural heritage apparatus must develop missing commemorative (in addition to heritage, museological, and pedagogical) infrastructure to engage and represent authentic experiences of Canadians, including those of genocide. In doing so, Canada's heritage institutions can move toward meaningfully supporting reconciliation, work essential to transforming current social ambivalence, underpinned by historic trauma/ historic guilt tensions, into social activism.

Synthesizing the various questions posed is this discussion, I analyze and critique the policies and practices of the HSMBC, arguing that it is the appropriate mechanism to commemorate IRS on a national scale, even if it does not yet possess the inclination, knowledge, capacity, and infrastructure to do so in a way that meaningfully engages Survivors and their communities. Drawing from emerging heritage discourse and practice, as well as examples of counter-commemoration in its various forms, I will show how the field of heritage is shifting and evolving from the ground up, creating potential for dialogic renegotiation of heritage spaces, and in particular those that are witness to difficult histories. In performing a rudimentary survey and analysis of 'unofficial', primarily Indigenous commemorations of IRS, both pre and pursuant to the IRSSA, I will also discuss the ways in which commemoration has been differently and diversely 
conceived and practiced to meet community and Survivor-centric needs, and in particular the need for collective healing from historic trauma. From these analyses I will present a series of considerations and recommendations to move toward bridging the gap between the ways in which HSMBC designates and commemorates heritage sites, and the needs of Survivors and other IRS stakeholders. The intent of this research is to provoke discussion, stimulate new research, and inspire innovation in federal place-based heritage practice.

\subsection{Methodological Considerations}

Although this project could be expanded to encompass Indigenous research methods such as oral histories, sharing circles, and ceremonial methods, for the purposes of managing its scope, I restrict the research methods to those listed below and discuss the research limitations. The ethics of post-positivist approach demand that I recognize and establish my specific subjectivities as researcher. Given my positionality as a settler-scholar, a neopositivist approach is neither possible nor ethical. I have worked for Aboriginal organizations in a senior capacity for the past decade. My last positions were held with the related not-for-profit agencies: the Legacy of Hope Foundation and Aboriginal Healing Foundation. In my position(s), I was privy to, and participated in commemorating IRS, and was also heavily involved in developing public information, exhibitions, and curriculum to raise awareness and educate the public, and specifically youth, on the history and impacts of IRS. I was also a project leader in the AHF/AHF IRSSA commemoration project that is profiled in Chapter 4. In these capacities, I regularly worked in collaboration with First Nations, Inuit, and Métis Survivors and 
intergenerational Survivors, Indigenous artists, curators, and educators, as well as Indigenous and non-Indigenous scholars, designers, and educators, and benefitted from the guidance of Indigenous Elders. I regularly participated in Indigenous ceremonies and practices. This experience provided me with a level of Indigenous cultural competency and a unique frame of reference, which allows me to critique policies from a more balanced perspective than what might be expected from an uninvolved non-Indigenous person. That being said, as a non-Indigenous person, I recognize that I unknowingly and unwilling represent bias, white privilege, and may inadvertently re-inscribe the very settler-colonist impulses that I attempt to resist through my research practice.

Drawing from theory in cultural studies and from a heritage lens, I critique 'official' models and practices of heritage management that are created and sustained through the application of the HSMBC and NPHC policy, primarily the General Guidelines, Specific Guidelines for Evaluating Subjects of Potential National Historic Significance (Parks Canada 2008), the National Program of Historic Commemoration System Plan (2000) and HSMBC Agenda Papers and Minutes related to applications for designation of former IRS sites.

Paraphrasing Dempsey, Gould, and Sundberg (2011), they ask us to consider the particular rationalities (representations, knowledges, and expertises) the practice of governing involves, and exhort us to observe and critique these representations, not merely as descriptive of the spaces and subjects to be governed, but as productive of space and subjects both epistemologically and ontologically (239). This critique examines how HSMBC's policies creates subjects and identities which become Other 
through processes of distancing and objectification; recognizes the mechanisms of official heritage designation and commemoration as forms of governmentality and political technology that function as political and cultural agents in influencing memory and identity; and, discusses how HSMBC deploys 'official' heritage discourse to manufacture consent.

My literature review contextualizes 'official' federal place-based heritage practice in Canada within existing and emerging theorizations and practices of heritage, including ‘Authorized Heritage Discourse', values-based heritage discourses, dissonant and subaltern discourses, as well as literature related to difficult knowledge and heritage, monumentalization and counter or anti-monuments, sites of conscience and pedagogies of witness. I also review a selection of pertinent examples of art used for countermemorialization in Canada and abroad to discuss: the role of art and artists in commemoration; Indigenous representation and counter-hegemonic voice; art as resistance; and, public art, its supplementation (layermaking), and archiving as a social corrective.

Through an initial analysis of 34 of the IRSSA commemoration projects performed in the planning states of this research, it became apparent that many of the projects shared the attributes of Aboriginal Healing Foundation (AHF)-funded healing programs. ${ }^{5}$

5 The AHF was an Aboriginal not-for-profit organization that operated between 1998 and 2014 for the purposes of funding community-based healing programs that address trauma related to physical and sexual abuse in IRS and of conducting related research and evaluation. As a Director in the AHF at the time of initiating this 
Recognizing the need to draw on Indigenous research and methodologies, this realization lead to a redesign of the analysis, which allowed me to draw more accurate comparisons, and also inspired investigation into the relationship between commemorative practice related to histories of trauma, and healing. These frameworks include, Deborah Chansonneuve's Healing Journey, developed as a resource for front-line health workers (72), Linda Archibald's Framework for Understanding Trauma and Healing (Appendix A), grounded in her assertion, "healing from historic trauma can be viewed as a path that borrows from learning in the trauma recovery field coupled with decolonization theory. ${ }^{6}$ The framework communicates the foundations of healing historic trauma, and identifies the program elements necessary for healing. A third, composite and comparative, Framework for Healing and Decolonizing, Appendix B, draws from 3 sources, Poka Laenui's Process of Decolonization and Judith Herman's Three Phases of Recovery from PTSD, and Archibald's own Healing and Decolonizing stages (Archibald 23).

Respectfully drawing from all three models and adapting them for use in designing and evaluating commemoration initiatives (as opposed to healing programs) that address historic trauma related to IRS, I have posited a bybrid model - Commemoration as a Decolonizing Healing Practice. This model is used as the framework for correlating and comparing the various practices and activities associated with IRS commemoration with

thesis, I was already familiar with AHF's body of work related to healing historic trauma.

${ }^{6}$ Wesley-Esquimaux and Smolewski agree that the treatment for PTSD makes sense in the initial phase of healing the effects of historic trauma" (qtd. in Archibald 20). "The aim of these therapies is to help traumatized people move from being dominated and haunted by the past to being present in the here and now, capable of responding to current exigencies with their fullest potential" (Wesley-Esquimaux and Smolewski 78). 
healing practices that address historic trauma. The analysis and results are also presented in Chapter 4.

For the purposes of reviewing and surveying Indigenous-lead IRS commemorations, I employ the following methods: review of secondary source material primarily drawn from the research of Anna Brace on pre-IRRSA commemorations, quantitative and qualitative analysis of IRSSA commemoration projects (Appendices C and D), using project descriptions provided by AANDC - Appendix F as source data, to gain insight into the concerns, values, approaches, and strategies of Survivors and their advocates. In order to manage the scope for this project, its subjects and sources are limited to: federal place-based heritage infrastructure, the HSMBC policies and practices as expressed in materials accessible to the public, its decisions related to IRS based on minutes, agenda papers, and supplementary reports provided by Parks Canada; IRS as defined in the IRSSA; limited secondary source research on pre-IRSSA commemoration, limited source material on IRSSA commemoration, being descriptions provided by and made publically available by AANDC.

My aspirations for this work is for it to contribute to the TRC Final Report, providing a source of research to inform a series of recommendations to effect change to the ways that Canada commemorates IRS. This research contributes to ongoing scholarly discussion on heritage policy in Canada and can also assist the work of the TRC in providing a rationale and recommendations to challenge the HSMBC (if the TRC is so inclined) to change and expand: the ways in which it interacts with applicants and the 
public; the criteria against which it evaluates potential objects of commemoration; and, the array of modes of commemoration it supports. The anticipated results of this works is a series of considerations and recommendations to stimulate discussion within TRC, and in turn, HSMBC and other members of the heritage profession in Canada, toward realizing a dialogic practice of heritage and commemoration, and to argue for recognition of sites of trauma within Canada such that their transformation into sites of conscience is made possible. This research is a first, rudimentary foray into identifying promising practices in commemorating IRS, which has the potential to impact broader commemoration of sites of trauma. It is my profound hope that this area of study receives broad academic interest. 


\section{Chapter: Remembering IRS: Trauma, Witnessing, Healing}

\subsection{Context}

In 2012, the TRC published its IRSSA-mandated interim report, prepared the previous year, under the title They Came for the Children: Canada, Aboriginal People, and Residential Schools. This 'historical report' sought to synthesize existing research, published testimony and other published materials, numbering over 200 sources, on the history and impacts of the IRS (Truth and Reconciliation Commission of Canada). As a condensed history plainly written, it is a credible starting point for a discussion on the impacts of residential school and the necessity for mobilizing heritage to support ongoing healing. Before progressing to a discussion of heritage and healing however, I present the briefest of overviews of the IRS system starting with the contested definition of 'residential schools'.

The IRSSA establishes the criteria for schools considered IRS in Article Twelve Additional Residential Schools, Section 12.01 - Request to Add Institution, Subsection (2), which stipulates that "a) The child was placed in a residence away from the family home by of under the authority of Canada for the purposes of education; and, b) Canada was jointly or solely responsible for the operation of the residence and care of the children resident there" (Indian Residential Schools Settlement Agreement). The system operated for over a century, the first IRS recognized in the IRSSA, the Mohawk Institute in Brantford, Ontario having opened its doors in 1831, and the last, Gordon IRS in Punnichy, Saskatchewan, having closed in 1996. The Aboriginal Healing Foundation favours a more expansive view of the IRS system, it asserts encompasses “...industrial 
schools, boarding schools, homes for students, hostels, billets, residential schools, residential schools with a majority of day students, or a combination of the above" (2001: 5). A contentious issue, many Survivors were left out of the IRSSA and its compensation and commemoration programs due to the failure of their schools or the circumstances of their residence to meet its criteria. For example, many IRS were provincially (as opposed to federally) funded or were funded by independent organizations, such as 5 schools situated in Nunatsiavut, which were funded by Moravian Missionaries and the Grenfell International Association. ${ }^{7}$

Although arguments for conferring heritage designation on IRSSA-recognized schools, those 139 for which Canada has admitted responsibility, are herein presented, a candid and open approach to commemorating IRS sites of trauma would necessarily be inclusive of all IRS, regardless of the details of their administration. According to AANDC's December, 2013 update on the implementation of the IRSSA, 9,457 people had applied to add 1,521 distinct institutions to the Agreement, of which seven have been added (Aadnc-aandc.gc.ca C). It was initially thought that approximately 150,000 Aboriginal children - mostly First Nations but also Métis, and later, Inuit, attended these schools, which were made mandatory after 1920. Yet given the number of Survivor claims external to the IRSSA, this number may represent only a fraction of the total. Mandatory attendance was enforced by Indian Agents with powers of Truant Officers pursuant to

${ }^{7}$ Class action lawsuits initiated by Survivors of 5 Nunatsiavut schools in 2008 allege "that the sole defendant in these actions, the Canadian Government, had the full responsibility for these residents after Newfoundland and Labrador joined the Confederation on March 31, 1949" (Kmlaw.ca). 
Indian Act Section 119 (6), which stipulates, “A truant officer may take into custody a child whom he believes on reasonable grounds to be absent from school contrary to this Act and may convey the child to school, using as much force as the circumstances require." These agents were assisted in their often coercive and forceful round-ups of children $^{8}$, some as young as four and five, by the Royal Canadian Mounted Police (RCMP). ${ }^{9}$

Almost all residential schools were situated off reserve and in many cases were established in remote locations, inaccessible to the parents of their pupils. Nicholas Flood Davin, a bureaucrat sent to the US in 1879 by Sir John A. Macdonald, concerned with government obligations to their 'Indian wards" ${ }^{10}$, to meet with the Department of Indian Affairs and learn about their 'aggressive assimilation' policy, later recommended the Canadian Government establish industrial boarding schools far from reserves (Miller 1996; Milloy 1999; Titley 1986). Two earlier recommendations, those of the 1842 Bagot Commission calling for the establishment of agricultural or industrial-based boarding schools, and Egerton Ryerson's 1847 report, which made similar recommendations but also exhorted the benefits to be gained from religious instruction, influenced the schools' design (Miller 1996). And so in 1892, the Federal Government and Catholic, Anglican, Methodist, and Presbyterian churches entered into a formal partnership to establish and

${ }^{8}$ Consider United Nations Convention on the Prevention and Punishment of the Crime of Genocide, Article II, Subsection e) Forcibly transferring children of the group to another group.

${ }^{9}$ One could only hope that the admitted involvement of the RCMP in enforcing IRS attendance (Rcmp-grc.gc.ca) would move state historiographers to dispel any lingering vestiges of the 'benevolent Mountie myth' in narratives of Canada. 10 Indians became wards of the crown under the British North America Act. 
administer a system of Indian industrial boarding schools (later called residential schools). The agreement stipulated that while the Federal Government would fund the schools, the churches would manage their operations. Although industrial training programs were gradually replaced in favour of less expensive 'formal' education, students continued on a half-day system with half of the day spent performing manual labour (often to support the operation of the school and its farms), and the other half in religious and rudimentary 'educational' instruction.

Varied archival sources indicate that, almost from the onset, parents and Indigenous leaders became concerned with the lack of qualifications of teachers (Barman, Hébert and McCaskill 11), and became cognizant of instances of abuse (10). Brought to the attention of government agents, their concerns "were of no legal consequence because under the Indian Act, all Aboriginal people were wards of the state. School administrators were assigned guardianship, which meant they had full parental rights over the students" (Legacyofhope.ca -A). According to Educator Celia Haig-Brown, "abuse at the schools was widespread: emotional and psychological abuse was constant, physical abuse was meted out as punishment, and sexual abuse was also common. Survivors recall being beaten and strapped; some students were shackled to their beds; some had needles shoved in their tongues for speaking their native languages" (Haig-Brown 1998, 16). AHF Researcher Vanessa Stevens explains that "broad occurrences of disease, hunger, and overcrowding were noted by government officials as early as 1897" (Legacyofhope.ca B). In 1907, Indian Affairs' Chief Medical Officer, Dr. P.H. Bryce, who, along with several other doctors, had surveyed the conditions of the schools, noted a death rate 
among the children "ranging from 15-24\% - and rising to $42 \%$ in Aboriginal homes, where sick children were sometimes sent to die" (ibid). In some individual institutions, for example File Hills IRS in Saskatchewan, 75\% of the students had died over the 16 years of the school's operation (Milloy, 91; Fournier and Crey, 49). The Department of Indian Affairs, under the leadership of Deputy-Superintendent Duncan Campbell Scott deliberately ignored recommendations by Bryce and failed to implement a standard of care that could have prevented the ongoing spread of tuberculosis and other diseases in the schools (Milloy 97). Instead, he terminated Bryce and expanded the IRS system through compulsory attendance (Titley 1998: 87, 90). The government's willful disregard for the basic needs of the children in their care, and the perpetuation of the conditions that were known to cause death, appears to approach United Nations Convention on the Prevention and Punishment of the Crime of Genocide Article II, subsection c) Deliberately inflicting on the group conditions of life calculated to bring about its physical destruction in whole or in part. Incidentally, Duncan Campbell Scott is the only person closely associated with the IRS system upon whom Canada has conferred Person of National Historic Significance Status. Scott is celebrated by the HSMBC as a poet of the "Sixties Group, advocate of education, and for his Christian ideals." On his commemorative plaque, a single sentence related to his darker past reads: "To Scott, the Indians were a people in evolution to be assimilated into white society through education and the teaching of Christian ideals" (Pc.gc.ca, Scott, Duncan Campbell National Historic Person). 
In his Epilogue of his influential 1999 work, a National Crime: The Canadian Government and the Residential School System - 1879 to 1986, Milloy discusses the schools' deepest secret, "persistent, widespread sexual abuse" that came to light through media reports and court cases in the 1980s (xvii). Convictions in the late 1990s against former Alberni IRS boys supervisor Arthur Henry Plint “on 36 counts of sexual assault committed between 1948 and 1968 and in 2003, against dorm supervisor Donald Bruce Haddock, who pleaded guilty to four counts of indecent assault which occurred at Alberni IRS between 1948 and 1954...led BC Supreme Court Justice Douglas Hogarth to declare "the Indian residential school system was nothing more than institutionalized pedophilia" (Thechildrenrememberd.ca). As of 2014, adjudicators in the Independent Assessment Process (IAP), a component of the IRSSA, the Federal Government, and the TRC are battling each other over what to do with the " 800,000 audio recordings, transcripts and other documents associated with 38,000 claims of sexual abuse, physical abuse and other heinous acts" (Wittmeier). Access to these valuable records, which offer the evidence, consistent with standards of proof used by civil courts "in matters of like seriousness" and becoming additionally rigorous "as the alleged acts become more serious," to support the $\$ 2.235$ billion in approved payments, are essential to understanding the nature of the abuses suffered in the schools. Given the average payment of $\$ 115,250$ (Aadncaandc.gc.ca - C) based on an accumulation of approximately 75 compensation points for acts proven, consequential harm, aggravating factors, and consequential loss of opportunity, with the most serious acts proven - code SL5, being, "repeated, persistent incidents of anal or vaginal intercourse, repeated, persistent incidents of anal/vaginal penetration with an object" (IRSSA, Schedule "D") rating only 45-60 points, one can 
infer the seriousness of the physical and sexual abuses endured at the schools. Despite the possibility of IAP records becoming available to researchers, because the number of Survivors who experienced acts of abuse ${ }^{11}$ but who did not participate is incalculable, we will never learn the extent of the abuse in the IRS. ${ }^{12}$

It is important to stress that not all children were abused, and that the conditions of the schools and the character of those who worked in them varied relative to time and place. Some Survivors, although they are proportionately very few, report positive overall IRS experiences (Legacyofhope.ca -A). One common feature, that all Survivors share, is the experience of being taken from their home and community for the purposes of indoctrination into settler society - in a system designed, as affirmed by Prime Minister Stephen Harper on the occasion of his historic apology to Survivors, to 'kill the Indian in the child'.

Until extant oral histories and archival records collected by the TRC and delivered to the National Research Centre for Truth and Reconciliation, are catalogued, aggregated, and analyzed across multiple vectors, our picture of residential schools will remain limited.

11 (of a nature or severity that might have met the requirements for compensation).

12 Among reasons for not participating was reluctance or inability on the part of Survivors to endure the vicarious trauma of communicating their experiences of abuse. Given that one of the documented negative impacts of the Common Experience Payment (CEP), a payment issued to every Survivor for whom records of attendance at an IRSSAapproved IRS were available, was suicide (Reimer and Bombay 54), one can imagine the multiple negative impacts of recounting serious childhood traumas and their ongoing impacts. In addition, consider the toll on Survivors of the emotionally-taxing labour involved in researching and gathering the records and resources required to meet the evidentiary standards of the IAP. 
Given that only those Survivors sufficiently advanced in their healing journey ${ }^{13}$ braved IRSSA processes and entrusted their mechanisms of witness with their stories, we will never fully know what Survivors experienced in the schools and will never fully grasp their legacy on Survivors, their families and communities, on Indigenous cultures, and on Canada as a whole. With that caveat, and considering the following chain of events that lead to extensive research we now possess, enough is presently known about the IRS and its legacy to compel, on the part of Canada and Canadians, an ethic of devoir de mémoire. The TRC, in its interim report asserts "Canadians have been denied a full and proper education as to the nature of Aboriginal societies, and the history of the relationship between Aboriginal and non-Aboriginal peoples," which has lead to racism, and hostility (Truth and Reconciliation Commission of Canada 86). Such an education is but one of the many ongoing calls on the part of Aboriginal peoples and their nonAboriginal allies for recognition of the IRS system - and indeed the violence of settler colonialism, as a genocide. Yet, as seen below, the drive to inscribe histories of violence and trauma upon our annals, committing them to our technologies of memory and in doing so realizing our duty to remember that is, at every pass, drawn in contention with Canada's equally motivated drive to contain and control its historiography.

\subsection{Witnessing}

Among the rationale and recommendations made in Volume 1 of the RCAP report: Looking Forward, Looking Back, part 2, c.10, "Residential Schools," Recommendation

13 In addition to being informed of the availability of IRSSA processes and possessing the means and capacity (mental, physical, emotional, financial) to participate. 
1.10.1 "The Need for a Public Inquiry," is the establishment of a "national repository of records" to facilitate the collection of testimony and to support ongoing research (Erasmus and Dussault Vol.1.2.c.10). The mechanism of a public inquiry was regarded by the commissioners, at the time, as the appropriate mechanism of investigation and the means to providing the evidence necessary to compel remedial action by the responsible parties. Subtending clauses further recommended the development of curricula and public education programs "on the history and effects of residential schools and remedies applied to relieve their negative effects" (ibid. 1.10.3). Despite a federal response to the report that involved setting aside funds for healing programs designed to address the effects of physical and sexual abuse in the schools ${ }^{14}$ RCAP's proposed manifestation of the 'will to remember' through a public inquiry was not supported. In the years following the report, litigation and a heavily criticized Alternative Dispute Resolution program became the primary means by which Survivors sought legal redress, while interest in the RCAP findings among the public waned and the report itself went out of print (Stanton 2010: 52-53). ${ }^{15}$ Legal scholar Kim Stanton suggests "the government could afford not to act on the Report given that RCAP had not built up public support ... [for] their recommendations" attributed by the Aboriginal Rights Coalition to "a decline in public sympathy for indigenous issues due to high profile land disputes and the rise of more conservative political movements that emphasized the need to treat indigenous peoples

\footnotetext{
${ }^{14}$ For more information on Gathering Strength: Canada's Aboriginal Action Plan, 1997, visit http://publications.gc.ca/collections/Collection/R32-192-2000E.pdf ${ }^{15}$ For a detailed discussion on the federal response to RCAP's call for a public inquiry and the eventual appointment of the TRC as a provision of the IRSSA, see Stanton, Kim Pamela. Truth Commissions and Public Inquiries: Addressing Historical Injustices in Established Democracies. Diss. University of Toronto, 2010.
} 
the same as other Canadians, an approach that RCAP 'had emphatically shown had been a policy disaster in the past"” (53-54). Thus the lack of public will to support the proposed mechanisms of memory, among the many other RCAP recommendations, was itself a byproduct of public ignorance of the disasters of past Indian' policy (of which land disputes is but one inheritance) buttressed by an intentional and ongoing policy of containment and erasure, founded in ages old systemic racism.

As Ernest Renan suggests, "forgetting... is a crucial factor in the creation of the nation which is why progress in historical studies often constitutes a danger for nationality" asserting that "historical enquiry brings to light deeds of violence which took place at the origins of all political formations" (11). The cost to the government of intentionally ignoring much of RCAP's report and forgetting the 'dangerous history' it began to uncover proved dearer than anticipated. Forced into litigation, Survivors brought "an enormous volume of civil lawsuits" against the government and churches, resulting in mushrooming defence costs and staggering projections (Stanton 2010: 73). Citing a study by the $\mathrm{AFN}^{16}$, Stanton states " the sheer volume of claims would have taken the courts an estimated 53 years to conclude, at a cost of \$2.3 billion to litigate" (ibid). In negotiating the IRSSA, Survivors and their advocates pushed not for 'another' public inquiry, but a truth commission, "that would acknowledge and witness the IRS system and its impacts, and that would also increase awareness of - and create a public record of - the system and the impacts" (ibid 78).

16 Assembly of First Nations, Report on Canada's Dispute Resolution Plan to Compensate for Abuses in Indian Residential Schools, 2004. 
Cognizant of the need to engage the public, the commissioners of the TRC courted the media, held well-publicized public events, and engaged high-profile honorary witnesses, such as former Governor-General Michä̈lle Jean, to draw attention and stimulate discussion among diverse population segments. Thus the will of Survivors and their advocates to remember is creating a sense of devoir de mémoire (duty to remember) among Canadians. As a key strategy and means to engage Canadians, intentional witnessing (truth) becomes a force for recognition (justice). Not to be confused with compensation, a component of justice entails recognition of culpability and the protection of memory from erasure, which promotes its sustainability across generations. The battle against forgetting is ongoing. The capacity of the National Research Centre for Truth and Reconciliation (NRC), RCAP's proposed national repository of records manifested through the IRSSA, is actively being thwarted (logistically and financially) in its attempts to acquire all relevant records and support ongoing research, by the current government. ${ }^{17}$ This is but one example demonstrating how intentional forgetting pervades government positions on 'Indian' policy.

\subsection{Understanding IRS Trauma}

${ }^{17}$ This is accomplished by limiting access to and withholding records, making and transferring illegible copies, and ailing to provide funding for ongoing record collection and research. See Chapter 6 of the 2013 Spring Report of the Auditor General of Canada for more information on challenges in creating a historical record of IRS: http://www.oagbvg.gc.ca/internet/English/parl_oag_201304_06_e_38191.html 
While competing desires to remember and forget hold recognition in the balance, Survivors employ memory for another purpose: healing. As has been well documented, abuse was rampant in the IRS system. For over a decade, the AHF conducted research on the experiences, nature, effects, and treatment of abuse originating in IRS. Significant findings from this extensive work, discussed here, relate to the unique and specific nature of the effects of abuse in IRS on Survivors, their families, and communities over generations, and to the culturally-based practices that have been demonstrated to foster and support healing. An understanding of these unique and related phenomena is necessary to interpreting the needs and uses of heritage of Survivors and their communities. In Reclaiming Connections: Understanding Residential School Trauma Among Aboriginal People, an AHF-sponsored resource manual for front-line health workers, Deborah Chansonneuve reports "increasingly, many Aboriginal therapists and frontline workers describe the abuse that occurred at the residential schools as ritual or 'ritualized' abuse” (Chansonneuve 35). Invoking the work of Psychologist Albert Biderman (1957), which charts out the tactics used by Chinese interrogators to elicit confessions from American POWs during the Korean War, Chansonneuve charts ritualized abuse in IRS against Biderman's eight conditions of tactics of power. To paraphrase Biderman, these are: isolating subjects from support systems, monopolizing perception by controlling stimuli, inducing debility and exhaustion, making continuous threats, granting occasional indulgences, demonstrating omnipotence, degrading and humiliating subjects, and enforcing trivial demands (ibid). Chansonneuve compellingly provides examples of the presence of all eight conditions in the context of IRS suggesting that children were subjected to multiple traumas even though ritualized abuse may not 
have been deliberate or intended (41). Here she introduces the concept of historic trauma, defining it as "traumatic experiences that are cumulative over the life span of individuals, as well as across generations" (40). A more detailed definition comes from Cynthia Wesley-Esquimaux and Magdalena Smolewski (2004), who discuss historic trauma as the effect of "Indigenous social and cultural devastation in the present,...the result of unremitting personal and collective trauma due to demographic collapse, resulting from early influenza and smallpox epidemics and other infectious diseases, conquest, warfare, slavery, colonization, proselytization, famine and starvation, the 1892 to the late 1960 s residential school period and forced assimilation" (1). They further assert that historic trauma manifests as an "endemic and complex form of post-traumatic stress disorder (PTSD)" (1).

Understanding psychological trauma as result of being helpless and unable to integrate emotional experience during a traumatic event, Chansonneuve constructs a profile of trauma Survivors in the context of IRS, which includes their descendants, also known as intergenerational Survivors (49). In this continuum across generations, Chansonneuve suggests Survivors are: those adults who as children suffered the trauma of forced removal and relocation; who endured multiple physical, emotional and sexual abuse and/or neglect by caregivers over many years of confinement in IRS; as well as, those generations of family and community members who suffered the loss of their own children and family members, denied the opportunity to raise them and be responsible for them; the descendants who suffered intergenerational impacts of abuse; and finally, 
Aboriginal youth and adults who have been re-victimized many times (49-50).

Examining the impacts of unresolved trauma, and noting its manifestations in substance abuse and addictions, self-harm, dissociation, and re-enactment, Chansonneuve stresses that "the seeds of lifelong mistrust and fear are planted when children are harmed and betrayed by the people they must depend upon for protection and care" and that "unresolved trauma from residential school abuse continues to impact individuals, communities and nations and will continue to do so [generation upon generation] until it can be expressed, validated and released in healthy, creative ways" (51).

Commemoration, as creative practice, can be one of these ways. Any discussion of commemoration or heritage in the context of IRS requires an understanding of the related concepts of healing (in Aboriginal terms) and decolonization. Most fully defined in the RCAP Final Report, Volume 3:

"healing, in Aboriginal terms refers to personal and societal recovery from the lasting effects of oppression and systemic racism experienced over generations. Many Aboriginal people are suffering not simply from specific diseases and social problems, but also from a depression of spirit resulting from 200 or more years of damage to their cultures, languages, identities and self-respect. The idea of healing suggests that to reach "whole health," Aboriginal people must confront the crippling injuries of the past" (17).

Cautioning against the conflation of trauma with disease and Western therapy with cure, Robyn Green further distinguishes Indigenous conceptualizations of healing from Western concepts in asserting that "healing is a process that does not arrive at an end," it subverts tropes of pathology, and it is tied to justice and sustainable self-determination (138). Defining decolonization, a term often defined through its active forms, is an endeavor fraught with contestation. While Sium, Resai, and Ritskes (2012; iii) suggest 
"the decolonizing project seeks to re-imagine and re-articulate power, change, and knowledge," Taiaiake Alfred asserts that decolonization can only be achieved through the "resurgence of an Indigenous consciousness channeled into contention with colonialism" (48). Notwithstanding the various nuances in definitions of decolonization, it stands to reason, that in the text of healing from historic trauma, decolonization is inextricably linked to healing.

\subsection{Healing}

Chansonneuve deploys the ubiquitous, but useful, trope of healing as a journey, referencing the Medicine Wheel healing model as one that promotes reconnection with our inner healing force/spirit to restore trust, self-worth, and our ability to love and to be kind to others in health (72). At the centre of this model is holism, maintaining physical, mental, emotional, and spiritual balance (ibid). The four steps of Chansonneuve's healing journey model are: Restoring a Holistic Life, A Commitment to Safety and Respect, ReEmpower by Restoring Control, and Remembering, Honouring, and Releasing (ibid). Unpacking these steps, it becomes apparent how healing-oriented heritage practices can support a healing journey. For example, discussing Restoring a Holistic Life, Chansonneuve suggests, "healing is said to begin at the point a commitment is made to leave an old way of life behind and begin a new path aimed at restoring balance" (72). This involves discarding old, negative patterns, associations, and memories, and creating new experiences, stories and memories - effectively re-storying. 
Part of the journey of many Survivors has been to revisit, confront, and in some cases, destroy, the site of trauma. Doing so enables them to re-story and reclaim the sites, ridding them of their power to re-victimize. Also on the site, safety and respect can be fostered, particularly if cultural practices are honoured and validated, important steps in restoring trust. Restoring control is equally important in commemoration at the site of trauma, particularly when control is surrendered to those who experienced the greatest harm at the site of trauma. This means relinquishing control with the knowledge that healing and transformation of the site may come at the price of complete destruction of extant material remains. The final step on the healing journey is Remembering, Honouring, and Releasing, which involves “developing a gentle relationship with the triggers that recall trauma such that Survivors can recognize them, anticipate them, and implement culturally-based strategies for managing, overcoming, and releasing them" (75). Implementing culturally-based healing strategies, such as sharing and healing circles (collective remembering in a personally and culturally safe space), ceremonies, song and dance, and art-based workshops at the site in the context of commemoration, can be both healing and decolonizing. Byrne exhorts us to "acknowledge that many of those who have to live in the present with the legacy of trauma are deeply committed to ensuring that their traumatic past ...occupies a permanent place in the landscape of everyday life" (239). Often, it isn't enough to make the site available for commemoration; the recognition that comes through heritage designation or transformation into an active site of conscience ensures that the site and what occurred there is never forgotten. 
In the course of writing the third volume in a series of evaluative reports for AHF-funded programs, Linda Archibald (2006) constructed her framework for understanding trauma and healing as a means to share information about healing practices that were working well in Aboriginal communities. (Archibald 1). It communicates the foundations of healing historic trauma, and identifies the elements required for promising healing practices to be effective, and the three pillars (programmatic elements) necessary to realize healing. At the top of the structure, Archibald identifies the need for healing and defines historic trauma in a manner consistent with previous descriptions. At the base is the environment, the conditions that influence both the need for healing and the success of the healing process (18). In the centre of the structure, the three necessary elements, Aboriginal Values/Worldview, Personal and Cultural Safety, and Capacity to Heal, rest on the three pillars or programmatic elements, Reclaiming History, Cultural Interventions, and Therapeutic Healing (ibid). According to Archibald, "healing from historic trauma can be viewed as a path that borrows from learning in the trauma recovery field coupled with decolonization theory. Wesley-Esquimaux and Smolewski agree that the treatment for PTSD makes sense in the initial phase of healing the effects of historic trauma" (Archibald; 20). Further, Wesley-Esquimaux and Smolewski assert, "The aim of these therapies is to help traumatized people move from being dominated and haunted by the past to being present in the here and now, capable of responding to current exigencies with their fullest potential" (78). Although this model was constructed to evaluation community-based Aboriginal healing programs that address the impacts of historic trauma, it is remarkably similar to Chansonneuve's Healing Journey and can be linked to heritage and commemoration practices in the same way. 
Another tool developed by Linda Archibald (23), draws on Poka Laenui's Process of Decolonization and Judith Herman's Three Phases of Recovery from PTSD in combination with her own formulation on the stages of healing from historic trauma (23). Several 'phases' are common to the three approaches to healing and decolonization, which respectively represent a Sociopolitical Process, a Personal Journey, and a Personal and Collective Journey. These phases are: 'remembrance and mourning' - recognizing, sharing, and grieving loss, 'dreaming ${ }^{18}$ - fully exploring one's culture and traditions while building visions of the future, and '(re)connecting', which may also include giving back or proactive action in the spirit of self-determination. Similarly, public commemoration encompasses the acts of remembrance, connection to the collectivity, and building visions of the future by constructing and commemorating the past in the present.

Applied to heritage, adaptation of promising practices from healing models such as those aforementioned, in designing and evaluating commemoration initiatives that address historic, or other mass traumas, has the potential to create a new ethic, approach, and practice of heritage - one that involves a shift from a 'heritage as conservation' paradigm to 'heritage as healing'. Place-based heritage in particular offers an ideal opportunity for collectively remembering IRS, bridging healing with witnessing (truth) and recognition (justice). In Chapter 4, as an illustration of a heritage practice based on an ethic of 'heritage as healing' I propose and apply to the evaluation of Aboriginal community-

18 Judith Herman's Three Phases of Recovery from PTSD does not explicitly mention 'dreaming' (Archibald 23). 
based IRS commemoration projects a hybrid commemoration model. Before looking at heritage and commemoration alternatives however, it is necessary to evaluate existing place-based federal heritage infrastructure, how is represents IRS heritage, and how it integrates the former IRS sites into the National Register.

\subsection{Conclusion}

It has been made apparent that the IRS system was indeed a national crime. The millions of records that have emerged from the various processes of RCMP investigations, civil litigation, criminal trials, the RCAP and the IRSSA, provide overwhelming evidence of the ritualized abuse visited upon the children who attended IRS, while the extensive research conducted and sponsored by the Aboriginal Healing Foundation and other agencies both isolate and demonstrate the devastating and ongoing impacts of historic trauma and provide proven strategies for healing and decolonization. The TRC have and continue to attempt to keep the memory of IRS in the public consciousness, calling upon our sense of devoir de mémoire. While the federal apology, made in the House of Commons on June 11, 2008, by Prime Minister Harper to Survivors of IRS established the basic facts that the system existed, was wrong, and has had detrimental effect on Aboriginal Peoples, Canada has demonstrated through notable absences in its apparatus of memory, its unwillingness to permanently inscribe these facts on the annals of its history. For example this history is conspicuously absent from the genocide gallery of the Canadian Museum for Human Rights, from the Canadian Museum of History's Canada 
History Hall ${ }^{19}$, and is mandatory in only two educational jurisdictions in Canada, and as we shall see, unrepresented in Canada's National Program of Historic Commemoration (NPHC).

This silence suggests that Canada lacks the vocabulary to accurately represent its own history of settler-colonial violence. Even less is Canada equipped to interpret its difficult heritage to a public long nurtured by nationalistic sentiment fattened on tropes of peaceable settlement by Canada's 'founding peoples' - the English and the French. Concomitant to this lack is the denial of recognition of both the suffering of Aboriginal Peoples and also of their rights and rightful place as distinct nations. Without change that would combat public ignorance and attendant racisms, we cannot as a nation, move into the phase of critical self-reflexivity required to renew our values of human rights, equity and democracy. We will continue to remain a place of myths and fragile solidarity. Although, as stated previously, the only institution of memory herein addressed is Canada's place-based federal heritage infrastructure, this discussion impacts and provides strategies for recognizing not only heritage as a healing and decolonizing practice, but also social and political action, archiving, participatory public art practice and witnessing in other contexts. It is with the assumption Canada needs to and inevitably will move into this phase, that I move first into a critique of the HSMBC and the current constraints that make it ineffective in addressing our difficult and incriminating heritage and subsequently into a discussion of culturally competent and appropriate alternatives.

19 The Canada History Hall of the Canadian Museum of History is currently undergoing renewal. 


\section{Chapter: Forgetting IRS: Containment and Erasure}

139 former Indian residential schools, some razed, some derelict, a few gingerly adapted to new uses, others rebuilt or renovated beyond recognition, litter the Canadian landscape. Geographer Geoffrey Carr questions, "whether the sheer geographic and temporal scope of this traumatic social memory could ever be managed by official bodies, such as the Monument Board or Parks Canada" (132), and indeed HSMBC's own record related to inquiries and applications to commemorate $\operatorname{IRS}^{20}$ appears to encourage Carr's skepticism. One might question whether Canada's NPHC and HSMB are the appropriate mechanisms to determine the heritage value of the 139 sites, either individually or as a national network, to decide when and how they should be commemorated, and to author appropriate Statements of Commemorative Intent, the narratives that rationalize their inclusion in Parks' system of National Historic Sites and by which Canadians become cognizant of their historic significance? While I would not question HSMBC's capacity in determining the heritage value of would-be historic places $^{21}$ on the basis of the range of values, such as architectural and aesthetic, it currently recognizes, and acknowledge that it routinely commissions research to assist in its determinations of these and other values - historical, cultural, natural, and now spiritual, I do question their legitimacy as arbiters of our collective history. Further, when a potential

\footnotetext{
${ }^{20}$ A summary of HSMBC responses to IRS inquiries and nominations is presented later in this chapter.

21 Canada's Historic Places uses the following definition: "A historic place is a structure, building, group of buildings, district, landscape, archaeological site or other place in Canada that has been formally recognized for its heritage value by an appropriate authority within a jurisdiction" (historicplaces.ca).
} 
object of commemoration is steeped in 'traumatic social memory', and additionally represents memory of a self-critical nature, a category largely unrepresented among the 956 designated sites, my confidence in their expertise wanes further. These apprehensions are substantiated in the ensuing critique of the legislation, policy, and practice that guides the Board's decision-making, which, as we will see, has proven unequal to the task of reckoning with the former IRS sites.

Concerning appropriateness of these programs to commemorate IRS however, consider the stated mandate of HSMBC, to "provide advice to the Canadian government on the designation of places, persons and events that have marked and shaped Canada," and their obligation to duly consider nominations, $95 \%$ of which are submitted by the public (Pc.gc.ca). HSMBC manages the one national program to which private citizens can apply to commemorate places, persons, and events they deem to be of national historic significance. The 139 IRS recognized in the IRSSA comprise a federal system of schooling that has had, by the Government of Canada's own admission, “.... lasting and damaging impact on Aboriginal culture, heritage and language" (Aadnc-aandc.gc.ca-A) and constitutes a "... sad era of our history" (Aadnc-aandc.gc.ca-B). ${ }^{22}$ It is on that basis, I argue, the IRS system - an acknowledged part of our history, which has marked and shaped Canada so profoundly that it warranted not only a federal apology, but a 10-year national healing strategy and its own TRC - merits greater attention from the HSMBC.

22 The first quotation is from the Statement of Apology offered by PM Stephen Harper in 2008 and the second is from Notes for An Address by Hon. Jane Stewart, then Minister of Indian Affairs and Northern Development on the occasion of the unveiling of Gathering Strength - Canada's Aboriginal Action Plan in 1998 - see Works Cited for bibliographic information. 
Not only are there persons associated with the IRS, some of whom have already been deemed Persons of National Historic Significance for other associations ${ }^{23}$, but also events of significance within the period of the system's formation, operation, and closure that warrant nomination. It is beyond the scope of this thesis, the subject of which is commemorating the network of former IRS sites however, to argue for their inclusion. ${ }^{24}$

There is evidence to suggest that there is interest on the part of HSMBC to designate one or more IRS, however, I believe that three major factors, later discussed, are impeding progress on this front: limitations imposed by the guidelines that relate to heritage value and commemorative integrity; pressure from AANDC to postpone or suspend designations of IRS pending the TRC Final Report and similar pressure to act in solidarity with AANDC in their response to that report; and, systemic reluctance to introduce state histories of trauma and victimization into the national narrative and social memory of Canadians. Historian John Gillis argues, “...for those who regard the national 'heritage' as a sacred text, the democratization of memory is equivalent to profanation, or, what is worse, cultural suicide" (19). Indeed, for HSMBC to meaningfully and candidly explore Canada's history and heritage of settler colonization, an unprecedented level of public (and largely Indigenous) inclusion, would be necessary, which may effect greater democratization of heritage processes and revised representations of Canada.

${ }^{23}$ Sir John A. Macdonald and Duncan Campbell Scott, for example, have been designated Persons of National Historic Significance, however persons such as Regina Industrial School student and prominent case study Thomas Moore, Medical Examiner and IRS critic Dr. Peter Bryce, and missionary E.F. Wilson, have not. 24 Despite this limitation, many of the arguments herein, particularly with regard to shifting understandings and uses of heritage, equally apply to and support persons and events. 
Heritage scholar LauraJane Smith (2206) describes this tension as one teetering between a desire to include and a hesitancy to surrender (38). Whether moving toward a greater democratization of heritage in Canada would effect cultural suicide or cultural awakening and consciousness-raising is unknown, however similar discussions and explorations have and are taking place to positive effect elsewhere, as we shall see in Chapter 4. Before moving into a critique of the 'sacred' national text and its protectors, followed by a discussion of competing and shifting heritage values and how they are interpreted and put to use by HSMBC and others, a very brief introduction to relevant debates in heritage is needed, and follows.

\subsection{Evolving Theorizations of Heritage}

Prominent heritage scholars LauraJane Smith (2006) and Rodney Harrison (2013), describe the field of heritage as rooted in 'official' or 'authorized heritage discourse' (AHD) that evolved from international (Western) heritage preservation and conservation movements led by the International Council on Monuments and Sites (ICOMOS) ${ }^{25}$ and the United Nations Education, Scientific and Cultural Organization (UNESCO) in the 1970s but with roots from the 1880s. Their charters and conventions ${ }^{26}$ have long since dictated the terms of heritage, constituting and legitimizing what heritage is, and defining

${ }^{25}$ ICOMOS, the International Council on Monuments and Sites, is the Advisory Body of the World Heritage Committee for the Implementation of the World Heritage Convention of UNESCO. Its mission is to promote the conservation, protection, use and enhancement of monuments, building complexes and sites (ICOMOS Mission). 26 The Getty Conservation Institute publishes an exhaustive list of cultural heritage policy documents including charters, conventions, resolutions and recommendation online. See https://www.getty.edu/conservation/publications_resources/research_resources/ charters.html 
who has the ability to speak for and about the nature and meaning of heritage (L. Smith 29). Harrison (2013) describes official heritage as the result of a lineage of actions and actors that evolved under the duress of perceived and real threats to sites valued by certain Western nations in the 1960s and 70s and totalized as sites of universal value.

Both Smith and Harrison critique the AHD or 'official' heritage discourse and elitism in the heritage profession, as inhibitors to a broader understanding and practice of heritage in society. Their theorizations of heritage, which are presented later in this text, are particularly useful to respond to challenges posed by difficult inheritances such as genocide and colonial violence, as well as those of epistemological and ontological diversity and dissonance. For this reason, they are featured prominently in this discussion. According to Smith, the AHD ascribes value and meaning (moral, aesthetic, historical, pedagogic) and identifies uses (political, moral, educational) of heritage in the present and the future. Harrison explains that the Hague Convention for the Protection of Cultural Property in the Event of Armed Conflict (1954) recognized "an explicit connection between cultural heritage and national identity, and the use of heritage in nation-building. It also put the destruction of 'cultural property' on par with the killing of civilians" (56). As described by Harrison, heritage became a specialized field, the purview of experts removed from the local, and "redeployed as a national, statecontrolled, professionalized practice" (56). The power of the state to construct [and willfully distort] history is actually enshrined in the AHD, which, as Smith suggests, constructs heritage as something that is engaged with passively (31). Thus the newly professionalized field of heritage established standards that supported elite heritage 
practice by states, which, concerned with protection of cultural property constructed as significant in their own nation-building, created narratives to be received by a passive public.

Post-modernity, or what Harrison calls 'late-modernity', he describes as a period that experienced a crisis in historicity, related to "an increasing inability to reconcile an understanding of history as presented with the live experience of everyday life" (77). This crisis has precipitated a phenomenon that has been alternatively theorized as the ‘acceleration of history' (Nora 1989), a ‘surfeit of memory’ (Maier 1993; Huyssen 2000), 'creeping heritage' (Lowenthal 1985) and a 'heritage boom' (Harrison 2013), characterized by an intense interest in history, heritage, and memory. In The Invention of Tradition, Historian Eric Hobsbawn (1983) distinguishes between 'political' tradition manufactured by the state and 'social' - invented the community (96). The 'social' tradition here can be interpreted as 'unofficial heritage', rooting in local experience and values - a counterpart and corrective to 'official' heritage. The heritage boom inspired fervent academic production, particularly in the area of collective memory. Considering would-be heritage sites, events or persons, French historian Pierre Nora (1989) posits that if 'lieux de mémoire' - sites of memory, are not constructed as history to replace milieux de mémoire - real environments of memory, that the significance of the milieux will fade from collective memory. ${ }^{27}$ Asserting that history eradicates memory, Nora asserts “...its

${ }^{27}$ Nora defines 'lieux de mémoire' in Realms of Memory Vol1, p6, by means of example: as "the archives and the tricolor; libraries and festivals; dictionaries and the Pantheon; museums and the Arc de Triomphe; the Dictionnaire Larousse and the Wall of the Fédérés" (12). According to Vietnamese historian Hue-Tam Ho Tai, 
true mission is to suppress and destroy it" (9) and that the two are in opposition with the effect of historiographical unsettling - casting historians as the victim of memories (10); burdened with the challenges of achieving polyphony not cacophony.

Nora limits the concerns of preserving memory through history (and heritage), indeed of historiographical objectification of memory, to modern nations - those possessing a history as opposed to cultural memory. He suggests, “... a process of interior decolonization has effected ethnic minorities [which he elsewhere describes as 'memory' cultures and 'primitive' cultures] ...that until now have possessed reserves of memory but little or no historical capital" (7). Such perspectives ring antiquated and out of place in Nora's discussions of the acceleration of history, however the relative paucity ${ }^{28}$ of both pre and post-contact Indigenous historical, as opposed to cultural, heritage designations in Parks Canada's heritage directory suggests he is not alone in this view. While Nora ascribes incredible power to the historian, archaeologist Denis Byrne (2009) cautions, “catastrophic events may be 'buried' by the state's control of official history but this does not mean they cannot be recuperated by local action" (234). Promisingly, Huyssen suggests, "as historiography has shed an earlier reliance on teleological master-narratives and has grown more skeptical of nationalist framings of its subject matter, today's critical

the range of 'lieux' can also be expanded to encompass other examples contained in the 6 volumes such as real people (Joan of Arc), mythic figures (the Good Soldier Marianne was excluded), battles, competitions (Tour de France) and novels (Tai 907).

${ }^{28}$ According to Park's Canada's National Historic Sites of Canada System Plan (2000), "Analysis of the strategic priorities supports the consultation feedback that there are, indeed, substantial system gaps" (Parks Canada - System Plan 39). Commemoration of Aboriginal history is listed as a strategic priority. 
memory cultures, with their emphasis on human rights, on minority and gender issues, and on reassessing various national and international pasts, go a long way to provide a welcome impetus for the writing of history in a new key" (435). But can we consider Canada the host of a critical memory culture, or more specifically, a popular critical memory culture?

In discussing difficult knowledge ${ }^{29}$ and commemoration it is imperative to consider heritage's inherent dissonance. McClelland and others citing Tunbridge and Ashworth define "dissonant heritage, as... discordance and disinheritance...integral to the concept of heritage, and are particularly evident in its use (or abuse) as a cultural, political and economic resource" (585). Tunbridge and Ashworth (1996) consider "atrocity heritage particularly prone to many types of dissonance" (21). Vinitzky-Seroussi (2002) citing Kertzer (1988) suggests that commemorating difficult pasts invariably creates multivocal/or fragmented commemorations (Vinitzky-Seroussi 2002), both of which are strategies to cope with dissonance. Vinitzky-Seroussi further asserts that multi-vocal commemoration "is about a shared space... a shared time, or a shared text that carries diverse meanings and thus can be peopled by groups with different interpretations of the same past" while fragmented commemoration "includes multiple commemorations in

${ }^{29}$ Sociologist Roger I. Simon (2011) suggests that knowledge presented in a curatorial context can be deemed difficult when: "it confronts visitors with significant challenges to their expectations and interpretive abilities - for example when historical narratives produce conflicting, complex, and uncertain conclusions; elicits the burden of 'negative emotions' ... revulsion, grief, anger, and/or shame that histories can produce...if they raise the possibility of complicity of one's country, culture, or systemic violence such as the seizure of aboriginal land, the slave trade, or genocide; or, evokes heightened anxiety that accompanies feelings of identification of the victims of violence, the perpetrators... or bystanders" (194). 
various spaces and times where diverse discourses of the past are voiced and aimed at disparate audiences" (31). Harrison considers dissonant heritage discourse a horizon of expansion for heritage, which is seen no longer simply as a celebration of national identity but also "as a space for the remembrance of atrocity and disaster" (194). As noted by other scholars, 'difficult pasts' in the context of commemoration, are "not necessarily more tragic than other commemorated past events; what constitutes a difficult past is an inherent moral trauma" (Wagner-Pacifici and Schwartz 1991), which I suggest may be further complicated by posing a present moral dilemma with political and economic implications.

It is not surprising that emerging subaltern and dissenting alternative heritage discourses focus on community inclusion and participation in heritage management; repatriation; shared authority (Frisch 1990); public historical practice and personal engagements with history (Thelen and Rosenweig 1998); as well as art-as-resistance approaches; countermonuments (Young 1992); and critical commemoration praxis all of which employ strategies to cope and even leverage dissonance. Dissenting and subaltern discourse may be a needed social and cultural corrective, existing in dialectical tension with the AHD. For heritage to change or to progress - to become and/or remain relevant, these correctives need to be encouraged and consistently present.

Lowenthal (1998) identified shifts in the dimensions of heritage "from the elite to the vernacular; from the remote to the recent; and from the material to the intangible" (14). Jameson $(2008,429)$ and Jokilehto $(2006,2)$, suggest that values represent attributes and 
intellectual and emotional connections and attachments: the 'social association of qualities to things', "indicating the necessity for an emotive communal attachment before something can become heritage" (McClelland et al. 589). In this regard, value is viewed as being socially ascribed rather than inherent (Lipe 1984; L. Smith 2006; Pendlebury 2009; G. Smith, Messenger and Soderland 2010) and is relative, "constituted through different relationships over time" (589; Nancy 2005; Zancheti and Jokilehto 1997). These debates challenge but also enhance values articulated within the AHD that have themselves expanded to encompass debates related to intangibility and authenticity. Emphasizing the responsibility that comes with assigning or ascribing value, citing Ashworth et al., Harrison asserts that the notion of social values has become increasingly important "alongside the recognition that the same heritage object, site or place may be attributed very different values by different stakeholder or members of society" (145).

According to McClelland and others, "in contemporary cultural heritage planning and management attention to values and a values-based approach have become the sine qua non in deciding what and how to conserve" (597). Drawing on de la Torre (2005), the authors ask us, "...if understanding all values of a particular structure or place is considered fundamental to a values-based approach, helping distinguish such approaches from more traditional ones, what about values that do not represent positive characteristics?" (McClelland et al. 595). Dolff-Bonekämper (2008) questions “How can anyone claim that cultural heritage only embodies positive historical, artistic and ethical values (truth, beauty and goodness), when heritage often comes down from periods of deep social and political conflict?" thus proposing 'discord value', arising from these 
contexts, as one necessary determinant of cultural heritage (135). McClelland and others consider "public recognition of alternative viewpoints a fundamental right"30 (597). 'Dark side values' a term borrowed from Yiftachel (1998) and discussed in McClelland et al. (2013)- describe values "which encompass a broad range of values that are often concealed, ignored, or are in direct opposition to those positive characteristics generally associated with expressions of heritage value" (585). These compelling arguments would deem it essential to consider dark side or negative values in any valuation of would-be objects of difficult commemoration, and pragmatic to apply these considerations broadly.

For Mason (2006), a values-based approach reflects "the multivalent nature of heritage and the contingent manner with which it is judged by different people and organizations over time" (McClelland et al. 594). Conversely, too narrow a range of values can exclude multivalent sites and landscapes. Whether because of the guidelines or their implementation, this appears to be the case of HSMBC as it relates to applications for designation of former IRS. Indeed, in contradistinction, McClelland and others suggest that "the application of positive values to a particular structure or place could be seen to create 'shadow values' at other structure or places, akin to the 'shadow effects' recognized by Tunbridge and Ashworth $(1996,26) "(596)$.

Citing Gamboni (1997), McClelland and others discuss ‘anti-values' which may both correlate with Harrison's (2010) discussion of iconoclastic destruction, but also work as a measure to disqualify and justify the destruction of sites of cultural insignificance (596).

30 Emphasis mine. 
The authors also suggest, "for some, a kind of rhetorical destruction of heritage can be said to have occurred without any physical intervention to a structure or a place, but can instead relate to the privileging of certain, particularly expert and national, values over those of the local community in the interpretation and management of cultural heritage resources" (587). Byrne suggests that approaches to heritage conservation that treats materiality as an end effects deformation of place ${ }^{31}-$ an excision of material from its social context, past and present, hollowed and deformed (231).

Given an increasing focus on the inherent dissonance of heritage within its discourse, compounded with growing disillusionment with nationalist master narratives fuelled by crises in historiography, is it any wonder that some in the heritage profession opine as does Gillis that, "we have no alternative but to construct new memories as well as new identities better suited to the complexities of a post-national era" (20)? Indeed Olsen suggests that national meta-narratives transition as we move out of modernity and into post-modernity (Olsen 46). I would suggest that the literature presented thus far asserts that dissonance is inherent to heritage, and particularly heritage related to difficult knowledge, and promotes inclusive and participatory approaches that embrace multivocality. It also appears that a range of appropriate physical interventions, even those involving acts of iconoclasm or similar destruction, may be desirable in contrast with

31 "In a recent article, Sally Ann Ness (2005) describes the manner in which, in the interests of manufacturing short-term 'paradise' experiences, destination tourism resorts effect a rupture with the pre-existing reality of the sites where they are constructed, as well as with the surrounding physical and social reality of the landscapes surrounding them, which can be considered a form of violence. The result is a deformation of place" (Byrne 231). 
either rhetorical destruction or heavy-handed interventions. Therefor, it behooves us to consider dark side and shadow values, and the social and cultural cost of neglect or deformation of place.

While keeping these considerations in mind, the theorization of heritage through which I attempt to answer the question: is heritage the appropriate mechanism to commemorate former IRS sites, is one posited by LauraJane Smith and supplemented with Harrison. In her influential 2006 work, Smith theorizes heritage, as " a multi-layered performance be this a performance of visiting, managing, interpretation or conservation - that embodies acts of remembrance and commemoration while negotiating and constructing a sense of place, belonging and understanding in the present" (3). Given, as Smith argues, that performance of heritage and the understanding or idea of heritage are mutually constitutive and reinforcing (3), the substance of Canada's federal place-based commemorative landscape reveals much about how the state conceives of and manipulates a particular idea of heritage. While Smith asserts heritage's inherently dissonant and contested nature, she emphasizes that state-sanctioned heritage is often "about the promotion of a consensus version of history...to regulate cultural and social tensions in the present" (4). Promisingly Smith reminds us that heritage is also used as a resource for subaltern groups to contest and redefine received values and identities (4). To lightly supplement Smith's definition of heritage, I add Harrison's assertion that heritage is "not simply a collection of 'things', but instead constitutes the social 'work' that individuals and societies undertake to produce the past in the present" (113). Moreover, as suggested by the rationale for expansion provided on the Durham World 
Heritage site website, built heritage "need not be monumental to be valuable," 32 and the social need for heritage practices of iconoclasm and destruction may supersede those of conservation. And so, it would seem that even the AHD has evolved to reflect changing notions, uses, and practices of heritage - but to what extent has heritage innovation been adopted in Canada?

\subsection{Canada's Place-based Federal Commemorative Landscape}

Canada's NPHC, managed by the HSMBC and sustained through a network of federal, provincial, and municipal partners, its infrastructure, policies, and agents, constitute Canada's place-based federal commemorative landscape in all its performative and material aspects. As Canada awaits the final report and recommendations of the TRC, Survivors struggle with what appears to be bureaucratic indifference to their requests for federal heritage designation of former IRS. In order to assess the outward silence surrounding the issue of IRS commemoration, we must first understand how HSMBC approaches subjects of 'difficult' commemoration in Canada, and consider how corresponding practices include or exclude applicants and constrain how commemoration and remembrance is practiced. This section examines how HSMBC policy and practice contextualizes difficult heritage within the narrative structure of the 'Canadian' history it

32 The original boundaries of the World Heritage Site (as inscribed by UNESCO in 1986) only included Durham Cathedral and Castle. This reflected an earlier understanding of architectural heritage as being 'historic monuments'. The commonly-accepted understanding of architectural heritage today recognises that buildings need not be monumental to be valuable - small, everyday buildings and spaces can also tell an important story or be remarkably significant. It also recognises that buildings don't necessarily have to be extremely old to be important (Durhamworldheritagesite.com).

See https://www.durhamworldheritagesite.com/heritage/site-boundaries 
creates. Understanding these contextualization strategies assists us in interpreting HSMBC decisions related to applications to designate IRS and how this in turn acts as a containment strategy to constrain commemorative practice. Applying Pierre Nora's (1989) assertion that 'milieux de mémoire' gain meaning only when those with the 'volonté de souvenir' - the will (and the power) to remember, construct them as 'lieux de mémoire' (19), this critique also discusses the implications of the decisions and actions of the HSMBC, those with state-willed power to remember, on our collective historical consciousness.

In one of prominent Canadian heritage scholar Christina Cameron's (2010) more recent works, she embraces the potential for engaging with difficult heritage, stating that "sites of conscience are poignant reminders of past injustices and powerful catalysts for making the world a better place"; moreover they have the power to involve ordinary citizens and can provide opportunities for healing, apology, and reconciliation (117). According to Brace (2012), "there is little evidence for the desire to 'forget' the collective experience of the IRS system within aboriginal groups" however, "selective forgetting has been demonstrated to provide a benefit for individuals where remembrance of traumatic experiences inhibits emotional reconciliation" (58).

Parks Canada's NPHC, Canada’s “bureaucracy of memory,” (Osborne 1996; 25) inhibits reconciliation and healing efforts by excluding subjects of 'difficult' commemoration that pose the risk of conflicting with extant celebratory national narratives. As such, commemoration of the former IRS sites, which occurs outside of federal commemorative 
infrastructure, remains fragmented - producing a spectral commemorative landscape comprised of what Brian Osborne (1996) describes as a "shadow-image of other sites...deemed to be unworthy of [official] commemoration or even of being recognized as meriting nomination" (36). Considering that "HSMBC has been a key player in deciding for Canadians what parts of their heritage are important and worthy of remembrance," (Ashley 481), Canadians are relieved of their own duty to remember. The HSMBC constructs, rather, a celebratory landscape that ultimately constrains the potential for the Canadian public to become reconciled to the violence of Canada's past. Thus I argue that the heritage constructs that aim to create social cohesion within Canada ultimately inhibit Canadians from reckoning with their difficult collective history.

Formed in 1919, the HSMBC has operated for the past 95 years to connect Canadians with their heritage and reflect an identity rooted in historic places that "capture the spirit of the nation" (Cameron 2010, 77). According to Susan Ashley, "National Historic Sites [a program that combines federal, provincial, and municipal site designation programs] is among those public institutions that play a central role in presenting Canadian culture, identity and community" (481). Over the course of its existence, the HSMBC has conferred heritage designation; installed various plaques and monuments; partnered with agencies to restore, protect, and in some cases, develop interpretation and exhibition components; and promoted its network of sites through various mechanisms of publicity and tourism. On the occasion of the first publication of the Historic Landmarks Association, a predecessor of the HSMBC, honorary president Sir Wilfrid Laurier, characterized "landmarks themselves as signs of progress" (35). Indeed, according to 
Osborne, "throughout the late nineteenth and early twentieth centuries, monuments and the ceremonies surrounding them were intimately tied to nationalism" $(1996,35)$. Although initially dedicated to inscribing places of architectural importance, military victory, forts, fur-trade outposts, and early settlements in the Canadian historical consciousness, the landscape later expanded to encompass "places, people and events that have marked and shaped Canada" (Parks Canada 2), the merits of which are determined at the sole discretion of the HSMB and the Minister responsible for the Parks Canada Agency (currently the Minister of the Environment).

Section 4 of the Historic Sites and Monuments Act, the legislation that created and structures the authorities of the Minister and the HSMBC, constitutes membership from direct appointments, as well as from candidates chosen from among Canada's other cultural heritage agencies by the Minister and/or the Governor in Council. Thus, the power to designate or not to designate, to "mobilize attachments and knowledge that serve specified present-day interests" (Rosenberg 10) and to create the 'prosthesis' that memory requires to remain in the public historical consciousness (Nora 14), remains in the hands of an elite of the Minister's choosing.

According to Parks Canada, "the national historic sites system covers the entire range of Canadian human history" (Parks Canada - Introduction). The National Historic Sites of Canada System Plan (Parks Canada) discusses how these themes correlate with the authorities set out in the Act and sets program priorities. Interpreted through the lens of Osborne, the plan's slogan, "proudly bringing you Canada at its best," can be seen as 
statement of intention to nurture "a symbolic space of national identity and the imagined nation-state" or more specifically to nurture "collective memory and social cohesion through the representation of national narratives in monumental forms, the construction of a symbolic topography, and the performance of identity through commemorative activity"(2001; 4). Stated differently, the collectivity of the HSMBC-designated sites can be interpreted as articulating an "invented history," grounded in an "imagined geography" (7), invented and imagined through their strategic isolation from a richer historic terrain.

\subsection{Observations on the HSMBC System Plan (2000) and Guidelines (2008)}

The purpose of the System Plan is to articulate the values and objectives of the historic sites program within a thematic framework that recontextualizes designations that reflect past priorities while identifying current and future program objectives. The framework articulates a nation-building narrative that privileges (and mythologizes) progress in economic, political, social, and even cultural terms. Like any policy document, it constitutes subjects and assigns identities. From the onset, in a foreword by Sheila Copps, then Minister of Canadian Heritage, it establishes Canadian history as celebratory, promising to "provide even greater opportunities for Canadians to understand and celebrate our national heritage" (iii). Further she commits to "address the imperative for constant improvement to the system to ensure that it truly reflects the diversity of our nation and fully represents the manifold of our history" noting that she has charged the

33 The full titles are: National Historic Sites of Canada System Plan and General Guidelines, Specific Guidelines for Evaluating Subjects of Potential National Historic Significance 
Board to "do more to mark the historic achievements of Canada's Aboriginal People ${ }^{34}$, women, and ethnocultural communities (iii). The exigencies of increasing opportunities for Canadians to celebrate our heritage and those to fully represent the manifold of our history are immediately brought into tension. Specific goals of the plan include: ensuring the commemorative integrity of sites, which involves "nurturing public support for the protection [surveillance]" of designated sites (50), increasing commemorations of social history and the achievements and experiences of 'everyday Canadians' (5), and creating a more representative system, "one that truly reflects the rich history and heritage that defines Canada" (6). If, as suggested by Shore and Wright, "policies encapsulate the entire history of a culture that generated them" (7) the history that unfolds in the Plan can be interpreted as reflecting the ideas, perspectives, and intentions of the state culture that created it.

Before discussing the Plan's narrative arc of Canada's history, it is important to note its emphasis on preservation and conservation as imperatives underpinning all heritage work. Well established in the UNESCO World Heritage Operational Guide and the raison d'être for ICOMOS, ethics of preservation and conservation have become normative values for the state, which, through neoliberal strategies, transfers the policing and upkeep of designated sites to Canadians. This ethic can come into conflict in commemorating of sites of conscience, which left unaltered, have the potential to further subjectify, and cast the historically oppressed (and their contemporary descendants) as

${ }^{34}$ The use of the possessive here is troubling. It is doubtful that the author would use the possessive if the list was differently ordered, for example: Canada's women, Aboriginal peoples and ethnographic. 
victims. As noted by Shore and Wright, policy often "creates the guise of rational, collective, universalized objectives" masking the political under the "cloak of neutrality" (11). So what is commemorative integrity and how does it constrain heritage and commemorative practice?

Parks Canada defines commemorative activity in the following manner:

Commemorative integrity refers to the condition or state of a national historic site when the site is healthy and whole. This is the desired state for a national historic site. To help understand the term, it is useful to look at the two words 'commemorative' and 'integrity'. The word 'commemorative' refers to why this place is a national historic site. 'Integrity' refers to health, wholeness and honesty. (Pc.gc.ca-Commemorative Integrity).

These following three statements are commonly referred to as the 'three elements' of commemorative integrity. A national historic site possesses commemorative integrity when: "the resources directly related to the reasons for designation as a national historic site are not impaired or under threat; the reasons for designation as a national historic site are effectively communicated to the public, and, the site's heritage values are respected in all decisions and actions affecting the site" (ibid).

Establishing commemorative integrity is the first in a series of hoops through which interested persons need jump to nominate a site for designation. Although Parks Canada offers a National Historic Sites Cost-Sharing Program, which "helps ensure the commemorative integrity of non-federally owned or administered national historic sites through financial contributions," (Pc.gc.ca - Cost-Sharing Program) the site must first possess enough commemorative integrity (and sufficiently meet HSMBC evaluation criteria) to be designated a national historic site. So what happens when the practice of 
commemoration involves destruction or reconstruction of a site as a curative or restorative action, without which it would remain in an unclean and haunted state? Reckoning with sites of trauma may involve ritual and cleansing burning or destruction, releasing memories of trauma and creating new memories and narratives of healing, validation and empowerment through reclamation. These types of commemoration certainly threaten the material 'resources directly related to the reasons for designation'. Moreover, commemoration by destruction can be seen as compromising some of the 'site's heritage values (including those not related to the reasons for designation as a national historic site)'. Therefore, if for example, a former IRS was nominated based on its historical value but the site's architectural or aesthetic value might be compromised in the course of public commemoration, it could be deemed lacking in commemorative integrity. What if 'the reasons for designation' were contested and could not be effectively communicated to the public with the limited narratives of the sort that comprise the various Statements of Commemorative Intent currently associated with federally designated sites?

Summarizing Bruce Trigger (1984) on forms and uses of archaeologies, Harrison suggests, "colonialist archaeologies are dominant in areas settled by Europeans, and sought to denigrate and dislocate Indigenous Peoples from contemporary nationhood" (97). As we shall see, HSMBC has historically privileged material settler remains, and mobilized policy, entrenching the primacy of establishing commemorative integrity marrying commemoration to conservation, further constrained by the 9 general standards for preservation, rehabilitation, and restoration (Standards For The Conservation Of 
Canada's Historic Places), which impact evaluation of sites, to continue to fabricate evidence supporting Canada's founding (and evolving) mythologies as constructed in the System Plan. Harrison suggests, "the connection between heritage and nationhood has traditionally found expression in the origin stories that account for relationships between national cultures and citizenship" (165). Who wants a messy multi-vocal rationale for designation when it contests the myth of settler colonialism as a peaceable and natural evolution of progress that heritage 'experts' have labored so painstakingly to create? Hopefully the subsequent sections may disillusion readers who believe that HSMBC objectively applies universally recognized standards in the evaluation of site nominations.

John Bodnar asserts, “official culture relies on 'dogmatic formalism' and the restatement of reality in ideal rather than complex or ambiguous terms... Normally official culture promotes a nationalistic, patriotic culture of the whole that mediates an assortment of vernacular interests. But seldom does it seek mediation at the expense of ascendancy" (265). Nowhere is this approach more evident but in the myth of settler colonialism as a peaceable and natural evolution of progress that lies at the heart of the NPHC System Plan. As mentioned previously, the framework employed in the System Plan breaks Canada's history into five themes: peopling the land, governing Canada, developing economies, building social and community life, and expressing intellectual and cultural life. Immediately from the onset, settler colonialism is presented as an inevitable mark of progress and natural evolution as evidenced in the introductory phrasing for Peopling the Land, "the land now known as a Canada has supported a human population for many thousands of years. The First Nations lived on the land and...Over time, ... were joined 
by people from all parts of the globe and Canada's cultural mosaic began to take shape" (11). Another statement, "Canadians, like people everywhere, form an attachment to the places where they live. This is true whether their families have been here since time immemorial of have arrived recently" (29) further naturalizes a concept of peopling Canada as a process of natural evolution, not a process marked by settler violence. Nation-making narratives that reinforce notions of settler-innocence through tropes of 'natural progress' or what Anthropologist Eva Mackey (1999) refers to as "the 'benevolent Mountie myth ${ }^{35}$, pervade the System Plan and the Canadian Register of Historic Places (CRHP), continuing to occlude and conceal authentic Indigenous histories. In Developing Economies, in contrast to Aboriginal economies situated in the pre-contact era, the development of canal and rail systems, and of manufacturing is characterized as "European investment on a large scale" that took Canada from a closed economic system to one that through the twentieth century continued to rely "on the rest of the world for markets and investments" (30). This constructs Indigenous Peoples' economic systems as immature and having since benefitted from foreign investment on which Canada's economy continues to rely. Governing Canada continues to propel an 'evolution as progress' construction forward with "from the origins of Canada's earliest peoples, through colonial governments and Confederation, systems of government have evolved in Canada" adorning a page embellished with an image of a rank and file RCMP parade marching toward the viewer of the page (18).

35 "... based on the idea that the process of civilising the frontier occurred in a gentler, less violent, manner in Canada than the USA, because of British systems of justice, and, in particular, the benevolent and tolerant behaviour of the Mounties" (Mackey 1999: 89). 
Othering, Naturalizing, Vanishing, and Replacing Indigenous peoples

Many Indigenous-oriented sites are categorized in the earliest period of this Canadian history (or pre-history) and in the Hunting and Gathering subsection of Developing Economies the distant past. In her critique, from an Aboriginal perspective, of how the World Heritage Site and US National Register construct the heritage value of cultural landscapes, Lisa Prosper (2007) discusses how designations that "undermine the dynamic temporality of all cultural landscapes" have the potential to freeze them in time and space (119). Of course, all heritage constructions create anachronistic space. However, situating Indigenous peoples in 'time immemorial' or even in the fur trade or early war alliance history perpetuates a state of constant vanishing. With the advent of the Canadian state, the 'founding' peoples of Canada - predator identities, ${ }^{36}$ the English and to a lesser degree the French, become the new Indigenous nations, a construct well-illustrated in the plentiful number of designations of English-Canadian, and to a lesser degree FrenchCanadian sites. With the advent of multiculturalism, imposition of the trope of progress and cultural mosaic formation, and efforts to better represent ethno-cultural communities, 'Canadian' identity stretches further, further relegating Indigenous sites to places of the past. Harrison posits, "multicultural policies have often been used by nation-states to disguise and avoid dealing with epistemic racism in circumstances under which social equality comes to be relabeled as cultural difference" (143). Although trading posts and similar 'contact zones', representative of places where Indigenous and settler history

\footnotetext{
${ }^{36}$ For further discussion of the 'threatened majority' and 'predator identities' see
} Harrison 162-163. 
intersect appear on the list of designations, few exist from the modernist era to confirm a contemporary or recent Indigenous presence.

Apart from the 139 former IRS sites, little material evidence of settler violence exists in the physical places of Canada. Viewed through the lens of Andrea Smith's (2006) framework for understanding white supremacy, the almost complete exclusion of a modern historical Indigenous presence from among the 956 existing cultural heritage designations construct Indigenous Peoples as vanished. The federal commemorative landscape thus expresses a 'logic of genocide ${ }^{37}$ which holds that Indigenous Peoples "must always be disappearing in order to allow non-Indigenous peoples rightful claim over this land" (68).

Historian Hue-Tam Ho Tai argues that Pierre Nora's distinction between primitive societies whose traditions of orality he equates to memory, and modern societies of people who "no longer live in memory but become conscious of the pastness of the past and need the aid of written documents [literacy] to recall it...echoes the discredited notion that only the West has history, while others have culture" (915). Nora (1989) frames decolonization as a process of animation, of awakening from the temporally arrested state of "ethnological slumber by colonial violation." He posits that 'pre-modern'

${ }^{37}$ Expanding on Rayna Green's (1988) formulation, A. Smith argues that, "through this logic of genocide, non-Native people then become the rightful inheritors of all that was indigenous - land, resources, indigenous spirituality, or culture" (2010: 53). Patrick Wolfe (2006) refers to the 'settler-colonial tendency as' a 'logic of elimination', suggesting that "settler colonialism is inherently eliminatory but not invariably genocidal" (387). 
societies exist anachronistically, possessing "reserves of memory [or culture] but little historical capital" (7). HBMBC approaches appear to be consistent with this view and reflect a prioritization of the cultural: traditional knowledge and practices, ways of life, and relationships to the land rather than on history. Describing a shift in HSMBC strategic priorities to address gaps in Indigenous 'history' identified in the 1990s, Cameron (2000) asserts that "the experiences of Canada's Aboriginal peoples are inextricably rooted to the land," and that Parks Canada is working with Aboriginal peoples to identify sites using "oral history, traditional knowledge, place names, archaeological artefacts of landscape features" (85). Although she suggests that "Aboriginal national historic sites are astonishingly varied in both type and age" (86), her examples, the ancient Algonkian petroglyph site near Peterborough, the Mi'Kmaq cultural landscape in Kejimkujik National Park, and Dene fortified village sites in the Northwest Territories, situate Indigenous history in Nora's ethnologically-arrested dreamland.

\section{(How) Does HSMBC Deal with Difficult Subjects?}

In performing a web search at Parks Canada's online Directory of Federal Heritage Designations using the term 'internment camp', the Nikkei Internment Memorial Centre National Historic Site of Canada appeared. The Centre is described as, "one of the few sites that still contains resources directly associated with this tragic episode in Canadian history [Japanese internment], and is located at the heart of one of the camps constructed under the authority of the British Columbia Security Commission" (HistoricPlaces.caNikkei). This description is troubling in several ways: because it does not make even a 
cursory attempt to explain what Japanese interment was; because it transfers blame from the federal government to an independent commission; and, because the value of the site appears to be rooted in the remaining [material] resources rather than in the understanding and acknowledgement of the immense suffering that took place there. These troubling aspects highlight some of HSMBC's strategies for dealing with difficult heritage, which include: selective narrative omissions, deflecting responsibility/culpability, and constraining heritage designations to sites that possess their standard of commemorative integrity.

A few examples well illustrate the use of these strategies. For example, mention of the Inuit high artic relocation, a program that resulted in extreme and unthinkable privation, implemented by the government in the 1950 s to assert Canadian sovereignty over the high arctic by establishing (Canadian) Indigenous human presence, is absent from the Canadian Sovereignty in the Arctic Archipelago National Historic Event (Pc.gc.ca Canadian Soverignty). The statement of heritage value of Boyd's Cove Beothuk National Historic Site of Canada describes the Beothuk thus, "Beothuk were the first North America Aboriginal People to encounter the Europeans, but they ceased to exist as a distinct people in the early $19^{\text {th }}$ century" (HistoricPlaces.ca-Beothuk), as it to absolve settlers of their culpability for Beothuk extinction. Similarly, strategies of deflection distort history. Africville National Historic Site of Canada cites heritage value as attributable to being an enduring symbol associated with "the emergence of a more politically conscious and confrontational spirit in Black culture" (HistoricPlaces.caAfricville). Grosse Ile and the Irish Memorial National Historic Site of Canada, the only 
one of the four sites mentioned that is actively promoted by HSMBC and described in greater detail on its website, transfers blame for the massive loss of life at the quarantine station to British colonial authorities, ignorance of the conditions required for health, and to the passenger ships that confined travellers to crowded and unsanitary conditions. In contrast, the narrative celebrates the achievements of the early confederation government, which "formulated a comprehensive policy on immigration and settlement, requiring the establishment of a reliable, efficient quarantine station" (Parks Canada - Grosse Île).

Although as Byrne suggests, Indigenous history is made less tangible through superimposition and eventual replacement by settlers' tangible traces, this is how settlers totalize their historical presence in the landscape (239). The physical sites of 139 IRSSArecognized IRS pose more than one problem for the HSMBC. Not only would due consideration for designation of some or all of the sites warrant a radical departure from the HSMBC's 'traditional' depiction of Indigenous history and sites, it would confirm Indigenous presence - a potential threat to the founding peoples myth, and also force attention to Canada's difficult heritage. Moreover, as we shall see in the subsequent chapter, the single federal commemoration program to which private citizens can apply to commemorate sites or events is tied to designation, which is tied to conservation.

\subsection{Interactions with HSMBC on IRS}

According to the HSMBC Guidelines, the criteria for places of National Historic Significance must meet conditions that recommend them as exceptional or original examples of type, symbolize a cultural tradition or way of life, relate to a significant stage 
in the development of Canada, or be explicitly or meaningfully associated with significant people or events, and possess commemorative integrity (3). HSBMC Criteria for Places of National Historic Significance

To be considered for heritage designation, sites must:

- illustrate an exceptionally creative achievement in concept and design, technology and/or planning, or a significant stage in the development of Canada; or

- illustrate or symbolize in whole or in part a cultural tradition, a way of life or ideas important in the development of Canada; or

- be most explicitly and meaningfully associated or identified with one or more persons who are deemed of national historic significance; or

- be most explicitly and meaningfully associated or identified with one or several events that are deemed of national historic significance.

Also, "only buildings, groups of buildings and places installed before 1975 may be

designated... and the integrity of its design, materials and execution, its function or environment maintained, inasmuch as these aspects are essential to understanding its historical significance" (3).

Schools of national significance must meet even more stringent criteria. Schools of national significance must meet one or more of the [specific guidelines], which follow:

1) The school building or complex (and its setting) retains its integrity and is representative of type, particularly in the relationship of form to function.

2) The school building or complex (and its setting) retains its integrity and is representative of significant developments or changes in educational practices and theory, which found expression through architectural design.

3) The school building or complex is a superior example of an architectural style prominent in the context of Canadian architecture.

4) The school building or complex is of national historic significance by virtue of its associations with:

- prominent Canadian educators;

- important and innovative educational practices;

- a number of individuals who, over time, graduated from it and gained prominence in later life (9). 
Geographer Geoffrey Carr (2009) likens the physical evidence of the network of IRS to detritus, questioning the ability of "mnemonic bureaucracies charged with preserving national memory" like the HSMBC to integrate it into their heritage designation schemes (113). Moreover, he and other scholars (Henderson and Wakeham 2009; Regan 2010; Green 2012) warn us of the risk of foreclosure that official reconciliation and heritage redress processes without corresponding political gains presents. Before moving into a discussion of how the HSMBC has responded to applications for designation of former residential schools with a particular focus on St. Eugene, ostensibly the test case for the application of HSMBC policy with regard to the IRS, it bears mentioning that many of the schools within the network defined in the IRSSA would not qualify for nomination for a few simple reasons: some were constructed after 1975, many have lost their 'commemorative integrity' as defined by HSMBC, consent from the property owners has not been (and cannot be) obtained in many cases and for some the sites have neither been precisely mapped nor owners identified. Finally, few have the aesthetic or architectural merit to recommend designation.

\section{HSMBC Decisions Regarding St. Eugene IRS ${ }^{38}$}

In 1996, the HSMBC considered the application of the Ktunaxa/Kinbasket Tribal Council to designate St. Eugene Indian Residential School. Although there was significant architectural interest, the Board determined that "it had lost much of its integrity as a

\footnotetext{
38 Unless otherwise noted, all information was obtained from the unpublished Minutes of HSMBC meetings held between June 1996 and June 2008, provided to me by email by Blythe MacInnis, Commemoration Programs Coordinator, Commemoration Branch, Parks Canada on March 11, 2014.
} 
school" and thus they were not prepared to recognize its national architectural significance (Johnson). In order to assess its historical significance, they commissioned an Agenda Paper with specific instructions to gain more background information on the IRS system and like schools (HSMBC Agenda Paper 1996). In the same year having learned that the HSMBC were considering a nomination to designate an IRS, INAC (now AANDC) stepped in to inform the Board that they were awaiting the Royal Commission on Aboriginal Peoples' (RCAP) final report and would thereafter be preparing a response on the part of the federal government (ibid). INAC cautioned HSMBC that their actions to designate the school might be misconstrued as that response and asked them to hold off on designation until they had the report (ibid). Once the RCAP report was tabled, the HSMBC was asked to await a report from Dr. John Milloy, whom the Commissioners had asked to prepare a supplementary report on IRS (ibid). This caused further delay.

On reviewing the RCAP report and Milloy's report, the Board concluded that "neither contributed in a significant way to fulfilling the goals of the HSBMC: neither focuses on extant cultural resources, and neither offers any historical information on the St. Eugene Residential School" (Johnson 336). The subject of designating IRS was deferred for a further 5 years (HSMBC Agenda Paper 1996). In 2002, in response to inquiries related to another proposed IRS designation by Chief Dennis Meeches of Long Plain First Nation, the HSMBC decided that a more comprehensive study of the establishment of IRS in Canada was required (HSMBC Minutes 2008). Their approach was to direct Parks Canada to make an inquiry with "the federal department responsible for residential schools" (AANDC) (ibid). In 2005, the acting secretary of the Board submitted a report 
on the pre-IRSSA Agreement in Principle, noting that commemoration was one of its elements (ibid). In 2007 the HSMBC confirmed the designation of Notre Dame des Victoires/Lac La Biche Mission as part of a larger commemorative site encompassing other structures. However as noted by Dr. Strong-Boag, the statement of commemorative intent, "does not mention the role of the Lac La Biche Mission in the IRS" (National Historic Sites Directorate). ${ }^{39}$ In response, the executive secretary reminded the HSMBC that "at an appropriate time, [Parks Canada] will bring forward for the Board's consideration a framework study on the residential school system and commemorative opportunities” (ibid). In 2008, “Mr. Qulaut noted that on June 11, 2008, Prime Minister Stephen Harper made a formal apology on behalf of the current government for known excesses of the residential school system, and for the creation of the system itself, and that in his view this represents a positive step towards reconciliation" (HSMBC Minutes 2008). According to representatives from the HSMBC secretariat as of March 2014, no other action has taken place regarding the IRS nomination, nor has the issue been a topic of discussion since 2008.

\subsection{Difficult Knowledge Elsewhere Explored}

The dominance of celebratory place-based heritage designations in Canada, the apparent scarcity of difficult commemorations, and the absence of criteria that considers 'sites of

39 The plaque text appears later this chapter, contrasted with text from an alternative commemoration program to illustrate the dissonance created by its use of a singular 'authoritative' voice. 
conscience $^{40}$ among established criterion within HSMBC policy, all suggest

unwillingness or unreadiness to engage in reckoning with the moral dilemma difficult knowledge poses. Given this apparent lack of intention and corresponding lack of policy, we must again ask: is federal heritage designation an appropriate mechanism to commemorate IRS? Chronicling the iconographic formation of the holocaust and its inscription in cosmopolitan memory, sociologists Daniel Levy and Natan Sznaider (2002) discuss narratives [and corresponding constructions and performances of heritage] that emerged in Germany Israel and the US in the latter half of the $20^{\text {th }}$ century. An observation by Jörn Rüsen, included in the article, could well be used to describe the narratives constructed by Parks Canada: “'Inventions of Nationhood' during the nineteenth century were based on heroic conceptions and formative myths that were transmitted by 'traditional' and 'exemplary' forms of narrativity" (103). There is little evidence among Canada's designated sites (and indeed its national museums) to suggest however, that the critical self-reflexive turn experienced by West European nations reckoning with holocaust legacies "...during the last quarter of the twentieth century, a period characterized by a self-critical narrative of their national past" (103) could be said of Canada to date. Although state-led commemorations of the holocaust and other genocides and atrocities have significantly expanded theorizations and practices of

${ }^{40}$ Here I am using Christina Cameron's definition of sites of conscience as "places that bear witness to human rights abuses including genocide, slavery and other violations of freedom," (Cameron 112), as opposed to Liz Ševčenko's more commonly used definition of sites of conscience as those already transformed into places of civic dialogue, "historic places that foster public dialogue on pressing contemporary issues in historical perspective" (Ševčenko and Russell-Ciardi 9). For Ševčenko, a site where atrocities have occurred only becomes a site of conscience through its reclamation and transformation. 
heritage, commemoration, and collective remembering and forgetting, many of which are self-reflexive and self-critical, these developments have not yet fully permeated the policies and practices of $\mathrm{UNESCO}^{41}$, much less the HSMBC, which remain preoccupied with inventions of nationhood/nationalist fantasies.

In its criteria for selection of sites to be included on the world heritage list, UNESCO distinguishes between two subjects of heritage: cultural (and expansion of historical material culture) and natural. As noted by art and architecture historian, and former World Heritage Committee Chair and Director General of Parks Canada's National Historic Sites Program, Christina Cameron "within the context of the UNESCO World Heritage Convention, which deals more comfortably with the physical manifestations of heritage places, sites of conscience present a challenge to determine the threshold of outstanding universal value [criterion vi] for their intangible dimensions" $(2010 ; 113)$. Nominations of the Auschwitz-Birkenau German Nazi Concentration and Extermination Camp, the Hiroshima Peace Memorial and Robben Island among them, examples of the precious few sites that have been listed, were met with trepidation and scrutiny - and in some cases outright opposition (115). Although some of the concerns on the part of the committee had to do with perceived risks to international peace and security, or the apparent problem of the conferring of designation implying a condemnation of the events that transpired on these sites, most of the issues debated had to do with the sites not meeting the tangible criteria for ascribing heritage value (115). As Cameron reminds us, "State Parties alone have the responsibility for nominating sites on their territory" (117). 
This begs the question: in what circumstances would a state nominate a site of conscience, cognizant that in doing so, national and international condemnation for their oppressive or violent actions would follow? In the case of Robben Island, the maximum security prison that had incarcerated Nelson Mandela for 17 years, the site served the political purposes of the nominating South African government in its moment of redefinition and distancing from the old regime.

Whether to consolidate national myths to serve as a platform for national identification, or to solidify and differentiate the position of emerging governments, as memory scholars William Logan and Keir Reeves (2009) have noted, the imbalanced power relations inherent in state-led heritage can and often lead to distortions of historical understanding and memory - retelling state-approved history can be or is often a "willful distortion of collective memory by governments" (2). As observed by historian Eric Hobsbawn (1997), "it is in nationalistic politics that willful distortion is at its worst, and certainly the history of wars and of colonialism shows the centrality of this propaganda play" (5). Adding to this sentiment, Logan and Reeves assert that "memory distortions and fabrication of myths also occurs commonly in postcolonial situations where the creation of national identity is necessary to achieve political and cultural cohesion" (2009). One of the technologies of memory is the creation of 'lieux de memoire' - the network or landscape of physical heritage sites. For W.J.T. Mitchell, landscape "is an instrument of cultural power... it 'naturalizes' a cultural and social construction, representing an artificial world as if it were simply given and inevitable" (2). Evidence of this naturalizing impulse is abundant within the language of HSMBC's System Plan, which 
marks the settlement of Canada as a natural process of social evolution. Applying a term borrowed from Barbara Kirshenblatt-Gimblett (1995), the effect of history constructed, naturalized, and publicized by the HSMBC is collective memory as "collaborative hallucination" (376), resulting in collective imaginings of Canada, innocent of conflict and settler violence (settler innocence). That being said subaltern and dissenting heritage discourses are gaining some traction and have the potential to influence the AHD and trickle down into the policies and practices of institutions like the HBMBC. To date, most commemorations of IRS in Canada have been fragmented, albeit a number of them have elements representing multi-vocality. Currently, one of the most constraining aspects of the HSMBC policy with respect to use of language pertains to the development of commemorative plaque text. While the System Plan states, "subjects designated for their national historic significance are usually marked by means of a bronze plaque prepared in consultation with the nominator and interested parties" (50) the Guidelines specify that the authorship of the plaque text lies with the Board, who also have final approval. ${ }^{42} \mathrm{An}$ example of plaque text approved by the HSMBC for the only federally designated heritage site that encompasses among other features, a former IRS, appears below:

\section{NOTRE DAME DES VICTOIRES MISSION}

Established by the Oblates in 1853 beside the Hudson's Bay Company post, the Mission was relocated to this site in 1855-1856 to serve as the warehouse for Northern Missions. It became the hub of a transportation system, which ran overland from St. Boniface to the Mission and on the Athabasca-Mackenzie river system to Fort Good Hope. Church, convent and residential school ministered to the needs of

42 The Guidelines further state that the text must conform to the length (maximum of 500 characters), style, tone, and arrangement of existing plaque inscriptions and clearly indicate the reason for national historic significance as described in the Board Minutes. 
the Métis community and the Cree and Dene of the area. The Mission also played a role in aiding the local people to make the transition from a hunting to an agrarian way of life.

In contrast, the following draft plaque text was developed for consideration of the AFN/AHF Commemorative Project Steering Committee (IRSSA-commemoration project), before the plaque concept was discarded in favour of an arts-based approach:

\section{THE MOHAWK INDIAN RESIDENTIAL SCHOOL, 1885-1970}

Operated by the Anglican Church of Canada

On this site stood one of 139 federal government-funded church-operated Indian Residential Schools designed to assimilate Aboriginal children into mainstream Canadian society. Many children suffered abuses of the mind, body, and spirit in these schools, which operated for over 150 years and were attended by over 150,000 children across Canada.

Clearly, existing provisions for the development of narratives would not allow for the multi-vocality required to commemorate difficult pasts and it is unlikely that the HSMBC's ambition to better represent the diversity of Canadian heritage and history can be realized within existing constraints on both form and authorship.

Although it would appear through the narratives in the System Plan and recent designations that Canada is embracing the shift toward less 'canonical' and more 'representative' models of heritage, it is still highly selective, dominated by 'experts', and ignores practice. Its recent self-relflexivity extends to multiculturalism but not to the kind of self-critical reflection required to decolonize the practice of commemoration, which risks undermining extant origin stories and founding mythologies.

\subsection{Conclusion}


Byrne pessimistically, or perhaps realistically, consigns Indigenous Peoples thus:

Indigenous minorities in settler colonies, in their newly landless state, must fit their lives as best they can in the redrawn map of their former country. Their genius must lie in fitting themselves and their lives into the interstices that exist on the settler map, poaching on the space of their colonisers, jumping their fences, walking in the shadows of the settler streetscape (238).

Yet even though many of the spaces occupied by the former IRS continue to blight the landscape, their commemoration remains mired in bureaucratic indifference. Barnett (1997) applying Herzfield (1992) deconstructs how bureaucratic indifference works through a sequence of 5 stages that progress from creating boundaries (values and norms) that establish subjects and corresponding identities, to applying rights (and privileging narratives) selectively, to establishing a bureaucratic class that then operates to maintain its privilege (562). When informed of the incoming RCAP report in 1996, Carr (2009) informs us that "according to an anonymous HSBMC insider, the general feeling at the time was that "'the Board had dodged a bullet" (127). The HSMBC found itself in a conundrum. While policy is intended to remove subjectivity and curtail exercises of agency on the part of the workers, what HSMBC perceived to be a vacuum of information, not on the IRS system, but on heritage approaches to dealing with their extant cultural resources, put it in a position of vulnerability. Its decision, to defer decision-making amounts to bureaucratic indifference. Indifference, related to the history and legacy of the IRS amounts to the denial of a common humanity, reduces Indigenous to an unequal Other, undeserving of 'heritage' and is an expression of ongoing settler violence. In a personal discussion with a manager of the HSMBC secretariat, she relayed 
to me the intention of the Board to await the final report of the TRC before considering

IRS designations anew. Thus within a years time, the HSMBC will once again be in a position to debate the merits of designating IRS. 


\section{Chapter: Actualizing the Will to Remember}

This chapter examines various considerations and examples of strategies that have been used in Canada and abroad to practice corrective or restorative heritage followed with specific examples of IRS commemorations. We begin at the level of the state, drawing knowledge from states that have committed to remembering and have or are in the process of negotiating their realization. From there, we consider the public and their response, resistance, and relationship with monuments and briefly trace the logics and emergence of the counter or anti-monument movement. This includes the role of artists and participatory public art and archiving as practices of resistance. Next, we examine space through spatial interventions as practices of heritage, and site reclamation. Finally, drawing on the research of Cultural Heritage Specialist Anna Brace as well as original research, we turn to the many examples of 'unofficial' commemoration, primarily lead by Survivors, and examine their uses of commemoration as a healing and decolonizing practice.

\subsection{The State and Monumentalization of Difficult Heritage}

Following World War II, new critique and counter-monumentalization practices emerged, largely attributed to the activity of Jewish scholars and artists (Gillis 1994; Hamilton 1994; Huyssen 1995). States, compelled to remember, were equally faced with the challenges of memorializing difficult heritage and presented with the opportunity to recreate their national identity on a new moral platform. This new critique questioned and ultimately rejected established forms monumentalization, better suited to celebrating heroic deeds than remembering traumatic pasts. In an introduction to Places of Pain and 
Shame: Dealing with 'Difficult Heritage' heritage scholars William Logan and Keir Reeves (2009) posit, "The question of at what point memories can be allowed to fade and memorialization end is a complex and difficult one (4). Citing Meskell (2002), and Huyssen (1999) respectively, Byrne asserts that "monuments undoubtedly have a constructive role to play in people's efforts to come to terms with the past, indeed of 'mastering the past, but they have also been used for political ends to pack the past away and encourage forgetting" (241).

Concerns of adequacy, of ensuring that the past was never forgotten, plagued the new memorialists. Illustrative of some of these challenges, Gillis discusses how the tactic of monumentalization and memorialization was mobilized by the German Democratic Republic (GDR) to build shared identity following the unification of the German Democratic Republic, (GDR) and Federal Republic of Germany (FRG) in 1990. He begins in citing Claudia Koonz, who suggests "like a common currency and culture, the public memory of historical events structures a sense of civil society across generations, classes, and regions" (qtd. in Gillis 16). Gillis explains that for decades following unification, the disparity between former GDR and FRG state historiography and public memory - particularly that of WWII - complicated [and undoubtedly continues to hinder] the creation of a shared identity under the German Democratic Republic (DDR), and that these efforts, which resulted in a number of contentious revisions, came in the form of museum memorials, commemorative signs and overhauled exhibits (169). 
Art Historian Annie Gérin (2006) reminds us, monuments [and arguably museums and heritage sites] as mnemonic devices allow or create conditions of what she calls "mnemonic promiscuity," that which privilege some narratives while evacuating "bits of inconvenient history (229)." The question of multi-vocality then becomes important in determining narratives. Discussing Chile's truth commission's unsuccessful attempts to interpret the roots of human rights violations while maintaining multi-vocality, extended in that situation to encompass even Pinochet apologists, Claudio Fuentes, former Director of FLACSO ${ }^{43}$ - Chile, emphasized, "for some the state's job is to reflect a plural memory, the memory of all sides, of a society as a whole....[however] the state has an essential role in defending and promoting human rights" (qtd. in Brett et al. 9). Brought into contention with human rights, the state then would seem to have an obligation to arbitrate narratives arising from multiple and conflicting points of view. Fuentes further asserts that "public policy must embrace the ideal of 'Never Again' ... public policy can never be neutral in the face of unjustified violence or flagrant violation of human rights" (ibid.). I argue however, that in the case of IRS, equally the state must not put the needs of championing human rights and national reconciliation before the needs of healing for Survivors.

Further complicating state attempts to memorialize dark pasts, Byrne suggests, "there are also situations in which the bereaved have pointedly refused to have their loss

${ }^{43}$ Facultad Latino Americana de Ciencias Sociales [Latin American Faculty on Social Studies] is an international organism of academic, regional and independent character created in 1957 by the Latin American and the Caribbean governments (Apsanet.org). 
represented in the form of monuments" (Smith and Akagawa 241). Logan and Reeves consider, "the question that faces some communities where it is seen to be important for some community identity reasons to keep memories alive but where the generations which experienced the pain and suffering are passing away" (4). Exploring the antimonument movement, Gillis opines,

The anti-monument movement represents a radical turn not only aesthetically but epistemologically. Its advocates reject the notion of memory sites and want to deritualize and dematerialize remembering so that it becomes more a part of everyday life, thus closing the gap between the past and the present, between memory and history. By dematerializing memory they also wish to strip it of all appearances of objectivity, thereby forcing everyone to confront her or his own subjectivity, while at the same time acknowledging a civic responsibility not to let the past repeat itself (17).

Byrne posits the idea that the performance of commemoration 'behind the scenes', which could be extended to Gillis' notion of the dematerialized quotidian practice of commemoration, constitutes a kind of counter-heritage. Without monuments, how then might states cope with their devoir de mémoire, that of preserving traumatic national memory? Through what mechanisms of heritage can they honour truth, recognize victims, express sorrow, offer redress, and prevent recurrence? Without monuments, how can states ensure that successive generations will never forget?

According to James E. Young (2000), “...the monument has increasingly become the site of contested and competing meanings, more likely the site of cultural conflict than one of shared national values and ideals" (374). Explaining the logic of counter-monuments, he states "in the cases of disappearing, invisible, and other counter-monuments, they have attempted to build into these spaces the capacity for changing memory, places where every new generation will find its own significance in the past" (ibid). One such example 
was created in Germany in 1987, when the City of Kassel invited Horst Hoheisel to create a monument to commemorate the destroyed Aschrott-Brunnen fountain in the City Hall Square. The original fountain, donated to the city in 1908 by the Jewish entrepreneur Sigmund Aschrott, had been condemned by the Nazis as the "Jew's Fountain" and demolished in 1938. Rather than mount a replica of the original fountain, Hoheisel inverted the original design, which was fabricated and countersunk into the square (Figure 3). Hoheisel explains, "I have designed the new fountain as a mirror image of the old one, sunk beneath the old place, in order to rescue the history of this place as a wound and as an open question, to penetrate the consciousness of the Kassel citizens so that such things never happen again.” (qtd. in Young 288).

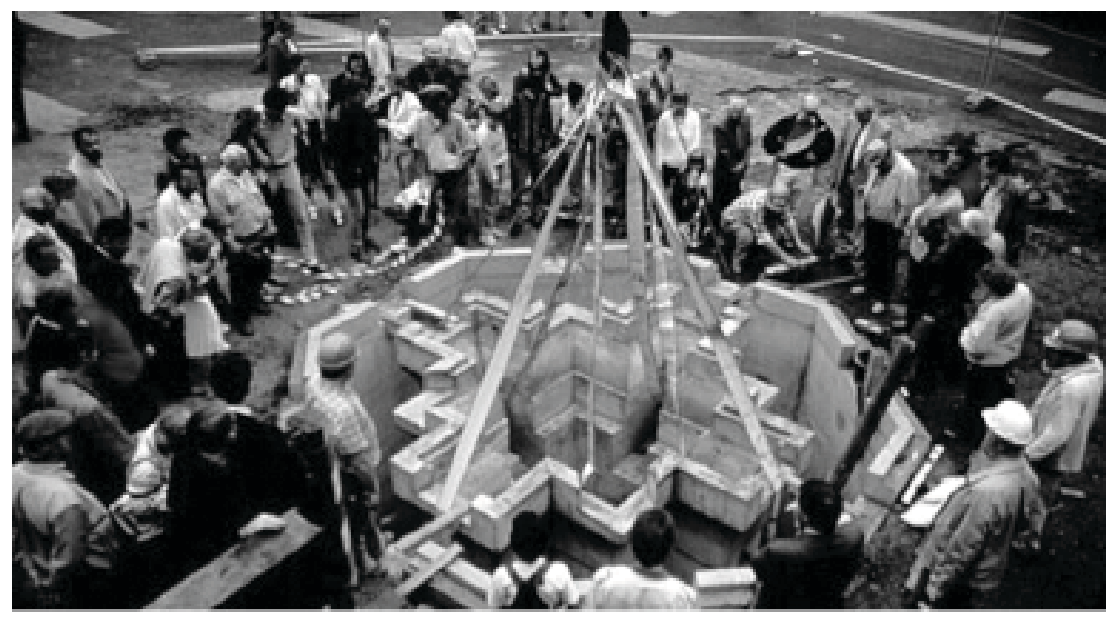

Figure 3: The Aschrott-Brunnen Monument, Horst Hoheisel, 1987.

Another example, Germany's Disappearing Monument Against Fascism in Harburg, features an obelisk plated in lead with a steel-pointed stylus with which to score the surface with graffiti attached at each corner by a length of cable. As one-and-a-half-meter sections were covered with memorial graffiti, the monument was lowered into the ground, into a chamber as deep as the column is high. After several lowerings over the course of several years, nothing was left on the surface but a burial stone inscribed to 
"Harburg's Monument against Fascism." The rationale behind the vanishing monument was to return the burden of memory to the people of Harburg and to "the memorytourists, forced to rise and to remember for themselves" (276).

Site protections, which may be undesirable to some, often accompany heritage designation, whether the site features a monument, counter-monument or other physical structure. Concerning the structural remains of IRS, Corntassel, Chaw-win-is, and T'lakwadze stress that community-based heritage practices for some, involves cleansing and freeing trapped spirits - accomplished through ceremonial destruction of the structure (Corntassel at al 143). Although framed in the context of promise of reparation or restitution by offenders, the notion of conditional reconciliation, attributed to Claudia Card, is also importantly invoked in Corntassel and others (145). Applied to heritage designation, the idea of conditional reconciliation further complicates processes designed to commemorate the past without making provision for the needs of future generations to reconcile with the same. This concern acknowledges what Carr refers to as atopoi and likens to Giorgio Agamben's "nomos of the modern," "places without place," "'exceptions"" to the realm of law" - of which the concentration camp may be the most extreme example Carr 124). As interpreted through Carr, Agamben “...cautions, however, that the camp is not an anomalous mutation but, rather, the 'hidden matrix and nomos of the political space in which we are still living', that 'decisively signals the political space of modernity itself"' (Carr 124). The atopoi are at once unsettling reminders of the Canadian state's history of violence, and the continued capacity of the state to exercise violence. For Carr, the implication "compels a rethinking of discourses 
of reconciliation...[and]...preclude[s] the use of the atopos as instruments of public relations [which would effect a deformation of place], in favour of sites of self-reflexive uncertainty" (Carr 132). Informed and multivalent counter-monuments as a strategy then, are limited reflections of the desires and truths of their issuing generation - this is a temporal challenge. For states to realize their duty to remember, the sites must be recognized as political spaces renegotiated and supplemented over time and by the public.

\subsection{Public Heritage Practice and Resistance}

On January 11, 2013, photographs of a vandalized monument to Sir John A. Macdonald in Kingston, Ontario appeared on Twitter (Figure 4). The photographs clearly show the spray-painted words 'murderer' and 'colonizer' on the steps leading to the plinth of the paint-splattered statue, and the statement 'this is stolen land' on both the plinth and its pediment (Forrest). This militant counter-hegemonic historiographical action, performed on the eve of what would have been the former Prime Minister's 198th birthday, challenged Canadians to remember Macdonald differently, frustrating attempts at peaceable and consensual commemoration scheduled the following day. Although the Twitter feed on which the photograph was originally published was followed by a slew of comments generally condemning the vandalism, political discussion ensued. The original 
Tweet was, in fact, retweeted 36 times and reaching a cumulative total of over 22,000

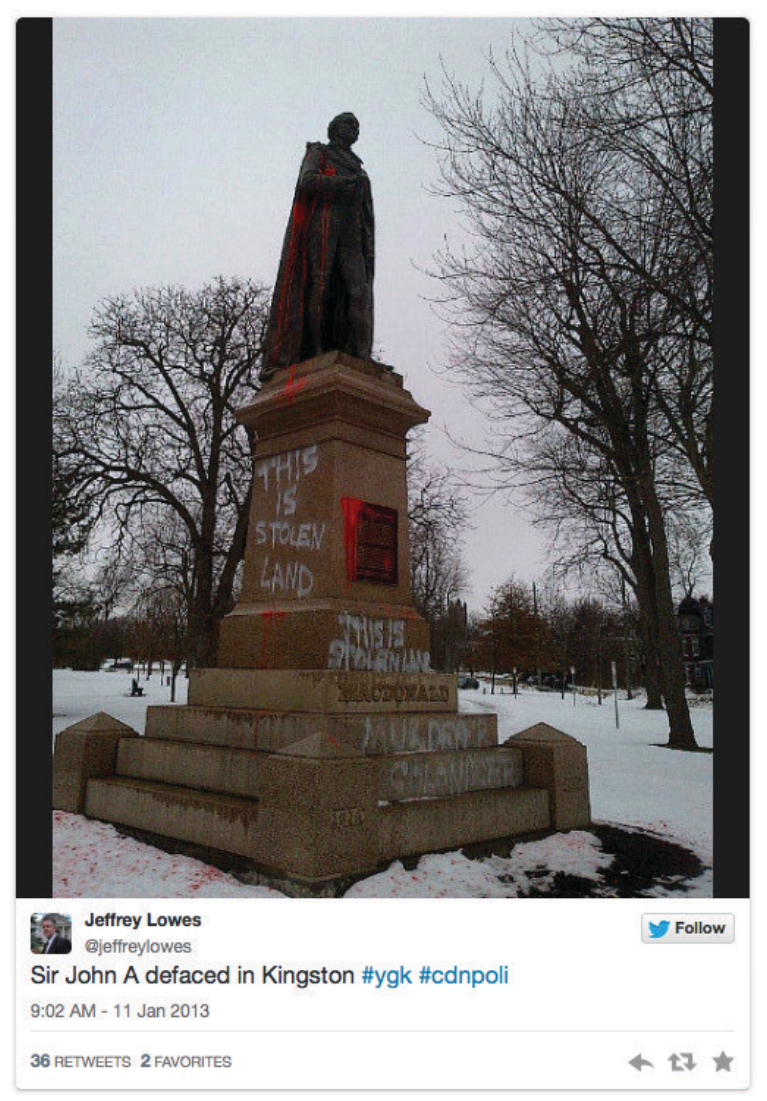

Figure 4: Sir John A. MacDonald defaced in Kingston. Photo attributed to Jeffrey Lowes. followers (Twitter.com). With coverage on Sun News Network, the National Post, the Toronto Sun, CTV News, the Globe and Mail, and CBC News, the countercommemoration received nation-wide attention, inciting countless debates. Of course, this is nothing new in Canada. Bringing critical perspectives to public art, Art Historian Annie Gérin (2009) reminds us that vandalism of monuments has been a documented form of resistance and political protest in Canada since as early as 1773, when a bust of King George III, "a symbol of the might of the British Empire," installed near l'Église Notre-Dame in Montreal was repeatedly vandalized (Gérin and McLean 3) until its removal and disposal by invading Americans in 1775 . 
In Monuments and Memory, Made and Unmade, editors Nelson and Olin (2003) invoke Anthropologist Alfred Gell's arguments “...that the monument is a particularly motivated form of an art object... Rather than a means of symbolic communication, the art object... is a means of acting, a way of transforming the world" (7). Contextualizing challenges to heritage in the late modern period, Harrison discusses art responses and the rise of pastiche. He notes that Fredric Jameson (1991) "pointed to frequent occurrence of pastiche, the imitation and mixture of styles or borrowing of aspects of other creative works in postmodern cultural forms...[and]... saw the widespread adoption of pastiche in postmodern creative arts as a reflection of the crisis in historicity, as it represents a form of juxtaposition without a normative foundation" (Harrison 77). Not restricted to the domain of artists however, public art and in particular participatory art has increasingly become a way of resisting 'official' heritage and mediating its message. Discussing repeated vandalism of Pierryves Anger's work of public art, Le malheureux magnifique,1972, as evidence of the Derridean supplement at play, Gérin (2006) suggests the grafitti draws the work in its material and immaterial aspect into dialectical ${ }^{44}$ argument, mirrored by a similar dialectics of memory and praxis. Generative of palimpsest and pastiche, Gérin asserts layers of supplementation articulate new identities in renegotiating the power of representation and function as visual social correctives to monologic narratives. Gérin further considers spatiality a supplement to language. Noting in Gilbert Boyer's Comme un poisson dans la ville, 1998, a "radical flirtatiousness of

${ }^{44}$ Gérin (2006) refers to Hegelian dialectics, which reduced to its simplest form can be expressed by the equation: thesis + antithesis=synthesis. Gérin describes this process as one that applies layered reasoning and exploration of layered meanings in moving toward truth or regenesis. 
language with spatiality [that] creates instability," she emphasizes the spatial dimension in the dialectical 'argument' with language (331-332). The form of Comme un poisson dans la ville, akin to a heritage plaque affixed to a work of architecture, further 'flirts' with space, usurping heritage conventions while, in this case, reclaiming linguistic dominance (333). In public, and particularly monumental art, Gérin asserts a dialectical relationship between different types of authorship - those who commission, and donate the work, those who accept/take possession of it, site and install it (with or without subinterventions), those who participate in its unveiling, and those who supplement it. Memorials reflect the type of society desired by their sponsors through their material contributions to collective memory and the production of historical myths. Public art and its supplement(s) then become a powerful social corrective and means by which the public can mediate heritage and memory.

To continue interpreting public art-as-resistance in Derridean terms, Sue Williamson's The Last Supper, 1981, an art installation composed of material detritus from the demolished District Six site, exhibited at a downtown gallery in Cape Town, (Hall 2002, 301) can be viewed as a construction of the trace, which Derrida (1973) defines as "not a presence but... rather the simulacrum of a presence that dislocates, displaces, and refers beyond itself," (156). Williamson's trace became the genesis (and source of initial funds) of what later became the District Six Museum. In 1993, Williamson supplemented her earlier work with The Last Supper Revisited, now part of the permanent collection of the Smithsonian's National Museum of African Art. Although it is not being exhibited at this time, the Smithsonian's narratives attest to its past influence," The encased remnants of a 
vibrant community life in the District are treated as witnesses to and survivors of racist apartheid system. The installation as a whole highlights the power of art to embody social action, shared memory, and forgotten histories" (National Museum of African Art).

In Witness and Trace: January 25 Graffiti and Public Art as Archive, Cassie Findlay (2102) characterized the removal of graffiti generated during days of protest leading to the Egyptian revolution in Tahir Square, Cairo as "an act of politically driven memory vandalism" (178). Dr. Khaled Fahmy, the historian in charge of the National Archives of Egypt's Committee to Document Jan 25, suggests "Closing people off from the sources of their own history is an inherently political gesture, and equally opening that up is a political - even revolutionary - act" (qtd. in Findlay 180). Using the concept of trace in its generic sense, Findlay asserts, "When a trace becomes a record by virtue of being part of a recordkeeping system, it assumes a new identity - one which brings with it greater power and possibility for societal understanding, reform and reconciliation" (179). Archiving-as-resistance then appears a worthwhile complement to art-as-resistance approaches. 


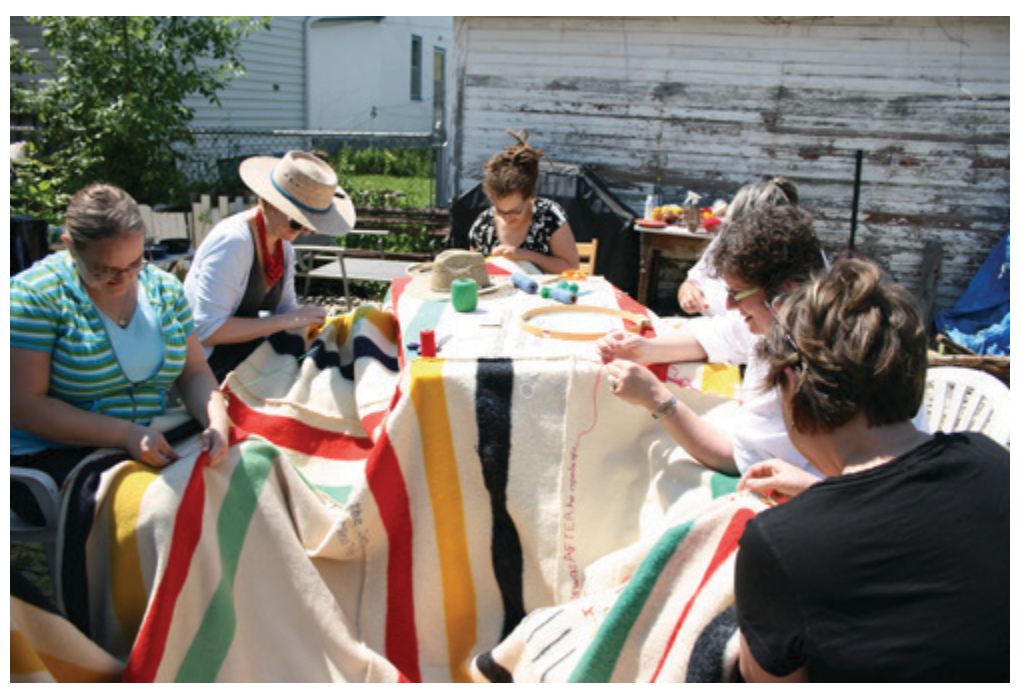

Figure 5: Leah Decter with guests stitching official denial: trade value (in progress), 2010 and ongoing.

Two artists whose recent works embody both art-as-resistance and archiving-asresistance approaches are Leah Decter with (official denial) trade value in progress, and Christi Belcourt in Walking With Our Sisters. Described as "an ongoing interactive project initiated by artist Leah Decter, curated by Jaimie Isaac, and activated in collaboration, '(official denial) trade value in progress' enacts exchange and elicits dialogue about contemporary conditions of settler colonialism and processes of decolonization and reconciliation in Canada"(leahdecter.com). The works, a composite blanket comprised of several Hudson's Bay Company point blankets stitched together pictured in figure 5, features words from both Prime Minister Stephen Harper's Apology to Survivors of the IRS and his statements made at the G20 asserting that Canada has "no history of colonialism" sewn onto it. Audience members are invited to write comments in an accompanying book and later, through 'sewing actions' their works are sewn onto the blanket - both a site of dialogue and a participatory archive. Walking with Our Sisters, a "commemorative art installation for the missing and murdered Indigenous women of Canada and the USA," invites participants to create moccasin vamps, "the tops of 
moccasins... intentionally not sewn into moccasins...[that]... represent the unfinished lives of murdered of missing Indigenous women, exhibited on a pathway to represent their path or journey that was ended prematurely" (walkingwithoursisters.ca). With thousands of vamps donated by participants in Canada and elsewhere, exhibition bookings into 2018, and a Facebook membership of over 14,000 members (as of June 24, 2014), Walking with Our Sisters represents a particularly publically-supported resistance project. The archives created through these projects, the creation of which Findlay would describe as a political act, serve as "important counters to those formed by business or government recordkeeping," (Findlay 181).

Just as Harburg's disappearing monument stimulates supplementation, dialogue, and remembering, these forms of commemoration provide a forum for sharing authority and practicing heritage as a political action and corrective to monolithic or temporally constrained narratives. Although participatory public art processes have begun to proliferate in art galleries and museums, this and other forms of public supplementation have yet to penetrate the vast majority of Canada's Historic Places.

\subsection{Considerations of Place}

One of the outcomes of an artistic incubation held on the site of the former Shingwauk Indian Residential School was a "deep realization ... of the value and importance of sitespecific collaboration" that if "a group of practiced creators come together for a period of investigation at a location that is rife with history and activity, there will be massive amounts of artistic output and future collaborations" (Dewar et al. 48). The Practicing 
Reconciliation research team, organizers of the incubation, concluded "the goals of reconciliation could be further served through active engagement with artistic practices" moreover "artistic expressions by Survivors can be integral to the healing process" (ibid). In Monumental Interventions: Jeff Thomas Seizes Commemorative Space, Art Historian Claudette Lauzon argues that Thomas' artistic work on the site of the base of the plinth of the Champlain monument formerly occupied by an Indian scout "prolong[s] the dialogue initiated by the controversy [over the removal in 1999 and subsequent relocation of the scout] in order to disrupt the monological narrative imposed by the commemorative space, and ultimately to reshape that space.” The monument to Samuel de Champlain, was originally erected without the scout at its base. The Indian scout - so named by Thomas, added in 1924, symbolized the necessary wild and savage Other, the very incarnation of the land, which seemingly invited civilization and cultivation in its deference.

Despite its colonial implications within the Canadian narrative project, Thomas argues: "Why do the Indians always have to move?" (Lauzon 84) preferring instead that the scout rest frozen in place - lending itself to reflexive post-colonial interpretation and interrogation. Thomas' occupation of the site vacated by the scout and his reinscription of its narratives through his art practice is described by Lauzon a process of intervention that "transform[s] monumental spaces into spaces of contestation between hegemonic colonial narratives and oppositional post-colonial narratives, or what Homi Bhabha terms the "Third Space"” (ibid 80). In 2013, Jeff once again "seized the space" reprising his earlier photographic work and together with Greg Hill, Indigenous Curator at the 
National Gallery of Canada, performed a restorying action in the form of a conversation between the artist and the scout - embodied by Hill. According to Art Historian Ruth Phillips (2003), Thomas "regards the re-membering of the pasts of aboriginal peoplepasts that have been overlaid with romantic and popular cultural stereotypes-as an essential defense against the threats to indigenous identity" (294). Phillips argues, "a key strategy of his interrogation of the Champlain monument is the juxtaposition of images that contrast the specificity and immediacy of living people and popular culture with the romanticization of historic monuments" (ibid). In examining race and space, Sherene Razack (1983) considers, the "symbolic meaning of spaces" and stresses the significance of "understanding ourselves as located in a [racialized] social system" relative to our constructed material landscape (8). Following her formulation, sites are lived: experienced by their various inhabitants, conceived as sites of assimilation as education, perceived through the regimentation of quotidian routine, and in some cases reconceived through commemoration. This may involve at one end of a spectrum, repurposing creating new memories as relived and re-perceived spaces, and at the other demolition and destruction, which also create opportunities for new (decolonized) memories, associations, and lived/perceived experiences.

Similarly concerned with sites and contested uses of space, is Art historian Geoffrey Carr. In Atopoi of the Modern: Revisiting the Place of the Indian Residential School, Carr considers how IRS sites are commemorated, memorialized, and repurposed. Carr categorizes IRS as atopoi or non-places, "places without place, ... without memory...both outside yet implicated in the juridical order of the state and the sociocultural bounds of 
indigenous communities" (Carr 112). He envisions these atopoi, "factories of modern colonialism," physical expressions of the "civilized' nation in a specific architectural form, building on the foundational work of Cole Harris who makes similar claims in Making Native Space (Carr 113). Disrupting traditional Indigenous land-use and embeddedness, Carr argues that the imposing presence of the residential schools served to "pacify the nation's Indigenous communities" while as Harris asserts, establishing "colonial hegemony in this western province" (133). Carr's contention, "that the analysis of the architecture of the Indian Residential School system allows for a shift in critique, so that personal narratives of the trauma are set alongside the materialization, in built structures, of policies intended to govern Indigenous peoples" (113) bears resemblance to that of Thomas to "introduce dialogue and debate into a space theretofore reserved for the official and executive monologue" (Lauzon 79). Both create third space, making possible restorying and reinscription of narratives. For Carr, considering the architecture and attendant complexities of the schools' uses of space contributes to truth-telling and healing.

In the face of time-space compression [Nora's acceleration of history], Huyssen articulates the collective need to "... secure some continuity within time, to provide some extension of lived space" (434). This however appears to call for Bhabha's 'third space', a space removed from the continuity of time to allow us to critically grapple with history and forge new understandings and new memories. I propose that Sites of Conscience allow us to materialize third space. Liz Ševčenko, founding Director of the International Coalition of Sites of Conscience describes sites of conscience as places [originally 
conceptualized as museums] that interpret history through historic sites; engage in public programs that stimulate dialogue on pressing social issues; promote humanitarian and democratic values as a primary function; and, share opportunities for public involvement in issues raised at the site (Wmd.org). She posits "Sites of conscience and the activities we organize at them can serve as powerful new tools in at least four processes: truth seeking and building a culture of 'never again'; reparations; reconciliation; and civic engagement, or democracy building." (ibid). As of 2014, there are 72 sites of conscience in the US, 62 of which are internally focused, exploring issues such as unlawful incarceration, slavery, racism, persecution, women's rights, and poverty among others. In contrast, Canada is also a coalition member, represented by two sites of conscience: the Canadian Museum for Human Rights, which as previously mentioned, refuses to acknowledge the IRS system as a genocide, and Children/Youth as Peacebuilders, an internationally-focused charitable advocacy group that defends the rights of children and youth living in sites of armed conflict. Although as previously mentioned, a few National Historic Sites of Canada do indeed focus on difficult knowledge, I feel it is fair to say however, that Canada has not yet fully embraced or made use of the Site of Conscience concept.

While many sites of conscience fall into the category of memorial museum, many of those are situated on, or include heritage sites and memorials, such as Andersonville National Historic Site, site of the infamous American Civil War-era military prison and cemetery and Bosque Redondo Memorial At Fort Sumner Historic Site in the US, the 
Gulag Museum at Perm-36 (Russia), and the Workhouse (England).$^{45}$ The Workhouse, last refuge for Victorian-era English paupers uncannily resembles many IRS. According to The National Trust (UK), its architecture like that of prototype residential school Carlyle Industrial School - and its Canadian counterpart, the Regina Industrial Schoolwas inspired by prison designs (Nationaltrust.org.uk). Its history of harsh disciplinary regimes, policies of segregation and labour, and poor food and provisions mirrors that of most IRS. Significantly, it was the prototype for workhouses throughout England and galvanized government attitudes and policy on pauperism. Now open to the public with exhibitions, live animation, and participatory exhibitions, the Workhouse educates new generations of visitors and stimulates dialogue on social policy and human rights. A school like St.Anne's IRS in Fort Albany, one of the schools where, according to Justice Paul Perrell of the Ontario Superior Court of Justice, "It is known, for example, that an electric chair was used to shock students as young as six years old, [and]...It is known, for example, that the staff at St. Anne's residential school would force ill students to eat

45 The Andersonville National Historic Site - At its most crowded, the 26.5-acre Camp Sumter Military Prison held more than 32,000 Union prisoners of war, many of them wounded and starving, in horrific conditions. During the prison's 14-month operation, 12,920 prisoners died and were buried in a cemetery nearby. The Bosque Redondo Memorial at Fort Sumner State Monument solemnly remembers the dark days of suffering from 1863 to 1868 when the U.S. Military persecuted and imprisoned 9,500 Navajo (the Diné) and 500 Mescalero Apache (the N'de) on a reservation known as Bosque Redondo - an area that encompassed 1,600 square miles (over one million acres). For more than seventy years, until the overthrow of communism in 1992, the Soviet government could enter any house or factory and simply take people away - to secretly execute them, or send them into exile or to one of thousands of prison camps known as the GULAG. Perm-36 was one of the most notorious of the camps. Built in 1824, the Workhouse at Southwell provided the British government with a "solution" to the problem of caring for those unable to care for themselves. Designed to act as a deterrent to poverty, this bold experiment influenced national policy on the poor became the blueprint for hundreds of workhouses subsequently built across Britain. (Sitesofconscience.org). 
their own vomit" (Galloway), would offer unparalleled insight into the day-to-day experience of Survivors, communicating the horror of IRS while cultivating a necessary culture of 'never again' in Canada. Of course, Survivors may neither wish for IRS sites to be used in this way, nor to encourage 'dark tourism' ${ }^{46}$ and as Brett and others caution, "monolithic state projects with insufficient community involvement can be resented by the very people they ostensibly honor" (2). Yet as Ševčenko (2004) notes, "historic sites are critical forums for ongoing dialogue on past traumas and their legacies. They are permanent place for democratic engagement, which itself helps to ensure against future suppression of human rights" (15), suggesting that site-specific education and healing (at least at a collective level) may be mutually supported drives.

While District Six Museum, one of the best-known sites of conscience, "came into being as a vehicle for advocating social justice, as a space for reflection and contemplation and as an institution for challenging the distortions and half-truths which propped up the history of Cape Town and South Africa" (Harrison 152), it did so from the bottom up, not the top down. That being said, it succeeded in becoming a "popular symbol of the subversion of apartheid and part of the new national history of resistance, rooting the current national political agenda in the past and providing a set of foundation stories for a post apartheid era" (155). Historical Archaeologist Martin Hall (2001) describes the lived quality of District Six Museum:

${ }^{46}$ According to Executive Director, Institute for Dark Tourism Research, Philip Stone, (2011), dark tourism can be defines as "the social scientific study of tourism and tourists associated with sites of death, disaster or the seemingly macabre" (318). For more on dark tourism, visit: The Institute for Dark Tourism Research (iDTR) at http://dark-tourism.org.uk 
The material world of District Six...signals a radically unstable space. Objects are continually reinterpreted and reclaimed, the ground is marked and paced out, and mosques and churches used in defiance of wasteland. In consequence, the space that is District Six is 'lived': active, defiant, contradictory, and contested. And this lived quality is founded in the material, the embodiment of 'third space' and the resistance of the margins (310).

Therein lies the power of sites of conscience - they provide a locus for recreating foundation stories based in human rights - through them states and their public can differentiate themselves from their forbears, reinventing the nation. However, if the 'reinvention' fails to provide justice and redress, it will be destined to remain inadequate and subject to ongoing resistance.

What would keeping sites open for self-reflexive uncertainty involve, and whom would such sites serve? Despite the importance of fostering multi-valence, as the example from Chile's Truth and Reconciliation Commission shows us, the duty on the part of the state to remember can come into conflict with the principle of multi-vocality, which can give voice and credibility to apologists for, and deniers of, human rights abuses including those of genocide. Uncertainty then, would appear to have its limits. Inevitable public supplementation, whether through art, archiving-as-resistance, vandalism or other public corrective social action, allows self-reflexive expression as a means to destabilize state narratives. States however, can embrace heritage sites as fora for dialogue necessary to public processes of reckoning with difficult collective histories. Just as Survivors may reconceive and relive spaces, as discussed through the example of District Six above, and IRS commemoration below, so too can the public. Such sites of conscience can communicate and affirm our collective commitment to human rights even as they create space for contestation and resistance. While providing an important mechanism of state 
and public witnessing, necessary for recognition - a precondition to reconciliation, we must also consider our moral obligation to privilege uses of sites of trauma for healing of affected communities. To gain an understanding of these uses and their relationship to healing, we now turn to a discussion of IRS Survivor-led commemoration.

\subsection{Heritage Practices of IRS Survivors, their Families, and Communities}

While Cultural Heritage Management Scholar Anna Brace has performed the major research and analysis of IRS commemoration projects that occurred before the implementation of the IRSSA commemoration fund, scholarship that I cite extensively, I have performed the only original research (albeit initial and preliminary) of which I am aware, on the IRSSA-funded commemoration projects. Consequently, both the presentation of themes and case studies related to the former rest on secondary sources, my analysis of the latter relies only on my own research and observations.

\section{A Quantitative Snapshot of Pre-IRSSA Commemorations}

Brace conducted her research largely from interviews, news sources, and various archives. She suffered a low participation rate from the Indigenous communities she contacted due to various reasons well documented in her (2012) work. She states, "of the 139 schools identified for inclusion in this study [corresponding with the 139 schools recognized in the IRSSA], information leading to coding classification [and analysis] was only available for 50\% (70) of the structures" (32). In fact, Brace's work is very site and structure-centric and did not extend to the kinds of commemorations, such as ceremonies and events not associated with IRS sites, cultural production, and healing practices, 
which were made possible (and motivated by the TRC) under the IRSSA commemoration fund. In this respect, her study speaks to the tangibility of a number of the remaining sites and structures and questions how to integrate destruction and intangibility into formulations of heritage in Canada. With that caveat, her findings follow:

- $47 \%$ (27) of classifiable structures have been adapted for reuse at least for a portion of time, with a small number including a commemorative component

- $61 \%$ (43) of classifiable structures were destroyed - information of the causes is lacking or anecdotal ${ }^{47}$

- $12 \%$ (5) of all destroyed buildings were done so in a ceremonial manner

- $31 \%$ (18) of classifiable structures had more than one classification attached, demonstrating the dynamic nature with which communities addressed them

- 245 (11) of sites had multiple entries and of these entries $61 \%$ show some form of continued use with development being the most common form, closely followed by relatively equal levels of replacement and ceremonial use

- $22 \%$ (10) indicated the presence of some form of commemorative marking on the site (33-34)

${ }^{47}$ Braces mention that she encountered multiple anecdotal comments indicating that the fires were started by Survivors (33). 
Brace also notes that "the number of structures and sites that have been left continuous vacant since their closure is particularly low," which she suggests demonstrates "the involved nature that many Aboriginal communities have had in establishing strategies to address these structures and site" (34).

In order to get a sense of some of the issues involved with the commemorations explored in her study, and which will be subsequently explored in the next chapter, if bears drawing closer scrutiny to two examples, which sit at either end of a spectrum that runs from construction to destruction.

\section{Example 1: Adaptive Re-use}

As discussed in the previous chapter, the Ktunaxa/Kinbasket Tribal Council in 1996 sought heritage designation of St. Eugene Indian Residential School, a large Catholic IRS located in Cranbrook, BC, which operated from 1898-1970, and was attended by students from Southern Alberta, the Okanagan and Shuswap, and the local Ktunaxa area. While the Tribal Council dealt with what must have been the many frustrations of

working with the $\mathrm{HSMBC},{ }^{48}$ they were also embarking on a $\$ 40+$ million renovation that saw the former school transformed (Figure 6) into a luxury resort complete with casino and golf course (Carr 127). Following the work of Benton and Cecil (2010) and Lowenthal (1975), Cultural Heritage Management Scholar Anna Brace (2012) suggests that "the tangible remains of traumatic events must adapt' to meet the [desired]

${ }^{48}$ As mentioned in the previous chapter, the HSMBC ultimately did not confer heritage designation on St.Eugene IRS. 
modifications of memory (8). She cites Lowenthal's (2003) five tactics for memory modification: to ignore, to erase, to celebrate, to transmute, or to commemorate, however favours a model that examines continuous creation and layermaking (8-9). She describes the results of modification of the object (artifacts, structures, and sites) as multi-layered objects (or landscapes), which "while initially constructed for a particular purpose," (Razack's conceived space), "take on additional significance through the use change or even removal of their tangible fabric" (10). In this context, layermaking appears to correspond with Gérin’s uses of Derridean ‘supplementation'. Spaces of difficult heritage, "originally constructed by oppressors, are now managed by Survivors" (10) thus become (re)lived, and (re)perceived. The radical repurposing of St. Eugene in this regard may also be an instance of symbolic repatriation.

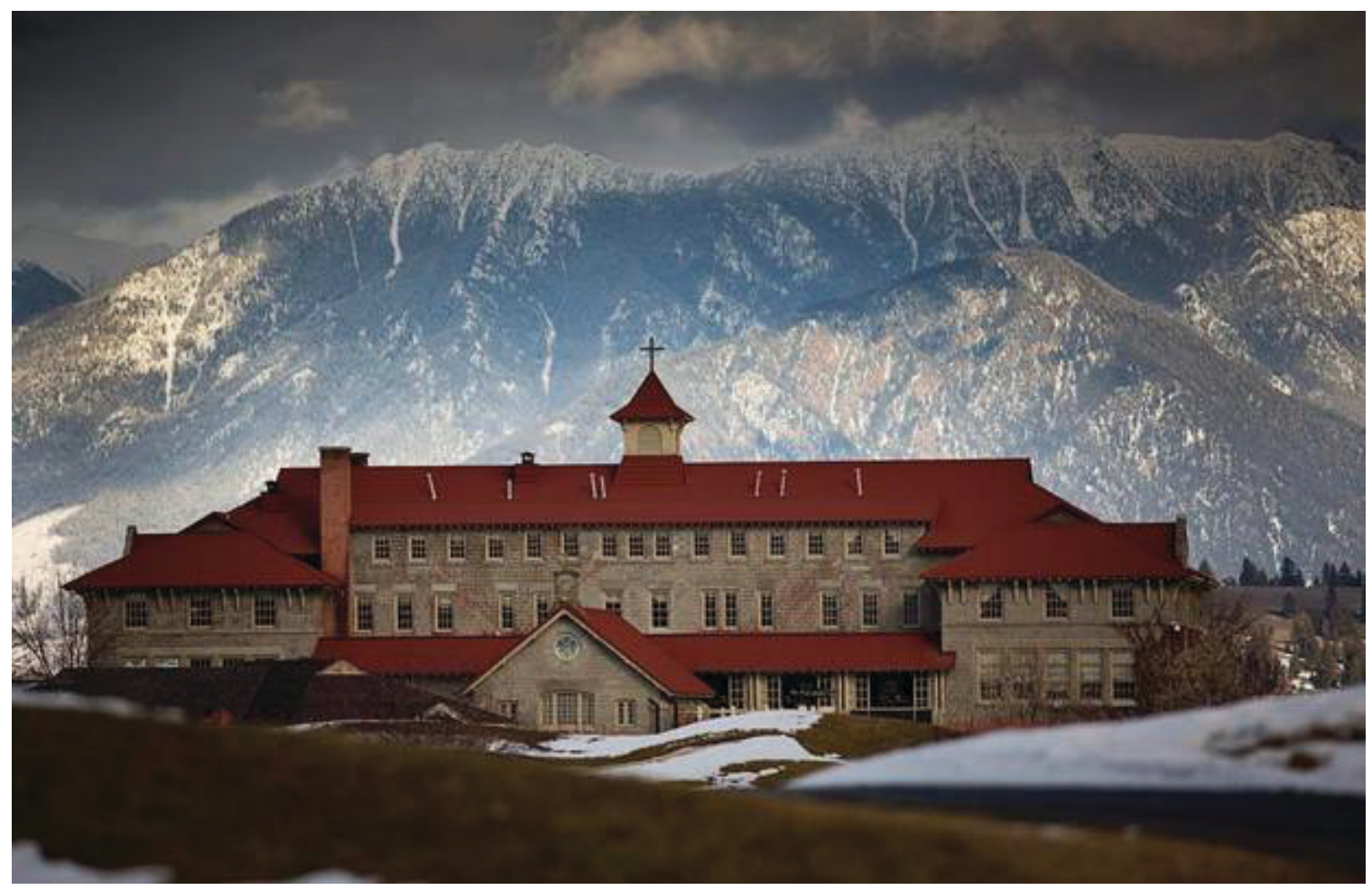

Figure 6: The Former St. Eugene Indian Residential School adaptively reused as a golf resort and casino. 
In the case of St. Eugene, it is interesting to note that in the midst of trying to come to community consensus on what to do with the school, the vision of an Elder, whose statement, "since it was within the St. Eugene's Mission that the culture of the Kootenay Indian was taken away, it should be within that building that it is returned" unified the community (Brace 38). Since that time, the reclamation and adaptive reuse of St. Eugene has reconceived and realized the conversion of an oppressive and abusive landscape into a powerful economic engine (Carr 130), and, "for the Ktunaxa-Kinbasket...a solution to historical and cultural devastation is enacted through mnemonic and material place transformation" (de Leeuw 311). As Cameron (2010) affirms, "sites of conscience, often lacking in physical material evidence, invariably have powerful intangible values that recall human rights abuses and other injustices. Reconstruction of lost physical fabric is often part of the process of coming to terms with the past" (118).

\section{Example 2: Demolition as Commemoration}

Article 6 (3) of the UNESCO World Heritage Convention states that state parties (of which Canada is one by acceptance of the Convention in 1976) have the responsibility to not "take any deliberate measures that directly or indirectly damage their heritage or that of another State Party to the Convention" (1972). For Brace (2012), layermaking occurs also in destruction, as she points out in invoking Viejo-Rose (2011), "Acts of destruction shape memory in several ways: by adding new memories, by adding new meanings, creating new associations with perpetrators, discourses, contexts, and sites of destruction, and by consigning to the realm of memory those sites that are destroyed" (59-60). Peake Hall, an IRS in Port Alberni BC, reputed to be "one of the worst Canadian residential 
schools in terms of the violence it imposed on Indigenous children" Corntassel et al 2009; 143), was actively and ceremonially destroyed in an event hosted by the Tseshaht First Nation on whose territory the school was situated. Survivors and their families were able to participate in the demolition where "Sage and cedar were burnt with the pieces" of the building pried off with crowbars and sledgehammers," in order to "cleanse and allow the trapped spirits to be finally freed (143). Both a political and healing action, the demolition was similarly an act and practice of reclamation, returning power to the communities from whom it had been robbed for decades through the schools operation and beyond. In her survey of 139 IRSSA schools, Brace (2012) noted that many for which she was able to find information, had been demolished by fire, some ceremonially, some by accident, and a number from inconclusive circumstances. Like the KtunaxaKinbasket, the Tseshaht First Nation consulted with the community to determine by which means to best commemorate their experiences. In their case, no application for heritage designation was put forward, it being inappropriate to their needs. Surely the HSMBC would have found the Tseshaht's desire to demolish the structure incompatible with their commemorative values, of which the premise of commemorative integrity is foundational.

Despite the drastically different outcomes of the two examples, both reclaim space, allowing their respective sites to be reconceived and relived. However, the persistence of settler violence is evident even in processes and mechanisms of apology, redress, reconciliation, and heritage. According to oft-cited settler/ally scholar Paulette Regan, "settler violence against Indigenous peoples is woven into the fabric of Canadian history 
in an unbroken thread from the past to the present, "...we must work as Indigenous allies to 'restory' the dominant culture version of history... as told by Indigenous peoples themselves" (Corntassel et al 138). In Indigenous Storytelling, Truth-telling, and Community Approaches to Reconciliation, haa-huu-pah, a practice of the Nuu-chah-nulth, refers to "teaching stories or sacred living histories that solidify ancestral and contemporary connections to place," core teachings that form the basis for regeneration (ibid.137). The profound rupture to the continuity of traditional practices like haa-huupah effected by the IRS system fundamentally inhibited regeneration, leaving Survivors, their families, and communities a limited toolkit with which to reconcile their histories and fractured cultural inheritance. It is not surprising that critics of 'official' reconciliation ask, "Given the origin of Canada, what can descendants of squatters or settlers offer Indigenous peoples by way of reconciliation?" (ibid. 139). Instead, they propose community-based approaches to reconciliation that involve, but are not limited to, processes of storytelling and truth-telling that connect place to lived and shared experiences, which ultimately contribute to restorying and restoration of haa-huu-pah and similar cultural practices.

\section{IRSSA Commemoration, the TRC, and AANDC}

Recognizing the need for commemoration, healing, and recognition - acknowledgement of the impact of IRS, Survivors and their advocates fought for the inclusion of a commemoration component in the IRSSA. The purpose of commemoration is defined in IRSSA Commemoration Policy Directive, Schedule J, as: Honoring, educating, remembering, memorializing, and/or paying tribute to former residential school students, 
their families, and their communities and acknowledging their experiences and the broad and systemic impacts of the residential school system (Indian Residential Schools Settlement Agreement). Although the process for evaluation developed by TRC and awarding funding developed by AANDC was somewhat bureaucratic, not unlike HSMBC nomination process, the most significant difference between the IRSSA commemoration program and the NPHC, was that the former was a funding program while the later a complete heritage designation program wherein the major activities leading to commemoration were performed internally. ${ }^{49}$ Another major difference, related to the creation of subjects, is that with the IRSSA commemoration project, Survivors were a major part of the evaluation process, hence those established as commemoration 'experts' were undifferentiated from the applicants.

The funding limits for individual projects were set at $\$ 50,000$ for a community, however the TRC Commemoration Initiative Call for Proposals Guide, hereafter referred to as the 'guidelines' (Appendix E), allowed up to 10 communities to collaborate on a single project with a budget up to $\$ 500,000$. The limit for national commemoration projects was set at $\$ 2$ million. To assist communities to conceptualize their projects, the TRC

${ }^{49}$ From a process standpoint, proposals were to be submitted to the TRC (first the Secretariat, then the Survivor Committee, then the Commissioners), who then made recommendations to AANDC, the party responsible for approving proposals within the limits of Treasury Board Guidelines. AANDC was ultimately responsible for administration (and management) of the funding. In contrast, the HSMBC nomination process involves intake at the Secretariat, review by Parks Canada Historian and preparation of a report for the Boards review. This is followed by review in session with the Board, recommendations sent to the Minister, and if agreed, an announcement of designation to the proponent - all in all, without complications, a two-year process - See Appendix $\mathrm{G}$ for a flowchart of this process. 
describes three kinds of projects communities could consider: lasting legacy initiatives with examples listed as monuments, plaques, traditional structures, one-time events such as feasts and gatherings (with the caveat that they must contain a lasting or permanent component), and cultural components, described as workshops, development of materials/resources, performance, among others. Proposals were evaluated against a grid that was also distributed with the guidelines. Its wording is often reflected in the project summaries, and I expect that the use of keywords, like reconciliation and collaboration, that reflect key messages of the TRC were used to advantage in unlocking funding dollars. Proposals were evaluated against 5 criterion: commemoration program objectives - a reflection of Schedule $\mathrm{J}$ with the noted addition of healing $(30 \mathrm{pts})^{50}$, collaboration and partnerships (20pts), cultural component (20pts), impact/reach (20pts), and overall proposal quality (10pts). Weight was placed on lasting legacy components, collaborations, and linking to other aspects of the IRSSA, such as Statement Gathering,

\section{${ }^{50}$ Commemoration Program Objectives}

The proposal clearly demonstrates how it meets at least three of the following Commemoration Initiative Objectives (as outlined in Schedule J of the Settlement Agreement):

- To assist in honoring and validating the healing and reconciliation of former students and their families, addressing their residential school experience;

- To provide support towards efforts to improve and enhance Aboriginal relationships and between Aboriginal and non-Aboriginal people;

- To provide an opportunity for former students and their families to support one another and to recognize and take pride in their strengths, courage, resiliency, and achievements;

- To contribute to a sense of identity, unity and belonging;

- To promote Aboriginal languages, cultures, traditional and spiritual values;

- To ensure that the legacy of residential schools and former students and their families' experiences and needs are affirmed; and

- To memorialize in a tangible and permanent way the Residential School experience. 
TRC National Events, TRC Closing Ceremony and TRC Community Events as well as to important dates such as the National Day of Healing and Reconciliation (May 26), IRS Apology Anniversary (June 11), National Aboriginal Day (June 21). Suggestions to perform commemoration activities on the IRS sites were absent from the Guidelines; in fact, mention of the sites was conspicuously absent. While emphasis was placed on cultural expression, commemoration was framed as an idea that did not necessarily contain a heritage component. I speculate there are two reasons for this. The first is that many of the IRS sites are located at great distance from the communities from which they drew children, the present owners may be unknown or unwilling to invite commemoration, and many participants prefer to host commemorative event onsite in their community. The second is that the TRC, at the time of developing their proposal, may have been unaware or only partially aware of the ways in which IRS had been commemorated before the IRSSA, and how those commemorations had contributed to healing from historic trauma. ${ }^{51}$

\section{A Quantitative Snapshot of IRSSA Commemorations}

The following section presents the quantitative findings of an analysis of IRSSA commemoration project descriptions published by AANDC - Appendix F. This basic analysis sought to capture information regarding: the nature and output of the projects

${ }^{51}$ Anna Brace's, MA Dissertation (see Works Cited) is an excellent analysis of preIRSSA commemorations activities. 
relative to their objectives; the applicants and participants involved; and, the sites where the commemorations were performed. ${ }^{52}$

\section{Characteristics and Outputs}

Cultural Ceremonies - 69\% percent of the total projects (100/144) held some form of event or gathering. 40 of the project descriptions mentioned holding or organizing gatherings. Of those 40, 32 overtly referenced Indigenous cultural activities and were categorized as cultural gatherings or ceremonies accordingly. Examples of the Indigenous cultural activities mentioned include ceremonies with Indigenous cultural features, practices, performances and workshops, which may include sharing/healing circles, community feasts, sweat lodges, powwows, potlatches, round dances, singing, drumming, dancing, language and craft-making workshops, and traditional healing circles. 28 of the project descriptions used the word ceremony to describe their events and included cultural features. 20 of the project descriptions used the word event, of which 15 overtly referenced Indigenous cultural activities. 9 of the projects represent conferences, of which 4 featured Indigenous cultural activities. 5 of these were also described as gatherings, events, or ceremonies elsewhere in their descriptions and were consequently eliminated from the total. Based on the total number of events (gatherings, ceremonies, events, and conferences $)=100,79$, or $79 \%$ can be described as Indigenous cultural events or ceremonies (containing 1 or more of the Indigenous cultural activities previously described), for a total of $55 \%$ of the overall number of commemoration projects.

52 See Appendices A and B for Evaluation Grid (coding) and results. 
Connecting and Sharing - In addition to a range of cultural activities, performances and workshops offered at the events, 38 or $48 \%$ of the cultural gatherings or ceremonies held sharing circles or facilitated similar forums, conducted or presented Survivor interviews, or collected statements from Survivors. Many of them did so in conjunction with healing circles and traditional counseling.

Monumentalization and Memorialization - 63 of the projects involved the development of monuments (40), plaques (21), and cairns (2). 18 involved the creation and cultivation of memorial gardens, paths, and the planting of trees and traditional medicines. 13 produced memorial art, many of which were totem poles and other carvings, as site-specific commemorative markers. A total of 94 such markers were developed (not including the 139 individual markers created by a single project - the AFN/AHF Commemorative Monument project, which appears later as a case study, nor the 13 created through the Project of Heart commemorative project).

Documentary and Creative Works - Many documentary and creative works were produced, donated, and performed to honour and preserve the experiences of Survivors and to communicate the history of the IRS to future generations and to non-Aboriginal Canadians. These include: exhibits (8), books or albums (21), videos (14), curriculum or pedagogical materials (7), art works including performance-based works (13). 63, or $44 \%$, of the total number of projects involved the production of documentary or creative works. 
Healing Together - By performing an advanced word search for individual terms and their variants, I was able to chart the frequency of specific words related to the objectives of the commemoration projects as described in English. The word healing appears 102 times in the complete text, however, if duplicates per description are eliminated, that number is reduced to 65 or $45 \%$ of the projects. Other objectives in order of descending frequency are: honouring, reconciliation, connecting, reclaiming culture, remembering, sharing, raising awareness, building resilience and strength, truth, and educating. ${ }^{53}$

\section{Applicants and Participants}

Individual First Nations and small multi-community First Nations groups were the most active applicants/participants in IRSSA commemoration. ${ }^{54}$ Only 16 or $11 \%$ involve nonAboriginal applicants or participants, while the total number of mentions of government participants (any level) was 2, TRC 8, and churches (any and all), 7. 86 descriptions list Survivors (otherwise identified as former IRS students) as applicants, participants or both, while only 13 mention intergenerational Survivors. The vast majority of projects (84) were either by or for individual communities or both. Families were mentioned in 40 or $28 \%$ of descriptions, while 84 or $58 \%$ mentioned communities. Descriptions

${ }^{53}$ Connecting (includes the search term gathering) Reclaiming culture (includes the search term tradition) Remembering (includes the search term history) Raising awareness (moves up 1 place if combined with educating) 5494 or $65 \%$ of the project descriptions identify the applicants as First Nations. 4 or . $03 \%$ of the project descriptions identify the applicants as Inuit, while 3 or .02\% identify as Métis. 28 or 19\% identify as Aboriginal (encompassing First Nations, Inuit, and Métis) 
specifically listing youth applicants or participants came in at 21, women and women's groups at 2, seniors at 2, and Elders at 28.

\section{Sites of Commemoration}

Many projects had multiple elements, with some activities taking place in the community (72) some at a multi-community hub (36), out on the land (2), or on the site of a former IRS or associated burial grounds (23). 36 of program descriptions failed to make explicit mention of the location of their activities. ${ }^{55} 13$ or $9 \%$ took place at the facilities of cultural heritage or health organizations although this is difficult to gauge based on existing information, because some of the multi-community or municipally-located activities may have been hosted by cultural organizations.

\section{Collaborations}

Although collaboration and partnerships were promoted in the guidelines at a weight of 20 points out of 100, most projects that involved collaborations were between First Nation communities or First Nation communities and First Nation organizations. Few projects linked to TRC and other IRSSA elements or important dates.

\section{An Important Outlier: AHF/AFN National Commemorative Monument Project}

Few projects attempted to mirror government heritage processes. One project however, attempted to create its own heritage plaque program, an endeavor that was transformed

${ }^{55}$ Although it might be reasonable to assume that these activities took place, at least in part, in the applicant community, unless explicitly mentioned they are not included as such. This accounts for the high number of 'location unspecified' entries in the data. 
over the course of the project. In December of 2010, at an AFN Special Chiefs Assembly, the Chiefs-in-assembly passed a resolution to: "direct the AFN to apply for a portion of the \$20 million for Commemoration Initiatives...for commemorative markers (monuments) for each and every Indian Residential School where First Nations children were placed and attended," and to "direct the AFN to make these funds available to First Nations and Tribal Councils [communities] located near the Indian Residential School sites for the markers (monuments)" (Assembly of First Nations). I became involved with this project in March on 2012 as a proposal writer and later as a project manager representing the AHF.

The strategy to achieve the Chief's objectives, which expanded to encompass all Survivors of IRS and their communities -Inuit and Métis in addition to First Nations, was based on a succession of stages that progressed from tasks performed centrally, under the guidance of a Steering (Project Governance) Committee and a specialist (heritage) Advisory Committee, to those performed at the community level. ${ }^{56}$ These involved mapping, legal, granting/funding, design and fabrication, cybercartographic, and community-based commemoration processes.

${ }^{56}$ These committees were designed to bring various stakeholders and experts (Elders, Survivors, representatives of the three national Aboriginal groups, and National Aboriginal Women's groups, and parties to the IRSSA, relevant academics, representatives of HSMBC Secretariat, Canadian Heritage, Health Canada, Indigenous artists, curators, and art historians and academics) together, to govern and guide the project. 
Delays in funding and a reduction in budget created problems for the outset. The funding delay reduced the 18-month project timeline to 1 year, shunting the marker distribution phase and IRS site commemorations into the 3rd and 4th quarters of the AANDC fiscal year, ending March 31, 2014. In addition, geographical data sourcing proved problematic. None of the three main sources of IRS site location data - AANDC's Research and Analysis Directorate, the TRC Research unit, and The Lake Huron Treaties Cybercartographic Altas, were able to provide a complete, or even near complete, set of validated geographic coordinates such that title searches and IRS site property owners could be identified.

At the first Steering Committee meeting, a number of project challenges were identified and discussed. The Steering Committee members were most concerned with the project timeline, which would require communities to immediately submit their grant applications, plan their events, and convene community members to develop text for the markers (which were then envisioned as individual plaques, each containing communityprovided text), negotiate with site owners, and then install access the sites and install the plaques in the fall or winter as opposed to the spring and summer as originally projected. The timeline was unrealistic and the possibility of an extension seemingly impossible despite attempts from various Steering Committee members and the AFN CEO to reason with senior management at AANDC, whose program and spending authorities ended on March 31, 2014. Instead AANDC suggested AFN identify and return funds that could not be spent by March 31,2014, an idea unpalatable to AFN who had fought for the inclusion of commemoration in the IRSSA. In the midst of meetings and negotiations, the call from 


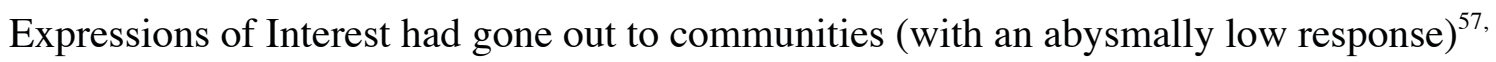
a Heritage Consultant had been contracted and the Advisory Committee convened. During this period the project transformed from what ostensibly had been an IRS site heritage plaque program to a community-oriented public monumental art project.

\section{Refining the Concept}

It was decided by the Steering Committee in late fall to make the community, rather than the IRS site, the destination point of the markers. This decision was made for several reasons including community preferences and lack of proximity to the IRS sites, inability to secure site permissions due to lack of mapping data, and the late award of funding from AANDC and the corresponding shortening of the timeline requiring winter groundbreaking, an impossibility in most locations. On the whole, the Steering Committee was satisfied with the decision to make communities the terminal point for the markers, which would allow for greater participation in the marker unveiling and commemorative activities, and provide the opportunity for ongoing commemoration through education.

${ }^{57}$ In October 2013, in an effort to stimulate applications, additional communications materials were developed and the application deadline extended. 


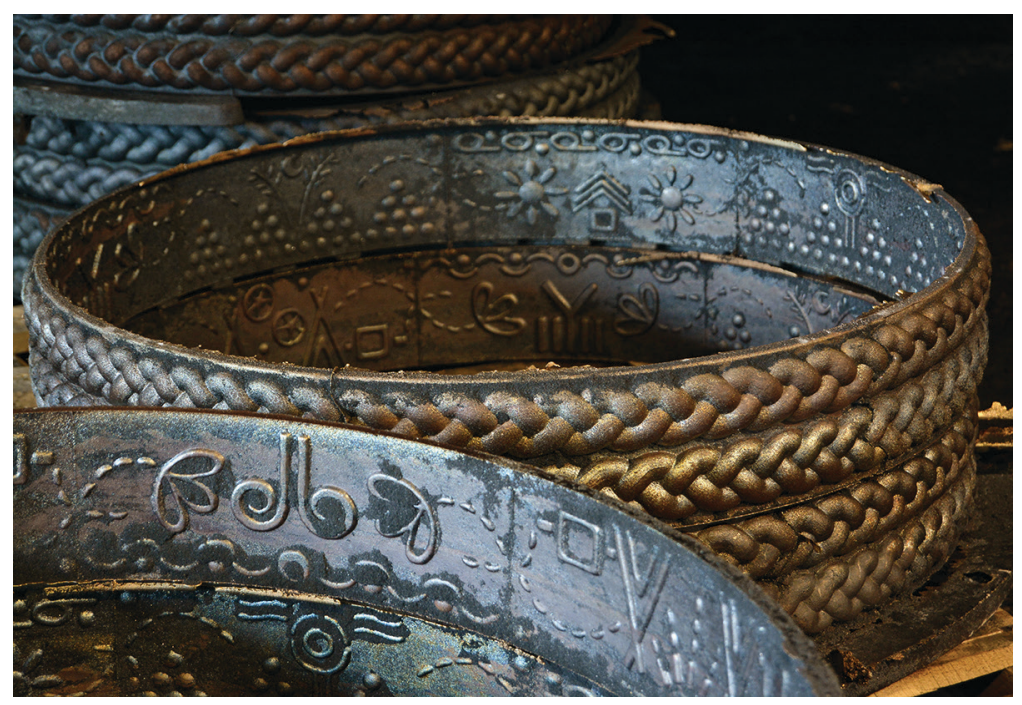

Figure 7: A number of AFN/AHF commemorative monuments mid-fabrication. Photo courtesy Tania Budgell.

Refinement to the marker concept came about in the course of Advisory Committee meetings, which the heritage plaque concept previously discussed was rejected in favour of a memorial art object. 5 Indigenous artists, Ursula Johnson, Marianne Nicolson, France Trépanier, Mathew Nuqingaq, and Cheryl L'Hirondelle, from across Canada and representative of Aboriginal diversity, selected by a specialist Advisory Committee subgroup, were commissioned and brought to Ottawa to participate in a 6-day design charette (held at Wabano Centre for Aboriginal Health) to collaboratively create the marker prototype. The Advisory Committee established the following requirements for the marker, which was by this time envisioned as a monument:

- The monument has to be durable, unforgettable.

- The monuments are for communities and for the world.

- Communities must be in control of the monuments.

- The artists responsible for the monument design need to create an object in which the narratives would be contained, rather than on which they would be inscribed.

- The shape, form, texture and iconography of the monument must respect First Nations, Inuit and Métis traditions.

- The process leading to the design, making and production of the monument must respect First Nation, Inuit and Métis traditions. 
- The community will decide what they want to include in the narratives, in their own time.

In preparation for the arrival of the artists at Wabano, the Advisory Committee further refined the monument concept and requirements. They determined that the monument must reflect Indigenous knowledge and experiences, and serve as an inclusive object of memory and education; encourage healing and reconciliation; and, remain open to the future, to changing dialogues and knowledge. Thus what was originally conceptualized as a heritage-style plaque or similar marker, was re-envisioned as an art object infused with symbolism and cultural meaning. Rather than continuing to pressure communities to develop narrative text to be inscribed on the markers, the monuments were conceptualizes as symbolic vessels - to be made meaningful through commemorative practice. The virtual commemoration tool set was expanded to allow communities to publish commemorative narratives online, which would allow them to be constructed over time, effectively extending the March 31, 2014 deadline.

\section{Realization}

The monument prototype (maquette) was launched in ceremony at a community and media event on March $12^{\text {th }}$, attended by many Steering and Advisory Committee members, Justice Murray Sinclair, Chair of the TRC, as well as members of the local arts, heritage, and academic community. Storytelling framed the unveiling, which was enriched with vocal and dance performances reflecting the four directions of the Medicine Wheel and in turn the diversity of Indigenous Peoples in Canada. An excerpt from their Artist Statement, delivered at the unveiling, follows: 
Charged with the responsibility to create an inclusive and participatory container to mark the place where every residential school was located and / or where every community was affected, we collectively decided to depart from the western concept of heritage commemoration and designation, and instead create a dynamic and versatile marker as much celebrating achievements as honouring loss; significant for survivors and communities, past, present and future. We were honoured to be asked to reclaim the Indigenous role of artist, to be in the service of the people making images and objects that while being utilitarian, remind people of their spirit and through use become animate, alive and integral. ${ }^{58}$

This Statement attests that, honoured as they were, the artists' challenge to create a marker for Survivors, their entire communities, and coming generations, weighed heavily on the them, some of whom are themselves intergenerational Survivors. The artists, however, were adamant in asserting the flexibility and polysemy of the monument, decentering it in the larger context of active commemorative practice. The paper maquette did not fully represent the monument's multivalence and multisensorial qualities, which became apparent at a subsequent visit to the foundry where they were being fabricated. There, we experienced the feel and sound ${ }^{59}$ of the monument, comprised of a bronze rod and ring featuring an outer bas-relief motif of braids, referencing the fibres of sweetgrass or hair, and a sequence of pictographic symbols of diverse Indigenous meaning in relief on the interior surface. Supportive of a healing and culture-centric heritage practice, inviting ceremony - connecting, sharing, remembering, the monument, ever-fluid in its meaning, is activated through practice. The unveiling employed the monument, then merely a maquette, to de and re-center our collective relationship through storytelling as restorying. Witnessing this performance implicated

58 This is excerpted from an unpublished artist statement associated with the AFN/AHF Commemorative Marker Project. It will be published online in the coming weeks.

${ }^{59}$ Created by suspending the ring like a gong and striking it with the rod. 
participants in the relationship and confirmed our obligations to one another. This one commemorative expression, among the 139 for which the monuments were created, illustrates the polysemic nature of the monument and the potential for diversity in its use.

\section{The Impact of Bureaucratic Constraints}

In late February, AFN was asked by AANDC to identify lapsing fund projections. Although management representatives at AANDC made efforts to secure new funding to compensate for losses in the new fiscal year, commencing April 1, 2014, no guarantees were offered. AFN elected to maintain their current project momentum and trajectory to expend all funds by March 31, 2014. Targeted outreach to communities was performed on a large scale. In general, communities expressed reluctance to organize commemoration activities and unveilings in the winter months, instead proposing a spring or summer gathering. As the deadline drew nearer, it became increasingly difficult to engage communities. They rightly argued that the spending and timeline requirements of the funding neither met their needs, nor respected how they wished to engage in commemoration. As a result, AFN was forced to lapse an undisclosed amount of funds, mostly from the community budget, which were clawed back to the Receiver General of Canada. The cyber-cartographic atlas and virtual commemoration website and application work is ongoing and will be made accessible to participating communities in the coming months. 50 of the 139 bronze monuments, which are breathtakingly beautiful but have proven extremely time-consuming for the contracted foundry to fabricate, are on the eve of distribution to communities identified by AFN (regardless of whether or not they applied for and received grant monies before March $\left.31^{\text {st }}\right)$. It remains to be seen what the 
majority of communities will $d o$ the monument, and this lack of project continuity and sustainability stands as one of the AANDC's programmatization of the IRSSA commemoration fund's most significant limitations.

\section{Looking Back}

An original consideration in the AFN/AHF commemorative project was to seek heritage designation for the entire network of 139 sites. Several challenges were identified, which initially motivated this research. These are:

1. The HSMBC does not have a mechanism by which gives control over many aspects of the commemoration is shared with or transferred to applicants and stakeholders, in this case Indigenous communities whose membership includes IRS Survivors.

2. The modes of commemoration recognized by HSMBC are rooted in 'Official notions of heritage value, commemorative integrity, while Indigenous modes of commemoration are diverse, oriented to the need for healing, and may put commemorative integrity of structure or sites at risk.

3. Commemorating IRS would require that existing NPHC narratives expand to encompass difficult and self-critical history, which will be interpreted by some as genocide, a position incompatible with current construction of Canada as presented in Park's NPHC System Plan.

4. Obligations to secure site protections in conjunction by heritage designation have the potential to inhibit reclamation and attendant healing processes for generations of intergenerational Survivors.

\section{Analysis of IRS Commemorations}

Attempts to parse and synthesize data from my limited analysis of the 144 IRSSA commemoration projects as well as from Brace's pre-IRSSA commemoration study to learn basic information about the concerns, values, approaches, and strategies of their applicants and participants are limited by the scant information available on these projects. However as a rudimentary analysis, it points to paths that should be pursued and 
questions that should be asked in designing heritage policies and programs that aim to facilitate the commemoration of IRS.

Many of the IRSSA commemorations were designed to create a lasting legacy by tangibly memorializing IRS experiences, and indeed that was a (flexible) requirement of the funding. Unveiling in ceremony, involving Elders, and including cultural practices and performances infused the commemorations with cultural and spiritual significance. The process of overcoming victimization and oppression, demonstrations of personal and cultural resilience created meaning and value. In some cases, as in that of St. Eugene IRS or Alberni IRS, the practice of commemoration transformed the site materially and symbolically. A few of the IRSSA commemoration fund art-based projects, such as the Witness Blanket ${ }^{60}$, a travelling multivocal participatory exhibition, commemorated and continues to commemorate through the iterative process of supplementation or layermaking. If, in accordance Alfred Gell's opinion, referenced in Chapter 4, the monument 'is a particularly motivated form of an art object', the role of the artist in commemoration must be considered synonymously with the role of the monument. This paper began with a quote from Haudenosaunee Artist Shelley Niro, stating that no monument-making traditions exist in her culture. In the context of a discussion concerning destroying monuments, McLelland and others note conservation scholar Seung-Jin Chung (2005) assertion,“...the very idea of the monument runs counter to prevailing values in some societies which do not produce many monumental buildings and do not emphasize the permanence of structures" (588). Conversely, art historian Jaś

${ }^{60}$ Visit witnessblanket.ca for more information on this project. 
Elsner (2003) suggests, “...the impulse to embed meaning and some of the visual methods by which meaning may be sparked in spectators are common to monuments across cultural divisions and across history" (210). A discussion of whether or not monuments have traditional meaning for Indigenous Peoples of Canada, and indeed what constitutes a monument, is well beyond the scope of this discussion. However, a significant finding among the IRSSA commemoration projects was the number of monuments ${ }^{61}$ produced.

Nearly two thirds of the IRSSA-funded commemorations involved the creation of some type of monument or memorial. Reasons for this most certainly include the fact that the creation of monuments or similar mnemonic devices were both explicitly mentioned, and implied, to be an appropriate use of commemoration funds, and were suggested as suitable examples of a lasting legacy component in the TRC guidelines. ${ }^{62}$ Another observable influence is the pervasiveness of plaques and monuments, used by HSMBC and other agencies, to identify places of historical significance in Canada. The AFN/AHF case study, discussed in the previous chapter, recorded the creative process as Indigenous artists commissioned to create a marker wrestled with notions of Western heritage, ultimately rejecting the traditional Western model and instead creating a multi-vocal work of monumental art (Figure 7). Many of the other projects developed variations on plaques and monuments, which ranged from traditional sculptural structures (such as totem poles) to abstracted art installations - all imbued with meaning, and many bearing

${ }^{61}$ For the purposes of quantitative analysis, only the project descriptions that made specific use of the word monument where counted as having produced a monument. 62 Refer to the discussion of Guideline phrasing in Chapter 4. 
the names of the Survivors as lasting testaments to their diverse experiences of trauma and healing. Some of these in turn where contextualized within memorial and medicine gardens, memorial walks, burial grounds, and arbours. Some of these were designed to change and evolve over time, but most were not. The majority were not situated on the sites of former IRS, but rather in the communities themselves, allowing members to extend the practice of commemoration (and remembering) to the quotidian. Some memorials, such as gardens and walk, required ongoing tending and care. Most were situated in the host community allowing access and promoting a relationship between the memorial and the ongoing practice of memorialization. For applicants and participants, developing a monument afforded the opportunity to reflect on and control their narratives, including its language of inscription, both figuratively and literally. Both the creative process and resulting the creation had the potential to become cultural practice. Artists were engaged in at least $18 \%$ of the activities, which if combined with the numbers for the production of documentary and creative works, rises to $53 \%$.

By progressing through a process of collectively remembering trauma and mobilizing cultural practices, which are often healing practices, to counter-memorialize and reclaim history (also by processes of internal decolonization), participants purge and replace memories of victimization with those of resilience. The vast majority of the commemorations involved ceremonies, which came in the form of sharing circles, feasts, powwows, storytelling and sharing circles, give away ceremonies, and healing activities. These were aimed primarily at Survivors but were most often also extended to their family members and other community members. The focus of the commemoration was 
the coming together of the community, honouring Survivors, and transmitting experiences in a culturally safe and appropriate environment. This fostered reconciliation between family members and entire communities. Honouring Survivors through memorialization was also a common theme. Some projects focused on documenting stories and creating educational products and archives, suggesting public education as an alternate or complementary focus of commemoration. Many projects also involved recording and archiving stories for younger generations. This, combined with the very low participation rates in the TRC statement-taking process (approx 6,200/80,000) ${ }^{63}$ suggests that these processes are not reflecting the needs of communities.

\subsection{Healing}

Based on percentages related to the objectives of the IRSSA projects, the most significant driver of the projects was to create opportunities for healing. This was expressed in the myriad cultural and therapeutic healing features of the individual projects. Applicants primarily focused on the needs of their own communities or banded together to host larger multi-community regional gatherings. Reclaiming culture through cultural ceremonies and practices was a major theme of the IRSSA projects, however reclaiming history and restorying (specific elements of healing) on the former sites of IRS through ceremonial destruction, adaptive re-use, development and commemorative marking of

63 According to the TRC's website, there are an estimated 80,000 Survivors. The website also states that the TRC has collected more than 6,200 statements (Trc.ca) http://www.trc.ca/websites/trcinstitution/index.php?p=807

Accessed June 30,2014. 
sites, and the dynamic process by which these strategies were implemented, emerged as

dominant themes in the pre-IRSSA commemorations studied by Brace (34).

Many of the features of the commemorations correspond with stages of a healing journey or form a complete framework for healing from historic trauma. Accordingly, this discussion correlates commemoration features with the 6 stages of the hybrid Commemoration as a Decolonizing Healing Practice framework (below) presented in the Methodology section and described in greater detail in Appendix H.

\section{Commemoration as a Decolonizing Healing Practice}

\begin{tabular}{|l|l|l|}
\hline Prerequisite: Recognizing the Need for Healing & \\
\hline Step 1 & Personal \& Collective Commitment to Healing & Committing \\
\hline Step 2 & $\begin{array}{l}\text { Creating the Conditions for Personal \& Cultural } \\
\text { Safety based in Aboriginal Values/Worldview }\end{array}$ & Trusting \\
\hline Step 3 & Remembering, Mourning \& Releasing & $\begin{array}{l}\text { Purging (destruction, } \\
\text { cleansing, purifying) }\end{array}$ \\
\hline Step 4 & Building a Transformative Vision & Dreaming \\
\hline Step 5 & $\begin{array}{l}\text { Reclaiming, re-empowering, re-storying, } \\
\text { re-membering, rebuilding }\end{array}$ & $\begin{array}{l}\text { Realization } \\
\text { (transformation,construction, } \\
\text { Replacement) }\end{array}$ \\
\hline Step 6 & $\begin{array}{l}\text { Recommiting to Self, to the } \\
\text { Collectivity/Community, and Culture- } \\
\text { consolidating new memories and new identities }\end{array}$ & Re-Commiting \\
\hline
\end{tabular}

\section{Personal and Collective Commitment to Healing}

There are 624 First Nation communities (Afn.ca), 60 Inuit communities - including urban centres with more than 90 Inuit residents (Itk.ca), and a contested number of distinct of Métis communities in Canada. The number of First Nations Survivors far exceeds the number of Inuit and Métis Survivors and as such it is not surprising that the majority (65\%) of the IRSSA commemoration projects were initiated by First Nations, as opposed to Inuit, Métis, 
Aboriginal, or non-Indigenous groups or partnerships. What the IRSSA data tells us, is that 64 First Nations projects, representing 129 communities out of a possible 624 communities, were funded. This equates to just over $20 \%$ of communities. The TRC estimates that they have collected over 6,200 individual statements (testimonies) out of a possible 80,000 - the estimated number of living Survivors (Trc.ca), representing .0775\% of the Survivor population. Committing to provide a statement (part of remembering, mourning, and releasing) and committing to commemorating IRS, is committing to a personal and/or collective healing journey. In the context of the IRSSA commemoration projects, I consider the participants who applied, initiated their project, and gathered to commemorate as a collective to have taken the first step of the healing journey.

\section{Personal \& Cultural Safety based in Aboriginal Values/Worldview}

Many of the IRSSA commemoration projects involved gathering, sharing circles, and cultural workshops, practices, and performances, many of them in a healing context. The premise of a sharing circle, otherwise known as a talking circle is to silently and respectfully allow each person in the circle a chance to speak - it is a First Nations pedagogy that uses a consensual model to create personal and collective safety (Firstnationspedagogy.ca). Ensuring cultural safety involves ensuring that healing (or commemoration) takes place in a culturally-appropriate environment - one where the participants are in control (Archibald 2830). In many cases, creating the conditions for personal and cultural safety also involves traditional healers, Elders, and therapists (ibid).

\section{Remembering, Mourning \& Releasing}


While many of the IRSSA commemoration projects involved Survivors in sharing their experiences of residential school as a form of remembering, mourning and releasing, other projects involved documenting and sharing creating works for larger public remembering. Brace's study of pre-IRSSA initiatives identified ceremonial destruction of former IRS structures as a major theme of commemoration, also referencing anecdotal evidence that many of the schools that had been 'unofficially' demolished, had been burned down by Survivors. Harrison suggests that "architecture [associated with oppressive regimes] does not just symbolize political violence, but mediates and re-mediates violence" (172). I suggest this can be generalized to encompass sites of settler violence such as the former IRS. Harrison, drawing on similar assertions of Viktor Mayer-Schönberger (2009) and Marc Augé (2004) reminds us that, "forgetting is a necessary force of cultural production" (201). That being said, I argue an interpretation that asserts the motivation to destroy sites is not necessarily bound with the desire to forget in reality, but to replace memories associated with trauma with those of conquest. Andrew Herscher (2010), speaking of heritage in the wake of the Kosovo conflict, posits violence and destruction as equally important forms of inscription and cultural production including production of [self-determining] identities and agencies.

In Chapter 3, the "visual trope of the humiliated and defeated monument" (Harrison 176), is presented in the form of a photograph of a vandalized statue of Sir. John A. Macdonald. Harrison, drawing on arguments posited by Tim Benton $(1999 ; 2010)$ on the role of symbolic humiliation in discrediting old regimes, might describe the stutue as a humiliation of settler Canada through the personage of the former Prime Minister. Sharon MacDonald's (2009) arguments on the uses of mockery in the "simultaneous production of new memories of 
conquest and defeat" are also discussed in Harrison who discusses destruction of and as heritage at length (qtd in. Harrison 173).

Memorialization is similarly an obvious practice of remembering and mourning, however not necessarily of releasing. Paul Gough teases apart the difference between monument and memorials, citing Michael Rowlands (1999) who argues, "monuments become memorials as a result of the successful completion of a mourning process" (qtd. in Gough 202). The process of symbolic (or actual) purging or destruction through remembering, mourning, and releasing, prepares for the next step - dreaming, which involves building a transformative vision that can be realized through reclaiming and rebuilding (construction).

\section{Building a Transformative Vision}

Citing Harding (1999), McLelland and others suggest "the Igbo people of Nigeria... are said to destroy or neglect artfully created structures such as the mbari houses to ensure the continued vitality of the urge to recreate, thereby privileging cultural processes rather than tangible end products" (588). Although I do not mean to imply the presence of this impulse among Indigenous Peoples in Canada, I would suggest meaningful commemoration of IRS most certainly privileges cultural processes [and culturally-based healing processes] over conservation of tangible heritage. Reclamation (of culture and history) is one such cultural process. Karen Till describes the Berlin Wall [which could equally be said of IRS] as "a place haunted with landscapes that simultaneously embody presences and absences, voids and ruins, intentional forgetting and painful remembering" (qtd. in Harrison 180). Indeed 'absent heritage' suggests an 'absent presence' (ibid 170). Harrison observes, “the 
commemoration of absent heritage often follows and act of iconoclasm, in which the physical memorials associated with a past religious, cultural or political regime are destroyed as a symbolic act of collective forgetting and defacement" (ibid). Dreaming or building a vision for the future is the pedagogy and healing step that bridges iconoclasm and destruction, and reclamation and construction, which in many of Brace's (2012) examples manifested as adaptive re-use. Dreaming instills cultural confidence, enabling the dreamer to recreate the past in the present.

Reclaiming, re-empowering, re-storying, re-membering, rebuilding

Evidence of symbolic 'construction' is ample in the exhibits, art and cultural productions and performances, documentary books and films, pedagogical resources, and in the various structures of memorial art that were created as part of the IRSSA commemoration projects. In the case of the AFN/AHF commemorative marker project, the heritage plaque genre itself was re-visioned and realized in its construction phase as an Indigenous art object. Although $47 \%$ of the classifiable IRS structures in Brace's (2012) study had been adapted for reuse, primarily by First Nations, a small portion of them included a commemorative component (33). This dual use may suit the twofold purposes of restorying yet 'never forgetting'. This concept of constructing new uses and accordingly new memories of place recalls the discussion at the beginning of Chapter 4 - where healing involving physical reclamation provides for space to be re-conceived (dreaming) and re-lived.

Recommiting to Self, to the Collectivity/Community, and Culture 
The step involves the process of consolidation and maintenance. While the AFN/AHF commemoration project was not afforded opportunities for maintenance and sustainability, it nevertheless created 139 bronze monuments, to be distributed across Canada in part as an enduring tangible reminder of culture reclaimed. Monuments by their very nature, are designed to endure - to signify histories past for generations to come. The various tangible instances of cultural production: carvings, art, books, videos, exhibits, and other objects created in conjunction with the IRSSA commemoration projects were produced to document, supplement - contesting dominant Canadian history narratives, like those of the NPHC System Plan with experience, to make layers and create archives, and finally to consolidate restorying.

\subsection{Conclusion}

One of the ways the projects most powerfully expressed Indigeneity was through selfdetermination. Overall, the survey of the 144 projects indicate that communities are capable judges of their own priorities and bend commemoration vehicles to their own uses. They mobilized their projects to gather, honour, and heal together as a community. That selfawareness is reflected in their commemorative practices, which are rooted in culture and ceremony. Reconciliation was a focus, not between Indigenous and non-Indigenous people, but between family and community members, laying necessary foundations for reconnection and healing. One of the findings from the AFN/AHF IRSSA commemoration case study was that communities were resistant to participating in a prescribed way and on a timeline that didn't meet their needs. These examples, which demonstrate how Survivors, their families, communities, and advocates across Canada are practicing commemoration for healing, 
validate an approach to commemorating sites of trauma through a healing and decolonizing framework. This will inform the recommendations to meaningfully mobilize heritage and commemoration processes to transform sites of trauma into sites to healing, learning, and restorying, which appear in the next and final chapter.

Together with the examples of public supplementation, art and archiving-as-resistance, counter-monumentalization, and uses of third space to create sites of conscience, we have explored the staggering diversity of commemorative practice and uses of heritage. Many of these examples depart dramatically from the limited range proffered by the HSMBC, and indeed some threaten the 'commemorative integrity' of built heritage as we understand it. Although not all of the aforementioned approaches and practices could be considered appropriate, realistic, or implementable by state heritage institutions, they exhort us to collectively reevaluate established principles of heritage, including universality, permanence, conservation, and even national history and identity. Innovation, borne in conflict and resistance, requires such a reevaluation - a process that is as deeply unsettling as it is transformational. At this juncture, on the eve of the conclusion of IRSSA implementation, and in the face of the TRC final report, which will expose the genocidal history and legacy of the IRS, and demand amends, the Harper Government must reconsider the narratives that form the basis of our collective identity, their logic, and how they are constructed. The following and concluding chapter presents considerations and recommendations toward stimulating HSMBC's post-modernist sensibilities and motivating the development of a needed process to unsettle and transform its practice of heritage. 


\section{Chapter: Conclusion}

Redefining Ourselves Through Commemoration

Citing scholarship from the US on collective dissonant and counter-hegemonic memory that "coincided with increasing disenchantment with nationalism and nationalist projects," (915) Hue-Tam Ho Tai asserts, "the collective memory of certain interpretive communities exists in a state of tension with national identity and history,...memorylocalized, diffuse, polysemic-is thus often seen as undermining nationalizing, totalizing projects" (916). Yet, even ICOMOS, gatekeepers of the AHD are beginning to acknowledge the benefits of localized, multivalent approaches, as seen in the Québec Declaration on the Preservation of the Spirit of Place (Québec Declaration on the Preservation of the Spirit of Place). Harrison posits heritage as dialogical, "the production of heritage emerges from the relationship between people, 'things' and their environments as part of a dialogue or collaborative process of keeping the past alive in the present" (216). For him, recognizing heritage as dialogical, a hybrid forum (and democracy) made up of 3 criteria - intensity, openness, quality, provides a new set of instruments for heritage decision-making (223-225). From this perspective, connectivity becomes a method and an ontology, and conservation a social process (228). The following set of considerations and recommendations were developed, based on the evidence and arguments presented herein, to stimulate discussion toward realizing a dialogic practice of heritage and commemoration, and to argue for HSMBC to implement the change necessary to recognize sites of trauma within Canada and to work in 
collaboration with Survivors and other stakeholders to effect their transformation into sites of conscience, where desired by Survivors.

\subsection{Considerations}

\section{Difficult Heritage Requires Different Strategies}

Promising heritage and commemoration practices relative to sites of trauma are those that prioritize healing, and in the case of traumas and settler violence endured by Indigenous Peoples, decolonization. This argues for a paradigm shift, putting the priorities of those who experienced and are affected by trauma first, which may involve embracing conservation as a healing practice, or conversely, seeking to destroy the material remains of the site of trauma, options which will undoubtedly change over time and generations. A radical redefinition of 'commemorative integrity' is a requirement of this shift.

\section{Art And Artists Have A Role To Play In Commemoration}

Artists inviting collaboration or public participation can reflect multi-vocality in their work in ways in which traditional monumental form cannot. Supplementation and layermaking through public engagement with heritage can offer a power social corrective to monological narratives. For that reason, public and participatory art approaches should be encouraged and sustained. In cases like IRS commemoration, heritage professionals must remain mindful that artists go through their own healing journey and are additionally burdened with the responsibility of creating works in which their audience can find and infuse their own meanings. 
We All Have a Right to a Role in Narrating Our Pasts

Michael Frisch suggests that the point of excursions into the past...is not to revere or imitate the past; rather, it is to understand the responsibility and freedom we have to shape the course of history in our own time and place, as our ancestors did with theirs" $(1990 ; 201)$. Heritage professionals must engage and challenge the public in ethically creating the past through determining what is, and is not, worthy of heritage, even if those decisions depart from existing plans and narratives. Heritage professionals should recognize and support the right of the public to have an active role in creating their own heritage, on an ongoing basis. In negotiating pasts of trauma, the needs of its Survivors should supersede those of the public and the state.

\section{Ethical Heritage Practice Involves Recognition and Repatriation}

Extending arguments for tangible forms of decolonization posited by Tuck and Yang (2012) to the heritage field, wherever possible, governments should relinquish (heritage) rights to the sites of trauma under their control to those affected in an act of symbolic or actual repatriation, rather than provide recognition (designation) alone - an offering that would be tantamount to foreclosure. The basis for my argument for surrendering heritage rights to sites within its control, which in the case of IRS sites would uphold Survivors' rights to commemorate them any manner they decide, is not ancestral claim to the land

itself, but an acknowledgement of the atrocity that occurred in the place in question and the understanding that reclamation is a requirement of healing the trauma of IRS.

\subsection{Recommendations}




\section{Honouring Our Truths}

According to Andreas Huyssen, in contradistinction to approaches such as those of Maurice Halbwachs, which presupposes relatively stable formations of social and group memory, "the clashing and ever more fragmented memory politics of specific social and ethnic groups raise the question whether forms of collective consensual memory are even still possible today, and, if not, whether and in what form social and cultural cohesion can be guaranteed without them" (431). Conversely for Harrison, cohesion is possible and the objective of our heritage practices, a position evident in his assertion, "it is only through an active engagement with the pasts we produce in the present that we can generate the individual and collective memories that will bind us together in the future "(231). At a micro level, the potential for building solidarity with victims, and by extension, degrees of greater societal cohesion, also merits consideration and is perhaps a more achievable object of our attentions. Practices of Othering, containment, and erasure, indicative of systemic racism, inhibits solidarity - and even new collective identity formation on shared moral and ethical values. 2014 marks the 20-year anniversary of the Rwandan genocide and the unanimous adoption of a resolution by the UN Security Council (of which Canada is neither a permanent or non-permanent member) to recommit the fight against genocide. In the prelude to the resolution, the Security Council "condemned without reservation any denial of the genocide and urged member States to develop educational programmes to help prevent similar events," (Un.org) affirming the widelyheld belief that remembering is a preventative factor in reoccurrence. We have collectively witnessed the tragic outcomes of the collapse of human solidarity, yet Canada's heritage narratives position Indigenous Peoples in the past, doing little to 
combat racism and foster solidarity with Indigenous Peoples. I recommend directing the HSMBC to depart from the AHD, to discard models promoting heroic nationalist narratives (fantasies), and to develop strategies to truly and fully represent the manifold of our history. Thereby the diversity of the experiences of Indigenous Peoples and other Canadians could be commemorated in ways that are meaningful and conducive to healing, reconciliation and social, cultural, and political redefinition of our nation. Finally, if we accept Nora's 'truth' of lieux de mémoire - that "without commemorative vigilance, history would soon swoop them away" (12), we accept our duty to honour our truths, to remember Canada's past as it was, not as we wish it had been, and take up the charge to work toward redressing the moral traumas and resolving the moral dilemmas that are inherent in being Canadian.

\section{Reimagining Processes}

The 2008 ICOMOS Charter for the Interpretation and Presentation of Cultural Heritage Sites [Ename Charter], promotes "inclusiveness in the interpretation of cultural heritage sites, by fostering the productive involvement of all stakeholders and associated communities in the development and implementation of interpretive programmes" (Enamecharter.org). As suggested by Glen Coulthard, the emancipatory struggle is as much about shedding the vestiges of internal colonization (449), as it about changing external conditions. Thus a process of desubjectification (450) is a requirement of transformative praxis, which can lend itself to the cultivation of critical commemorative praxis. Brace (2012) exhorts, "we, as heritage professionals, must change our perception to allow that the process by which a community decides to alter or destroy the intangible 
and tangible materials, constitutes its own heritage and be worthy of respect and study" (59). Thus I recommend that HSMBC ensure that processes of heritage and commemoration engage Indigenous peoples as full participants in heritage processes and that the Historic Sites Act be amended to ensure an Indigenous presence on the HSMBC and in the secretariat.

\section{Reimagining Sites}

Citing Byrne (1991), Harrison critiques the twofold assumption upon which universal heritage values are founded. These are, that "all humans necessarily share an interest in the physical aspects of the past as 'heritage', and that they do so in the same way," and that people in one country would necessarily be interested and concerned for the conservation of certain types of physical remains in another country" (64). Harrison calls our attention to characterizations of constructions of universal heritage value by Byrne and others as hegemonic and Western (64). One of the findings of the IRSSA commemoration projects was that commemoration did not have to take place at the former IRS site in order to be meaningful. Other findings, based in Brace's (2012) study, and validated through healing models, inform my recommendation to explore commemorative models that allow for the concept of 'commemorative integrity' to be modified or bypassed, to privilege cultural (and healing) processes of forgetting, mourning, and releasing that involve destruction of sites.

\section{Reimagining Public Commemorative Practices}


Alternative ontologies and worldviews open up creative possibilities for thinking about heritage differently (Harrison 214). Sharing the authority and power to determine the mode or form of commemoration and to develop language or narratives is critical and necessary not only to address dissonance but to also keep as Sharon Rosenberg suggests, "a past-present relationship animated and open" (6). Her considerations of crossgenerational public memory (19) and call "to take up the charged ambivalence of memory as a resource for opening the present" to more fully encounter loss suggests alternate methodologies to 'difficult' commemoration (6) that remain to be explored. A dialogic process with the public needs to be set in motion to inform the development of new models of engaging with the past, ones that promote multi-vocality, and active engagement through supplementation and layermaking.

\section{Enacting A Pedagogy Of Witness}

While Richard Sennett posits, "Truthful memory opens wounds which forgetting cannot heal; the traces of conflict, failure and disaster are never erasable in time," he also asserts that collective memory is a source of social strength (283). For Sennett, “...Remembering well requires reopening wounds in a particular way, one which people cannot do by themselves; remembering well requires a social structure in which people can address others across boundaries of difference” (284). In discussing 'lost in mass' - mass commemorations for mass atrocities, Byrne considers "the possibility of experiencing, at second hand and through the medium of a heritage site, the suffering of past individuals, the possibility of bearing witness to their individual lives and deaths, the possibility of making the intangible tangible" (244). This is the foundational power of sites of 
conscience. It is recommended that HSMBC study the International Coalition of Sites of Conscience 'sites of conscience' model in preparation for evaluating potential sites of conscience $^{64}$ in Canada, the first of which would be the 139 IRS.

\subsection{Final Remarks}

Byrne predicts that authoritarian conservation will be rejected as morally unsustainable and inadequate to the needs of the local, eschewing as it does their emotional and spiritual beliefs and practices. "We cannot look to UNESCO for leadership here, mired as it appears to be in its own fantasies of universal value. It will come from below rather than above" (249). For Byrne, heritage practice properly belongs to the local (250). Concerning Canada's need for reconciliation, the potential for heritage redress through existing mechanisms of commemoration and heritage conservation would appear an easy win for a federal government ostensibly determined not to exceed its court-ordered obligations. Criticisms that the "amelioration of social ills through

${ }^{64}$ In considering the heritage of the World Trade Centre in New York, Meskell (2002) alerts us to the risk of fetishizing the experience of suffering through musealization, seen as a form of capture and commodification (Qtd in Byrne 244). Historian Sara Wills (2009), in Places of Pain and Shame, discusses strategies to remember migrant pain and shame associated with hostels and detention centres in Australia. She cautions against fetishizing pain, "transforming the wound of pain into an identity for the nation that fails to effectively address other histories" and further, "this 'fetishisation' of the wound of detention into an identity for a 'wounded nation' would assume an equivalence between what have to be recognized as very different injuries" (275). Huyssen however, suggests that new media "...as carriers of all forms of memory," makes it "...no longer possible...to think of the Holocaust or of any other historical trauma as a serious ethical and political apart from the multiple ways it is now linked to commodification, [however]....that does not mean that each and every commodification inevitably banalizes it as historical event. There is no pure space outside of commodity culture" (431-432). 
commemoration...saps momentum from social movements seeking more substantive change" (Carr 113) abound, yet, as we have seen, Survivors and their communities have already lead and partaken in multiple empowering and healing commemoration activities, decolonizing from within, creating an archive that has the potential to change the practice of heritage and commemoration 'from the ground up'. As Huyssen asserts, "memory can be no substitute for justice" (435), however new foundation stories (restorying) for a decolonized era, could help non-Indigenous Canadians to creatively confront our most harmful national myths and redefine ourselves as a society on shared democratic values. As a prerequisite for change, HSMBC must first acknowledge their own complicity in the settler colonial project; as Sium, Desai, and Ritskes (2012) remind us, "there is no escaping complicity within a settler-colonial state" (iii), and then, recognizing that "decolonization does not exist without a framework that centres and privileges Indigenous life community, and epistemology" (ii), support Indigenous heritage practice.

Without fundamental change to the manner in which sites are 'managed', allowing for Survivors and their communities to become involved in the process, any state-involved commemoration efforts risk inhibiting healing, instead of promoting and supporting it. ${ }^{65}$ Rather, now is the ideal time for HSMBC to witness the truths of Survivors and their communities, to share models of negotiating space differently, and ultimately, to participate in decolonizing the practice of commemoration. In terms of heritage redress, one needed offering among many, this involves the state enacting Simon's "pedagogy of

${ }^{65}$ Also, any attempt to integrate Indigenous cultural traditions into HSMBC's commemorative repertoire without the concomitant transfer or sharing of control with Indigenous people would amount to cultural appropriation. 
witness," acknowledging the totality and magnitude of the devastation caused by Indian Residential School System, and recognizing that decolonizing methods, "a cultural pedagogy capable of bridging past and present without reducing one to the other or dictating the terms on which this is to be accomplished" (207), are the only ones that will take us closer to [re]conciliation. 


\section{Appendices}

\section{Appendix A}

\section{IRSSA Commemoration Project Quantitative Evaluation Grid}

A. What did people do/produce?

1. gatherings

2. cultural ceremonies (all)

3. sharing circles

4. events

5. conferences

6. monuments

7. plaques

8. cairns

9. memorial gardens and other site improvements

10. on-site memorial art and structures

11. land-based camps

12. exhibits

13. videos

14. curriculum

15. art production and performance

B.

What were the objectives of the commemoration activities?

\begin{tabular}{|l|l|}
\hline 1. Healing & \\
\hline 2. Honouring & \\
\hline 3. Reconciliation & \\
\hline 4. Connecting & \\
\hline 5. Reclaiming culture & \\
\hline 6. Remembering & \\
\hline 7. Sharing & \\
\hline 8. Raising awareness & \\
\hline 9. Building resilience and strength & \\
\hline 10. Truth & \\
\hline 11. Educating & \\
\hline Who was involved? & \\
\hline 1. First Nations & \\
\hline 2. Inuit & \\
\hline 3. Métis & \\
\hline 4. Aboriginal & \\
\hline 5. Non-Aboriginal & \\
\hline 6. Survivors & \\
\hline Intergenerational Survivors & \\
\hline
\end{tabular}




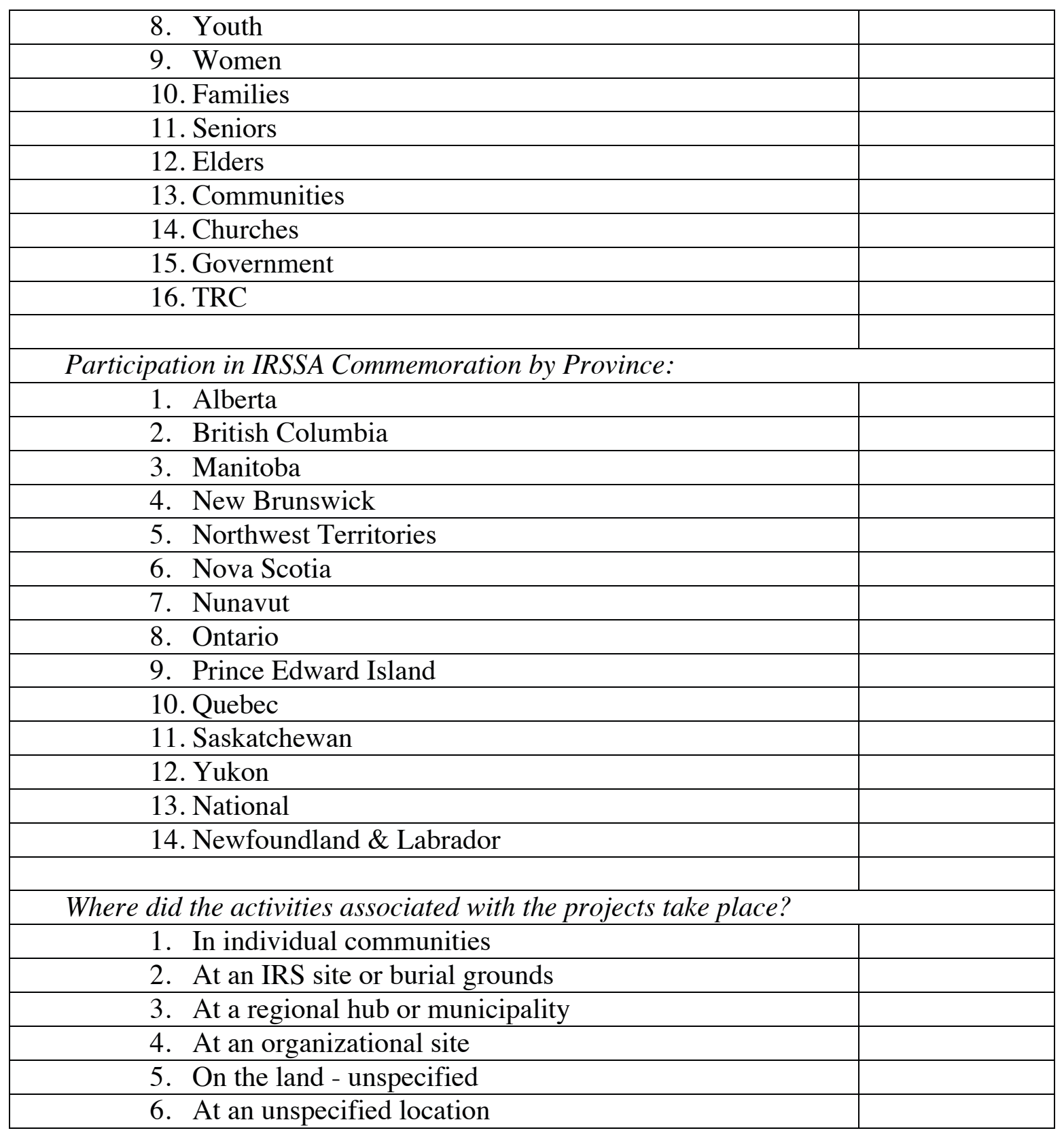




\section{Appendix B}

\section{IRSSA Commemoration Project Quantitative Evaluation Grid}

C. What did people do/produce?

\begin{tabular}{|c|c|}
\hline 16. gatherings & $40 / 32$ cultural \\
\hline 17. cultural ceremonies (all) & 28 \\
\hline 18. sharing circles & 38 \\
\hline 19. events & $20 / 15$ cultural \\
\hline 20. conferences & $\begin{array}{l}4 \text { (originally } 9- \\
5 \text { were duplicates }\end{array}$ \\
\hline 21. monuments & 40 \\
\hline 22. plaques & 21 \\
\hline 23. cairns & 2 \\
\hline 24. memorial gardens and other site improvements & 18 \\
\hline 25. on-site memorial art and structures & 13 \\
\hline 26. land-based camps & 7 \\
\hline 27. exhibits & 8 \\
\hline 28. books and albums & 21 \\
\hline 29. videos & 14 \\
\hline 30. curriculum & 7 \\
\hline 31. art production and performance & 13 \\
\hline \multicolumn{2}{|l|}{ D. What were the objectives of the commemoration activities? } \\
\hline 12. Healing & $\begin{array}{l}65 \text { (102 before } \\
\text { duplicates per } \\
\text { desc. removed) }\end{array}$ \\
\hline 13. Honouring & 52 \\
\hline 14. Reconciliation & 50 \\
\hline 15. Connecting & 41 \\
\hline 16. Reclaiming culture & 39 \\
\hline 17. Remembering & 36 \\
\hline 18. Sharing & 27 \\
\hline 19. Raising awareness & 22 \\
\hline 20. Building resilience and strength & 14 \\
\hline 21. Truth & 12 \\
\hline 22. Educating & 11 \\
\hline \multicolumn{2}{|l|}{ Who was involved? } \\
\hline 17. First Nations & 94 \\
\hline 18. Inuit & 4 \\
\hline 19. Métis & 3 \\
\hline 20. Aboriginal & 28 \\
\hline 21. Non-Aboriginal & 16 \\
\hline 22. Survivors & 86 \\
\hline
\end{tabular}




\begin{tabular}{|c|c|}
\hline 23. Intergenerational Survivors & 13 \\
\hline 24. Youth & 21 \\
\hline 25. Women & 2 \\
\hline 26. Families & 40 \\
\hline 27. Seniors & 2 \\
\hline 28. Elders & 28 \\
\hline 29. Communities & 84 \\
\hline 30. Churches & 7 \\
\hline 31. Government & 2 \\
\hline 32. TRC & 8 \\
\hline \multicolumn{2}{|c|}{ Participation in IRSSA Commemoration by Province: } \\
\hline 15. Alberta & 15 \\
\hline 16. British Columbia & 37 \\
\hline 17. Manitoba & 11 \\
\hline 18. New Brunswick & 1 \\
\hline 19. Northwest Territories & 4 \\
\hline 20. Nova Scotia & 6 \\
\hline 21. Nunavut & 3 \\
\hline 22. Ontario & 19 \\
\hline 23. Prince Edward Island & 1 \\
\hline 24. Quebec & 11 \\
\hline 25. Saskatchewan & 19 \\
\hline 26. Yukon & 3 \\
\hline 27. National & 13 \\
\hline 28. Newfoundland \& Labrador & 0 \\
\hline \multicolumn{2}{|c|}{ Where did the activities associated with the projects take place? } \\
\hline 7. In individual communities & 72 \\
\hline 8. At an IRS site or burial grounds & 23 \\
\hline 9. At a regional hub or municipality & 26 \\
\hline 10. At an organizational site & 13 \\
\hline 11. On the land - unspecified & 2 \\
\hline 12. At an unspecified location & 36 \\
\hline
\end{tabular}




\section{Appendix C}

\begin{tabular}{|c|c|c|c|c|c|c|}
\hline 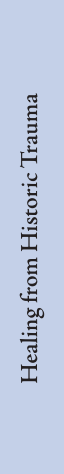 & 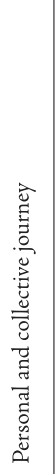 & 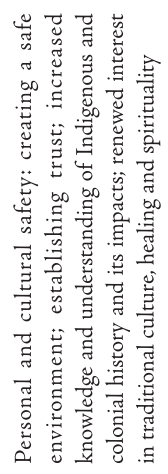 & 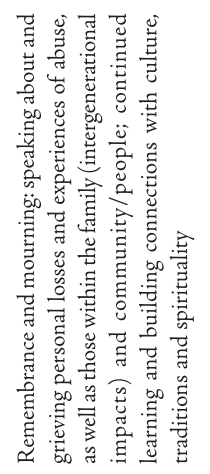 & 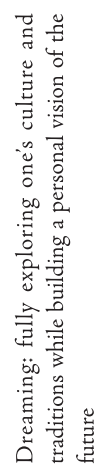 & 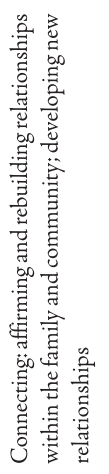 & 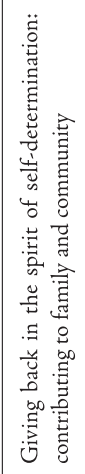 \\
\hline 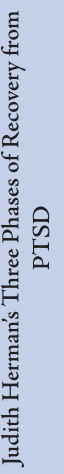 & 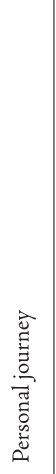 & 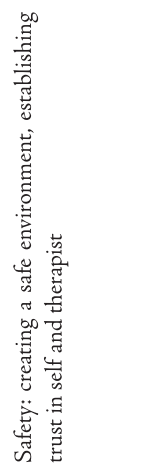 & \multicolumn{2}{|l|}{ 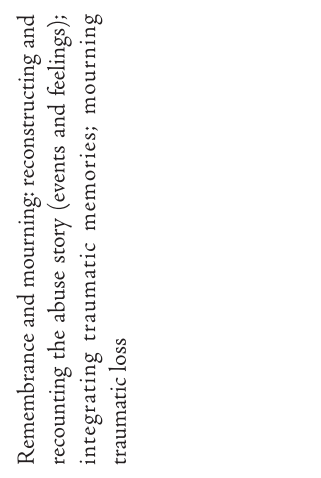 } & \multicolumn{2}{|l|}{ 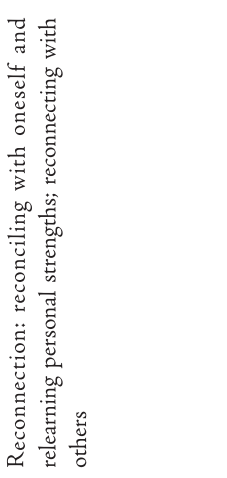 } \\
\hline 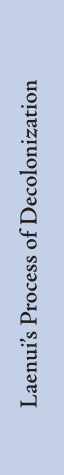 & 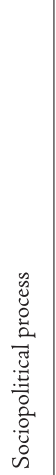 & 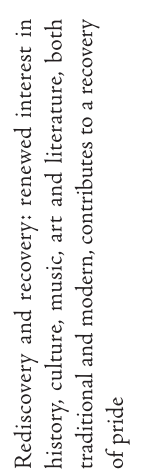 & 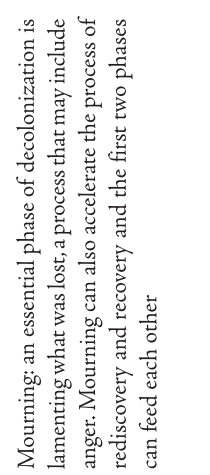 & 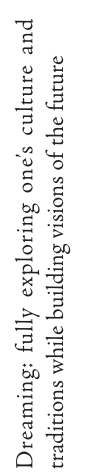 & 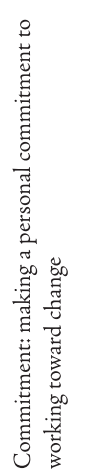 & 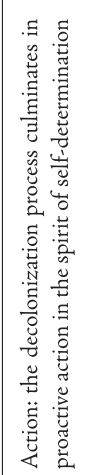 \\
\hline
\end{tabular}

VOLUME III: PROMISING HEALING PRACTICES IN ABORIGINAL COMMUNITIES 
Appendix D - Attached as separate document

Appendix E - Attached as a separate document

\section{Appendix F}




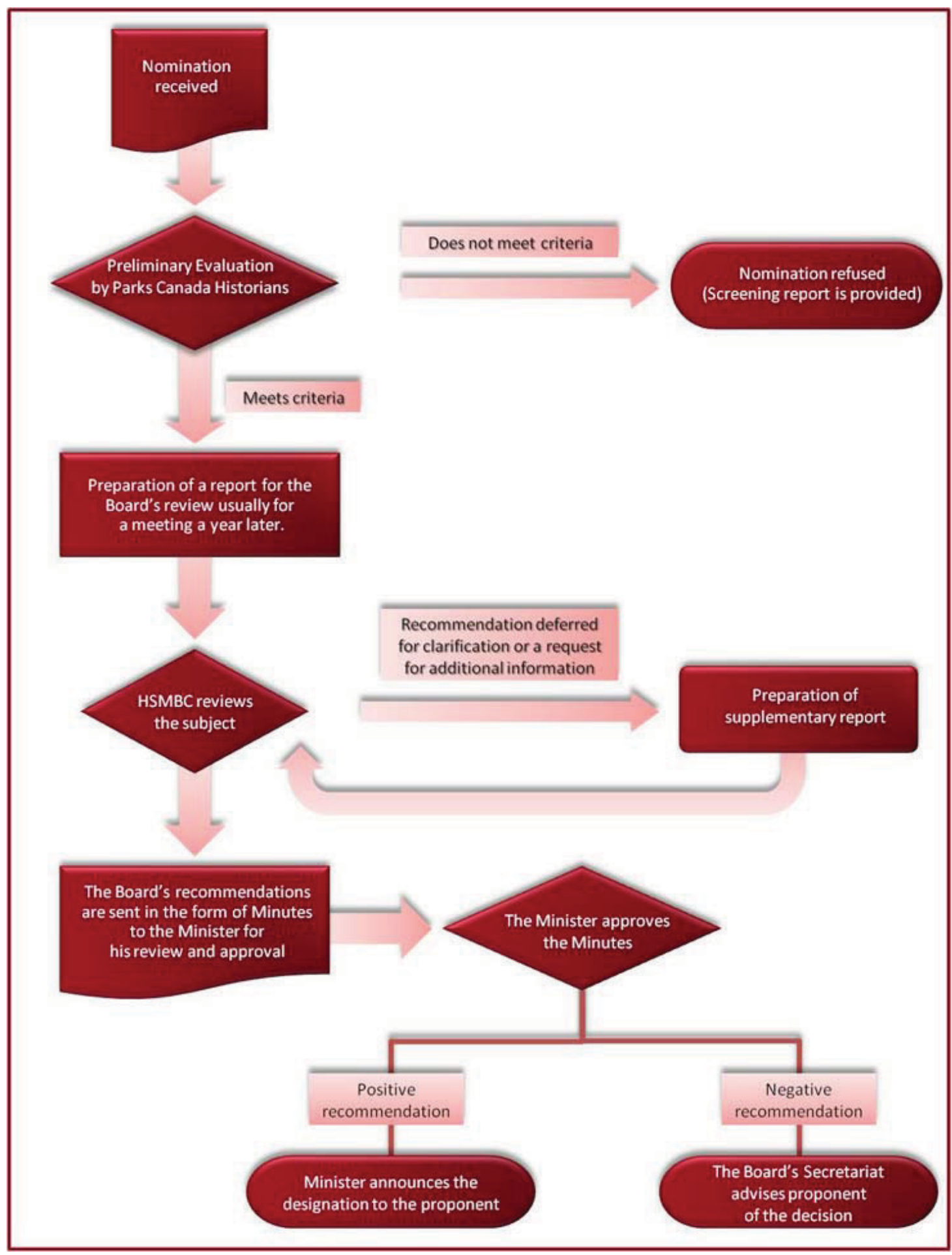




\section{WORKS CITED}

A - Aadnc-aandc.gc.ca,. 'Statement Of Apology'. N. p., 2010. Web. 18 Jun. 2014.

B - Aadnc-aandc.gc.ca,. 'Notes For An Address By'. N. p., 2010. Web. 18 Jun. 2014.

C - Aadnc-aandc.gc.ca,. 'Statistics On The Implementation Of The Indian Residential Schools Settlement Agreement'. N. p., 2014. Web. 25 Jun. 2014.

D - Aadnc-aandc.gc.ca,. 'Commemoration'. N. p., 2013. Web. 29 Jun. 2014.

Aboriginal Healing Foundation Program Handbook. 3rd ed. Ottawa, ON: Aboriginal Healing Foundation, 2001. Print.

Alfred, Taiaiake. "Colonialism and state dependency." Journal de la santé autochtone, (2009): 42--60. Print.

Archibald, Linda. Promising Healing Practices In Aboriginal Communities. 1st ed. Ottawa, Ont.: Aboriginal Healing Foundation, 2006. Print.

Ashley, Susan. "The changing face of heritage at Canada's national historic sites." International Journal of Heritage Studies, 13.6 (2007): 478--488. Print.

Afn.ca,. 'Assembly Of First Nations - About AFN - Description Of The AFN'. N. p., 2014. Web. 1 Jul. 2014.

Assembly of First Nations. 'Resolution No. 66/2010'. Special Chiefs Assembly. Assembly of First Nations, 2010. PDF.

Apsanet.org,. 'Latin American Faculty Of Social Sciences (FLACSO) I APSA'. N. p., 2014. Web. 23 Jun. 2014.

Assembly, UN General. "United Nations Declaration on the Rights of Indigenous Peoples." UN: Washington 12 (2007).

Barman, Jean, Yvonne M Hébert, and Don N McCaskill. Indian Education In Canada. 1st ed. Vancouver: University of British Columbia, 1986. Print.

Barnett, Michael N. "The UN Security Council, indifference, and genocide in Rwanda." Cultural Anthropology, 12.4 (1997): 551--578. Print.

Benton, T. and C. Cecil. "Heritage and Public Memory." Understanding Heritage and Memory. By Benton, T. (ed.) Manchester: Manchester University Press, 2010. 7-43. Print. 
Bhabha, Homi K. "DissemiNation: Time, Narrative, and the Margins of the Modern Nation" in Nation and Narration. New York: Routledge (1990) pp, 291-322 . p. 291-322

Biderman, Albert D. 'Communist Attempts To Elicit False Confessions From Air Force Prisoners Of War'. Bulletin of the New York Academy of Medicine 33.9 (1957): 616. Print.

Bodnar, John E. Remaking America. 1st ed. Princeton, N.J.: Princeton University Press, 1992. Print.

Brace, Anna. "Heritage alternatives at sites of trauma: Examples of the Indian Residential Schools of Canada." Diss. University of York, 2014. Print.

Brett, Sebastian, et al. "Memorialization and democracy: State policy and civic action." Memorialization and Democracy: State Policy and Civic Action, Santiago, Chile (2007).

Byrne, Denis. 'A Critique Of Unfeeling Heritage'. Intangible Heritage. LauraJane Smith and Natsuko Akagawa. 1st ed. New York: Routledge, 2009. 229-252. Print.

Cameron, Christina. "World Heritage Sites of conscience and memory." World Heritage and Cultural Diversity (2010): 112.

Cameron, Christina. “The Spirit of Place: The Physical Memory of Canada”. Journal of Canadian Studies 25, 1 (2000): 77-94.

Carr, Geoffrey. "Atopoi of the Modern: Revisiting the Place of the Indian Residential School." ESC: English Studies in Canada, 35.1 (2009): 109--135. Print.

Chansonneuve, Deborah. Reclaiming Connections: Understanding Residential School Trauma Among Aboriginal People. Ottawa: Aboriginal Healing Foundation, 2005. Print. AHF Research Series. Print.

Chung, Seung-Jin. "East Asian values in historic conservation." Journal of Architectural Conservation 11.1 (2005): 55-70. Print.

Corntassel, Jeff et al. "Indigenous storytelling, truth-telling, and community approaches to reconciliation." ESC: English Studies in Canada, 35. 1 (2009): 137--159. Print.

Coulthard, Glen S. "Subjects of empire: Indigenous peoples and the "politics of recognition'in Canada." Contemporary Political Theory 6.4 (2007): 437-460.

De Leeuw, Sarah. "Intimate colonialisms: the material and experienced places of British Columbia's residential schools." The Canadian Geographer/Le Géographe canadien, 51. 3 (2007): 339--359. Print. 
Dempsey, Jessica, Kevin Gould, and Juanita Sundberg. "Changing land tenure, defining subjects: Neo-liberalism and property regimes on native reserves." Rethinking the Great White North: Race, Nature, and the Historical Geographies of Whiteness in Canada (2011): 233-255.

Derrida, Jacques. Speech And Phenomena. 1st ed. Evanston: Northwestern University Press, 1973. Print.

Dewar, Jonathan, David Gaertner, and Ayumi Goto. Practicing Reconciliation - A Report Commissioned By The Truth And Reconciliation Commission On Indian Residential Schools. Kamloops: CiCAC, 2013. Print.

Dolff-Bonekämper, Gabi. "Sites of memory and sites of discord: Historic monuments as a medium for discussing conflict in Europe." GJ Fairclough, R. Harrison, JH Jameson et J. Schofield,(sous la dir. de) The Heritage Reader, London \& New York. Routledge (2008).

Durhamworldheritagesite.com,. 'Site Boundaries: An Evolving Definition Of Heritage Durham World Heritage Site'. N. p., 2014. Web. 19 Jun. 2014.

Elsner, Jas, R. S. Nelson, and M. Olin. "Iconoclasm and the Preservation of Memory." Monuments and Memory, Made and Unmade (2003): 209-231.

Enamecharter.org,. 'The ICOMOS Ename Charter'. N. p., 2014. Web. 22 Aug. 2014.

Erasmus, Georges, and René Dussault. Report of the Royal Commission on Aboriginal Peoples. Vol. 5. Ottawa: The Royal Commission on Aboriginal Peoples, 1996.

"Every G20 nation wants to be Canada, insists PM." Reuters, 2013. Web. 22 Dec 2013. $<$ http://www.reuters.com/article/2009/09/26/columns-us-g20-canada-advantagesidUSTRE58P05Z20090926>.

Findlay, Cassie. 'Witness And Trace: January 25 Graffiti And Public Art As Archive'. Interface 4.1 (2012): 178--182. Print.

Firstnationspedagogy.ca,. 'Talking Circles Overview From The First Nations Pedagogy Online Project'. N. p., 2014. Web. 1 Jul. 2014.

Forrest, Ben. 'Sir John A. Macdonald Statue Vandalized Ahead Of Birthday Celebration, Idle No More Protest'. National Post. N. p., 2014. Web. 20 Jun. 2014.

Fournier, Suzanne, and Ernie Crey. Stolen From Our Embrace. 1st ed. Vancouver: Douglas \& McIntyre, 1997. Print.

Frisch, Michael H. A Shared Authority. Albany: State University of New York Press, 1990. Print. 
Galloway, Gloria. 'Judge Orders Ottawa To Release St. Anne's Residential-School Documents'. The Globe and Mail, N. p., 2014. Web. 23 Jun. 2014.

Gamboni, Dario. "The destruction of art." Iconoclasm and vandalism since the French Revolution (1997).

Gathercole, P. W, and David Lowenthal. The Politics Of The Past. 1st ed. London: Routledge, 2003. Print.

Gérin, Annie. "Maîtres Chez Nous." Canadian Cultural Poesis: Essays on Canadian Culture 5 (2006): 323. Print.

Gérin, Annie, and James S McLean. Public Art In Canada. 1st ed. Toronto: University of Toronto Press, 2009. Print.

Gillis, John R. Commemorations. 1st ed. Princeton, N.J.: Princeton University Press, 1994. Print.

Gough, Paul, "Invicta Pax: Monuments, Memorials and Peace" in International Journal of Heritage Studies, 8 (2002). Print.

Green, Robyn. "Unsettling Cures: Exploring the Limits of the Indian Residential School Settlement Agreement." Canadian Journal of Law and Society, 27.1 (2012): 129--148.

Print.

Haig-Brown, Celia. Resistance And Renewal. 1st ed. Vancouver, B.C.: Arsenal Pulp Press, 2006. Print.

Hall, Martin. 'Cape Town's District Six And The Archaeology Of Memory'. Eds. Robert Layton, Peter Stone and Julian Thomas. Destruction and Conservation of Cultural Property. 1st ed. London: Routledge, 2001. 298-311. Print.

Harding, Sarah. "Value, obligation and cultural heritage." Ariz St. LJ 31 (1999): 291.

Harrison, Rodney. Heritage. 1st ed. Milton Park, Abingdon: Routledge, 2013. Print.

Hc-sc.gc.ca,. 'Indian Residential Schools Resolution Health Support Program'. N. p., 2014. Web. 1 Jul. 2014.

Henderson, Jennifer and Pauline Wakeham. "Colonial reckoning, national reconciliation?: Aboriginal peoples and the culture of redress in Canada." ESC: English Studies in Canada, 35.1 (2009): 1--26. Print.

Herscher, Andrew. Violence Taking Place. 1st ed. Stanford, Calif.: Stanford University Press, 2010. Print. 
Herzfeld, Michael. The Social Production Of Indifference. University of Chicago Press, 1992. Print.

Historic Sites and Monuments Act. R.S.C., 1985, c. H-4. Department of Justice. Web. 11 Jan 2014.

Historic Sites and Monuments Board of Canada. General Guidelines, Specific Guidelines for Evaluating Subjects of Potential National Historic Commemoration. Ottawa:

Government of Canada, 2008. Print.

Historic Sites and Monuments Board of Canada. St. Eugene Residential School, Cranbrook, British Columbia - Agenda paper. Ottawa: Government of Canada (1996). PDF.

Historic Sites and Monuments Board of Canada. Minutes. Historic Sites and Monuments Board of Canada. Montreal and Quebec City: 2008.

Historicplaces.ca,. 'Historicplaces.Ca - About Us'. N. p., 2014. Web. 24 Jun. 2014.

HistoricPlaces.ca - Africville. "HistoricPlaces.ca." Historicplaces.ca, 2014. Web. 14 Apr 2014. <http://www.historicplaces.ca/en/rep-reg/place-

lieu.aspx?id=1153\&pid=8627\&h=Afric ville,National,Historic\%20(5)>.

HistoricPlaces.ca - Beothuk. "HistoricPlaces.ca." Historicplaces.ca, 2014. Web. 14 Apr 2014. <http://www.historicplaces.ca/en/rep-reg/place-lieu.aspx?id=10557\&pid=0>.

HistoricPlaces.ca - Nikkei. "HistoricPlaces.ca." Historicplaces.ca, 2014. Web. 14 Apr 2014. <http://www.historicplaces.ca/en/rep-reg/place-lieu.aspx?id=15382>

Hobsbawm, E. J, and T. O Ranger. The Invention Of Tradition. 1st ed. Cambridge [Cambridgeshire]: Cambridge University Press, 1983. Print.

Hobsbawm, E. J. On history. New York: New Press, 1997. Print.

Huyssen, Andreas. 'Present Pasts: Media, Politics, Amnesia'. Public Culture 12.1 (2000): 21--38. Print.

Indian Residential Schools Settlement Agreement. Rep. Canada, Plaintiffs Represented by the National Consortium and The Merchant Law Group, Independent Counsel, The Assembly of First Nations, Inuit Representatives, the General Synod of the Anglican Church of Canada, the Presbyterian and United Churches of Canada and the Roman Catholic Entities, 2006. Web. 25 June 2014.

Itk.ca,. 'Inuit Population I Inuit Tapiriit Kanatami - Canada's National Inuit Organization'. N. p., 2014. Web. 1 Jul. 2014. 
Jameson, J. H "Presenting Archaeology to the Public, Then and Now: An Introduction" in G. Fairclough, R. Harrison, J. H. Jameson, Jr. and J. Schofield (eds), The Heritage Reader. London and New York, Routledge, 427-56. (2008) Print.

Jameson, Fredric, ed. Postmodernism, or, the cultural logic of late capitalism. Duke University Press, 1991. Print.

Johnson, Dana. St. Eugene Residential School, Cranbrook, British Columbia (Supplementary Report \#2). Ottawa: HSMBC, 1997. Print.

Jokilehto, Jukka. "World Heritage: Defining the outstanding universal value." City \& time 2.2 (2006): 1.

Kertzer, David I. Ritual, politics, and power. New Haven: Yale University Press, 1988. Print.

Kirshenblatt-Gimblett, Barbara. "Theorizing heritage." Ethnomusicology, 39. 3 (1995): 367--380. Print.

Kmlaw.ca,. 'Newfoundland Residential Schools I Koskie Minsky LLP'. N. p., 2014. Web. 25 Jun. 2014.

Koonz, Claudia. "Between memory and oblivion: concentration camps in German memory." Commemorations: The politics of national identity 258 (1994). Print.

Laurajane Smith, The Uses of Heritage, London and New York: Routledge, (2006), pp. vii-351.

Lauzon, Claudette. "Monumental Interventions: Jeff Thomas Seizes Commemorative Space" in Cronin, J. Keri and Kirsty Robertson. Imagining Resistance. Wilfrid Laurier University Press, 2011. Print.

Layton, Robert, Julian Thomas, and Peter G Stone. Destruction And Conservation Of Cultural Property. 1st ed. London: Routledge, 2001. Print.

Leahdecter.com,. 'Home'. N. p., 2014. Web. 24 Jun. 2014.

A - Legacyofhope.ca,. 'A Brief History I Legacy Of Hope Foundation'. N. p., 2014. Web. 30 Jun. 2014.

B - Legacyofhope.ca,. 'Conditiona \& Mistreatment I Legacy Of Hope Foundation'. N. p., 2014. Web. 30 Jun. 2014.

Levy, Daniel and Natan Sznaider. "Memory Unbound The Holocaust and the Formation of Cosmopolitan Memory." European Journal of Social Theory, 5.1 (2002): 87--106. Print. 
Lipe, William D. "Value and meaning in cultural resources." (1983). Print.

Logan, William Stewart, and Keir Reeves. Places Of Pain And Shame. 1st ed. London: Routledge, 2009. Print.

Lowenthal, David. "Past time, present place: landscape and memory." Geographical Review, (1975): 1--36. Print.

Lowenthal, David. "Tragic traces on the Rhodian shore." Historic Environment, 17. 1 (2003): 3. Print.

Lowenthal, David. The Past Is A Foreign Country. 1st ed. Cambridge: Cambridge University Press, 1985. Print.

Lowenthal, David. The heritage crusade and the spoils of history. Cambridge University Press, 1998. Print.

Macdonald, Sharon. Difficult heritage: negotiating the Nazi past in Nuremberg and beyond. Routledge, 2010. Print.

Mackey, Eva. The house of difference. London: Routledge, 1999. Print.

Maier, Charles S. 'A Surfeit Of Memory? Reflections On History, Melancholy And Denial'. History and Memory (1993): 136--152. Print.

Mayer-Schönberger, Viktor. Delete. 1st ed. Princeton: Princeton University Press, 2009. Print.

McClelland, Andrew et al. 'A Values-Based Approach To Heritage Planning: Raising Awareness Of The Dark Side Of Destruction And Conservation'. Town Planning Review 84.5 (2013): 583--604. Print.

Meskell, Lynn. "Negative heritage and past mastering in archaeology." Anthropological Quarterly 75.3 (2002): 557-574. Print.

Miller, J. R. Shingwauk's vision. Toronto: University of Toronto Press, 1996. Print.

Milloy, John Sheridan. A national crime. Winnipeg: University of Manitoba Press, 1999. Print.

Mitchell, W. J. T. Landscape and power. Chicago: University of Chicago Press, 2002. Print.

Mitchell, Don. "Cultural Landscapes: the Dialectical Landscape" in Progress in Human Geography 26 (2002). 
Mundorff, Kurt. "Taking 2 (E) seriously: forcible child transfers and the convention on the prevention and punishment of the crime of genocide." University of British Columbia, (2007): Print.

Nancy, Jean-Luc. "The Insufficiency of 'Values' and the Necessity of 'Sense'." Journal for Cultural Research 9.4 (2005): 437-441. Print.

National Historic Sites Directorate. Report to the Status of Designations Committee. Report No. 2007-CED-SDC-22. Historic Sites and Monuments Board of Canada (2007) PDF.

National Museum of African Art, Smithsonian. N. p., 2014. Web. 24 Jun. 2014.

Nationaltrust.org.uk,. 'The Workhouse, Southwell - Visitor Information - National Trust'. N. p., 2014. Web. 23 Jun. 2014.

Nelson, Robert S, and Margaret Rose Olin. Monuments And Memory, Made And Unmade. 1st ed. Chicago: University of Chicago Press, 2003. Print.

Ness, Sally Ann. "Tourism-terrorism: The landscaping of consumption and the darker side of place." American ethnologist 32.1 (2005): 118-140. Print.

Nora, Pierre, "Between Memory and History: Les Lieux de Mémoire" in Representations No. 26, Special Issue: Memory and Counter-Memory (Spring, 1989), pp. $7-24$.

Olsen, Bjornar. "The end of history? Archaeology and the politics of identity in a globalized world." The Destruction and Conservation of Cultural Property (2001): 42-54. Print.

Osborne, Brian S. "Landscapes, Memory, Monuments, and Commemoration:

Putting Identity in Its Place" in Canadian Ethnic Studies Journal, Vol. 33, No. 3 (2001).

Osborne, Brian S. "Figuring space, marking time: Contested identities in Canada." International Journal of Heritage Studies, 2. 1-2 (1996): 23--40. Print.

"Parks Canada - Grosse Île and the Irish Memorial National Historic Site - Natural Wonders \& Cultural Treasures." Pc.gc.ca, 2009. Web. 14 Apr 2014.

$<$ http://www.pc.gc.ca/eng/lhn-nhs/qc/grosseile/natcul.aspx>.

Parks Canada. National Historic Sites of Canada System Plan. Ottawa: Government of Canada, 2000. Print.

Pc.gc.ca,. 'Scott, Duncan Campbell National Historic Person'. N. p., 2012. Web. 22 Aug. 2014. 
Pc.gc.ca,. 'Parks Canada - Parks Canada's National Historic Sites Cost-Sharing Program Introduction'. N. p., 2014. Web. 24 Jun. 2014.

Pc.gc.ca,. 'Parks Canada - Guide To The Preparation Of Commemorative Integrity Statements - 1.1 The Concept Of Commemorative Integrity'. N. p., 2009. Web. 19 Jun. 2014.

Pc.gc.ca,. 'Parks Canada - Historic Sites And Monuments Board Of Canada - National Program Of Historical Commemoration'. N. p., 2014. Web. 18 Jun. 2014.

Pc.gc.ca,. 'Parks Canada - National Historic Sites Of Canada System Plan - National Historic Sites Of Canada System Plan - Labour'. N. p., 2009. Web. 18 Jun. 2014.

Pc.gc.ca,. 'Parks Canada - Riding Mountain National Park - Commemorative Integrity'. N. p., 2012. Web. 29 Apr. 2014.

Pc.gc.ca,. 'Canadian Sovereignty In The Arctic Archipelago National Historic Event'. N. p., 2012. Web. 22 Aug. 2014.

Pendlebury, John. Conservation in the Age of Consensus. Routledge, 2008. Print.

Phillips, Ruth. 'Settler Monuments, Indigenous Memory: Dis-Membering And ReMembering Canadian Art History'. Monuments And Memory, Made And Unmade. Eds. Robert Nelson and Margaret Olin. 1st ed. Chicago: University of Chicago Press, 2003. 281-304. Print.

Prosper, Lisa. "Wherein Lies the Heritage Value? Rethinking the Heritage Value of Cultural Landscapes from an Aboriginal Perspective." 24. 2 (2007): 117--124. Print.

"Québec Declaration on the Preservation of the Spirit of Place: Adopted at Québec, Canada, October 4th 2008." International Journal of Cultural Property 15.4 (2008): 3936. ProQuest. Web. 30 June 2014.

Razack, Sherene. "When place becomes race." Race and racialization: Essential readings (2007): 74-82. Print.

Rcmp-grc.gc.ca,. 'The Role Of The Royal Canadian Mounted Police During The Indian Residential School System - Royal Canadian Mounted Police'. N. p., 2012. Web. 25 Jun. 2014.

Regan, Paulette. Unsettling the settler within. Vancouver: UBC Press, 2010. Print.

Reimer, Gwen, and Amy Bombay. The Indian Residential Schools Settlement Agreement's Common Experience Payment And Healing. 1st ed. Ottawa, Ont.: Aboriginal Healing Foundation, 2010. Print. 
Renan, Ernest. 'What Is A Nation?'. Nation And Narration. Homi Bhabha. 1st ed. New York: Routledge, 1990. 8-22. Print.

"Residential schools called a form of genocide." The Globe and Mail, 2012. Web. 22 Dec 2013. <http://www.theglobeandmail.com/news/national/residential-schools-called-aform-of-genocide/article547129/>.

Ricœur, Paul. Memory, history, forgetting. Chicago: University of Chicago Press, 2004. Print.

Rowlands, Michael. "Remembering to forget: sublimation as sacrifice in war memorials." (1999): 129-145. Print.

Rosenberg, Sharon. "Neither Forgotten nor Fully Remembered Tracing an Ambivalent Public Memory on the 10th Anniversary of the Montreal Massacre." Feminist Theory, 4. 1 (2003): 5--27. Print.

Rosenzweig, Roy and David P Thelen. The presence of the past. New York: Columbia University Press, 1998. Print.

"Schedule "N"." Schedule "N" Mandate for the Truth and Reconciliation Commission, 2013. Web. 20 Nov 2013.

<http://www.trc.ca/websites/trcinstitution/File/pdfs/SCHEDULE_N_EN.pdf>.

Rüsen, Jörn. History: narration, interpretation, orientation. Vol. 2. Berghahn Books, 2005. Print.

Sennett, Richard. '1 Disturbing Memories'. Memory 10 (1998): 10. Print.

Ševčenko, Liz, and Maggie Russell-Ciardi. Foreword to "Sites of Conscience: Opening Historic Sites for Civic Dialogue.” Public Historian 30, no. 1 (2008): 9-15. Print.

Ševčenko, Liz. "Activating the past for civic action: the international coalition of historic site museums of conscience." 19. 4 (2002): 55--64. Print.

Shore, Cris and Susan Wright. Anthropology of policy. London: Routledge, 1997. Print.

Sitesofconscience.org,. 'Andersonville National Historic Site (USA) I Sites Of Conscience'. N. p., 2014. Web. 23 Jun. 2014.

Simon, Roger L. "The Turn to Pedagogy: A Needed Conversation on the Practice of Curating Difficult Knowledge" in Erica Lehrer and Cynthia Milton (Eds.) Curating Difficult Knowledge. New York: Palgrave MacMillan (2011). Print.

Sium, Aman, Chandni Desai, and Eric Ritskes. "Towards the 'tangible unknown': Decolonization and the Indigenous future." Decolonization: Indigeneity, Education \& Society 1.1 (2012). Print. 
Smith, Andrea. 'Heteropatriarchy And The Three Pillars Of White Supremacy'. Incite (2006): n. p. Print.

Smith, George S, Phyllis Mauch Messenger, and Hilary A Soderland. Heritage Values In Contemporary Society. 1st ed. Walnut Creek, Calif.: Left Coast Press, 2010. Print.

Smith, Laurajane. Uses Of Heritage. 1st ed. London: Routledge, 2006. Print.

Smith, Laurajane, and Natsuko Akagawa, eds. Intangible Heritage. Routledge, 2008. Print.

Standards For The Conservation Of Canada's Historic Places. 2nd ed. Canada's Historic Places, 2010. Web. 24 Jun. 2014.

Stanton, Kim Pamela. Truth Commissions and Public Inquiries: Addressing Historical Injustices in Established Democracies. Diss. University of Toronto, 2010.

Stanton, Kim. "Canada's Truth and Reconciliation Commission: Settling the Past?." The International Indigenous Policy Journal, 2.3 (2011): 2. Print.

Statcan.gc.ca,. 'The Daily - 2011 National Household Survey: Aboriginal Peoples In Canada: First Nations People, Métis And Inuit'. N. p., 2013. Web. 1 Jul. 2014.

Stone, Philip R. 'Dark Tourism: Towards A New Post-Disciplinary Research Agenda'. International Journal of Tourism Anthropology 1.3 (2011): 318--332. Print.

Tai, Hue-Tam Ho. "Remembered realms: Pierre Nora and French national memory." American Historical Review (2001): 906-922.

Thechildrenremembered.ca,. 'Alberni Indian Residential School - The Children Remembered'. N. p., 2014. Web. 25 Jun. 2014.

The Government of Canada. Prime Minister Harper offers full apology on behalf of Canadians for the Indian Residential Schools system. 11 June, 2008. Print.

The Government of Canada. Notes for an Address by the Honourable Jane Stewart Minister of Indian Affairs and Northern Development on the occasion of the unveiling of Gathering Strength - Canada's Aboriginal Action Plan. January 7, 1998. Print.

Karen E. Till. The new Berlin: Memory, politics, place. U of Minnesota Press, 2005. Print.

Titley, E. Brian. A narrow vision: Duncan Campbell Scott and the administration of Indian affairs in Canada. UBC Press, 1992. Print. 
Titley, Brian E. "Reclaiming a Heritage: First Nations Education in the Late Twentieth Century." Monographs in Education 23 (1996): 55-68. Print.

Trc.ca,. 'Truth And Reconciliation Commission Of Canada (TRC)'. N. p., 2014. Web. 1 Jul. 2014.

Trigger, Bruce G. "Alternative archaeologies: nationalist, colonialist, imperialist." Man (1984): 355-370. Print.

Truth and Reconciliation Commission of Canada. They Came for the Children: Canada, Aboriginal peoples, and Residential Schools.. Winnipeg: Truth and Reconciliation Commission of Canada, 2012. Print.

Tunbridge, J. E and G. J Ashworth. Dissonant heritage. Chichester: J. Wiley, 1996. Print.

Twitter.com, 'Twitter / Jeffreylowes: Sir John A Defaced In Kingston ...'. N. p., 2014.

Web. 20 Jun. 2014.

Un.org,. 'Unanimously Adopting Resolution 2150 (2014), Security Council Calls

Forrecommitment To Fight Against Genocide'. N. p., 2014. Web. 21 Aug. 2014.

Viejo Rose D. "Destruction and Reconstruction of Heritage: Impacts on Memory and Identity." H.K. Anheier, Y.R. Isar and D. Viejo-Rose (eds.), Heritage, Memory and Identity, Vol.4. London: Sage Publications Ltd. 2011. 53-69. Print.

Vinitzky-Seroussi, Vered. "Commemorating a difficult past: Yitzhak Rabin's memorials." American Sociological Review, (2002): 30--51. Print.

Wagner-Pacifici, Robin and Barry Schwartz. "The Vietnam Veterans Memorial: commemorating a difficult past." American journal of Sociology, (1991): 376--420. Print.

Walkingwithoursisters.ca,. N. p., 2014. Web. 24 Jun. 2014.

Wesley-Esquimaux, Cynthia C, and Magdalena Smolewski. Historic Trauma And Aboriginal Healing. 1st ed. Ottawa: Aboriginal Healing Foundation, 2004. Print.

Wills, Sara. "Between The Hostel And The Detention Centre." Places of Pain and Shame: Dealing with 'Difficult Heritage' (2008): 263.

William Logan and Keir Reeves. 1st ed. London: Routledge, 2009. 263-280. Print.

Winnipegfreepress.com. 'CMHR Rejects 'Genocide' For Native Policies'. N. p., 2014. Web. 29 Apr. 2014.

Witness Blanket,. 'Witness Blanket'. N. p., 2014. Web. 30 Jun. 2014. 
Wittmeier, Brett. 'Residential School Abuse-Claim Documents Should Be Destroyed, Adjudicator Argues'. www.edmontonjournal.com. N. p., 2014. Web. 25 Jun. 2014.

Wmd.org,. 'Interview With Liz Sevcenko, Director, Secretariat Of International Coalition Of Historic Site Museums Of Conscience I World Movement For Democracy'. N. p., 2014. Web. 23 Jun. 2014.

Wolfe, Patrick. 'Settler Colonialism And The Elimination Of The Native'. Journal of Genocide Research 8.4 (2006): 387--409. Print.

Yiftachel, Oren. "Planning and social control: Exploring the dark side." Journal of Planning Literature 12.4 (1998): 395-406.

Young, James E. At memory's edge: After-images of the Holocaust in contemporary art and architecture. Yale University Press, 2000.

Young, J. E. Memory and Counter-Memory. (1999) The End of the Monument in Germany. Harvard Design Magazine [online] 9. Available from http://www.gsd.havard.edu/research/publications/hdm/back/9young.html

Young, J. E. The Texture of Memory: Holocaust Memorials and Meaning. (1993) New Haven and London: Yale University Press. Essay: Horst Hoheisel's Counter-memory of the Holocaust: The end of the monument. [online] Available on http://www.chgs.umn.edu/museum/memorials/hoheisel/zermahlene.html

Young, James E., "The Counter-Monument: Memory against Itself in Germany Today" Critical Inquiry, Vol. 18, No. 2. (Winter, 1992), pp. 267-296. Print.

Zancheti, Silvio Mendes, and Jukka Jokilehto. "Values and urban conservation planning: some reflections on principles and definitions." Journal of Architectural conservation 3.1 (1997): 37-51. Print. 